The copyright of this thesis vests in the author. No quotation from it or information derived from it is to be published without full acknowledgement of the source. The thesis is to be used for private study or noncommercial research purposes only.

Published by the University of Cape Town (UCT) in terms of the non-exclusive license granted to UCT by the author. 


\title{
THE EFFECT OF ORE BLENDS ON THE MINERAL PROCESSING OF PLATINUM ORES
}

A thesis submitted to the Faculty of

\section{ENGINEERING AND THE BUILT ENVIRONMENT}

of the

UNIVERSITY OF CAPE TOWN

in Fulfilment of the Requirements of the Degree of

MASTER OF APPLIED SCIENCE

\author{
By \\ Erika van Tonder \\ BSc Honours in Chemistry
}

\author{
Centre for Minerals Research \\ University of Cape Town \\ Rondebosch 7700 \\ South Africa
}




\section{ABSTRACT}

This thesis investigates the effect of ore blends on milling and flotation performance. Anglo Platinum's Waterval UG2 concentrator in Rustenburg processes ore from various shafts. The thesis was initiated to gain a better understanding of the type of interactions between the ores that consequently affect metal accounting at the concentrator. Four ores were sourced from the following shafts: Salene ore $\left(\mathrm{x}_{1}\right)$, Waterval UG2 ore $\left(\mathrm{x}_{2}\right)$, Paardekraal ore $\left(\mathrm{x}_{3}\right)$ and Townlands ore $\left(\mathrm{x}_{4}\right)$. The literature review indicates various experimental mixture designs that could possibly be used. The mixture designs that are most evident in the literature are the simplex centroid design, the simplex lattice design and the axial (augmented) design. The simplex lattice design was selected for this research as it is commonly used in, for example, the pharmaceutical industry, chemical industry and the food industry. None of these mixture designs has ever previously been applied to the field of mineral processing and the thesis aimed to establish the experimental mixture design as a foundation for a methodology to evaluate and interpret the effect of ore blends.

The thesis involved the characterization of four pure ores. Laboratory milling and flotation tests were conducted in order to standardize a milling time and quantify the uncertainty around the test work. Laboratory batch milling tests were performed using a standard Yaskuwa $0.25 \mathrm{~kW}$ rod mill, and laboratory batch flotation tests were performed using a standard Denver laboratory flotation cell. The simplex lattice experimental mixture design was then used to generate design points where ore from the four sources were blended in specified proportions. Ten-ton bulk samples of each ore were collected and sub sampled. The material was crushed to $-12 \mathrm{~mm}$ using a cone crusher and split 12 ways with a rotary bulk splitter. The subsamples from splitting were combined and resplit for homogenization. Material was then crushed to $-3 \mathrm{~mm}$ using a jaw crusher and $40 \mathrm{~kg}$ of this material was split 8 ways with a rotary splitter to render $5 \mathrm{~kg}$ portions. Each $5 \mathrm{~kg}$ portion was split 10 ways using a rotary splitter to render $500 \mathrm{~g}$ portions, which were used to make up the experimental design points.

Laboratory milling and flotation experiments were conducted on these ore blends for each design point. Different polynomial models were fitted to the design and the special cubic model was found to describe the data adequately. By evaluating the coefficient for binary and ternary terms, the polynomial model was then used to interpret antagonistic and synergistic interactions between the various ores. Binary and ternary plots were further used to visually interpret interactions. A 
binary plot is a graph of the predicated variable (recovery, grade etc.) as a function of the relative proportion of two (binary) components. A ternary contour plot is a graph of the interactions between three components represented by a triangle. Each side of the triangle represents the proportion of an ore source, and contour lines inside the triangle represent the predicted variable (recovery, grade etc.). Results and their implication on metal accounting for the cumulative milling, recovery and grade are summarized individually hereafter:

Cumulative milling: The results obtained from the milling experiments were not conclusive. Data analysis showed a lot of uncertainty in the model and the binary plots showed some deviations between the experimental data and the predicted data. The ternary plot was used as a visual reflection of the polynomial equation and assisted in evaluating the data. It did not appear as if the blending of ore has a significant effect on milling.

Cumulative recovery: Data analysis showed some uncertainty in the polynomial model but the binary plots showed better relation between the experimental data and the predicted data. The dominant effects were linear, but there were antagonistic interactions in the binary term for Salene $\left(\mathrm{x}_{1}\right)$ and Townlands $\left(\mathrm{x}_{4}\right)$ and synergistic interactions in the ternary terms containing Paardekraal $\left(\mathrm{x}_{3}\right)$ and Townlands $\left(\mathrm{x}_{4}\right)$. These findings are in line with what is known about the quality of the ore. It was found that the interaction between ores as well as the relative proportion on the blend affect recovery.

Cumulative grade: The accumulative results obtained from the flotation experiments were very conclusive. Data analysis showed little uncertainty in the model and the binary plots showed good relation between the experimental data and the predicted data. The model showed clear antagonistic interactions in all binary terms containing Salene $\left(\mathrm{x}_{1}\right)$ and synergistic interactions in ternary terms containing Paardekraal $\left(\mathrm{x}_{3}\right)$ and Townlands $\left(\mathrm{x}_{4}\right)$. Here the antagonistic effect of Salene $\left(\mathrm{x}_{1}\right)$ was much stronger than for recovery, and the higher grade of the pure ores $\mathrm{x}_{3}$ and $\mathrm{x}_{4}$ was also accentuated by the significant synergistic interaction of the ternary terms containing both Paardekraal $\left(\mathrm{x}_{3}\right)$ and Townlands $\left(\mathrm{x}_{4}\right)$. It was found that the quality of ore as well as the relative proportion on the blend will affect grade. This model is therefore a useful tool to detect the effect of blending on cumulative grade. 
The findings on cumulative recovery and grade will affect metal accounting as the concentrator will not be able to explain losses/gains in the final product. Any contractual agreements where recoveries and grade are based on pure ore will never be accurate as interactions between ores result in synergistic/antagonistic effects. Yet it was concluded that if the concentrator can control its blends it will be possible to still process ore blends in small portions without decreasing the metal accounting output. The simplex lattice design was found to be a useful methodology to evaluate the effect of blending on cumulative recovery and grade. 


\section{ACKNOWLEDEGMENTS}

I would first of all like to thank God for never leaving my side throughout this journey.

I would also like to express my sincere thanks to the following people:

My supervisor, Dr Dave Deglon, for his valuable advice and guidance in this study

My co-supervisor, Professor Tim Napier-Munn, for assisting with the data analysis

The management at Anglo Platinum for giving me this opportunity

Doug Phillips and the staff at Anglo Research for their assistance in the sample preparation and flotation test work and analysis

All staff at Anglo Platinum for their valuable advice and encouragement

My mother for her infinite love and faith in me

My friends and family for their encouragement and moral support 


\section{DECLARATION}

I declare that this thesis, submitted for the degree of Master of Applied Science at the University of Cape Town, is my own work. It has not been submitted prior to this for any degree or examination, at this or any other university.

Signed.......................... Date.

Erika van Tonder 


\section{TABLE OF CONTENTS}

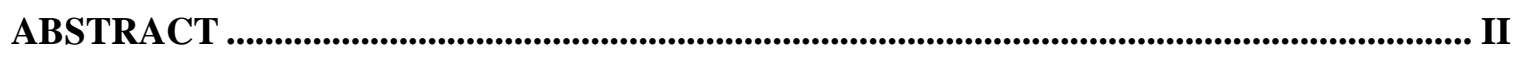

ACKNOWLEDGEMENTS .................................... ERROR! BOOKMARK NOT DEFINED.

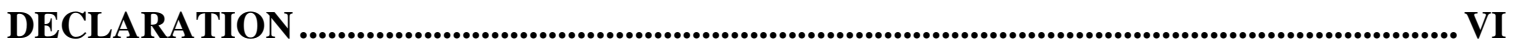

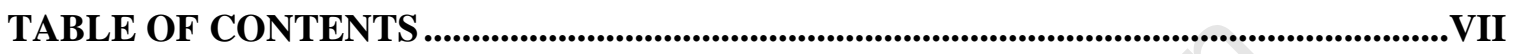

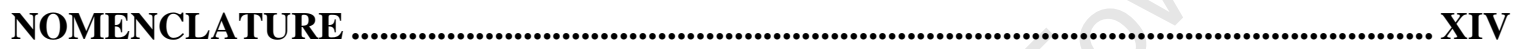

CHAPTER 1 INTRODUCTION..................................................................................................

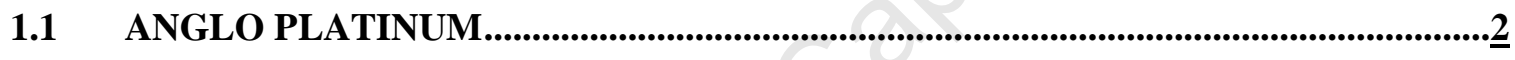

1.2 METAL ACCOUNTING ..............................................................................................................

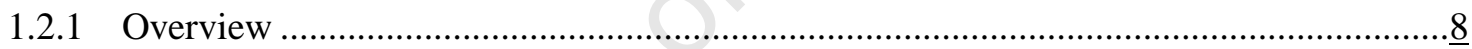

1.2.2 Metal accounting at the Waterval UG2 concentrator ..................................................

1.2.2.1 Bulk mass measurement ..............................................................................

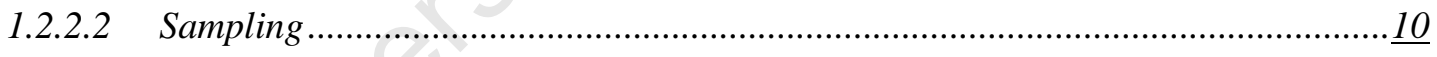

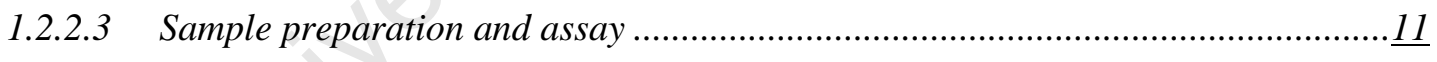

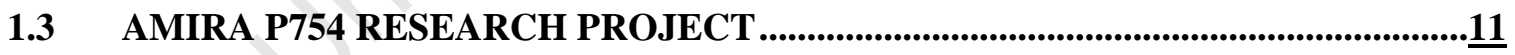

1.4 OBJECTIVES OF THIS RESEARCH THESIS .....................................................11

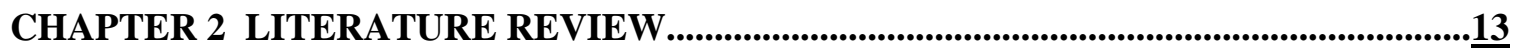

2.1 MILLING AND FLOTATION …...............................................................................................13

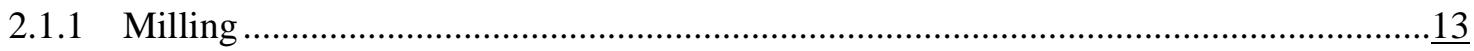

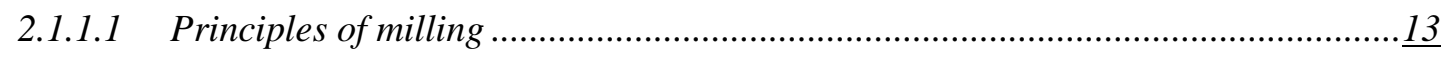

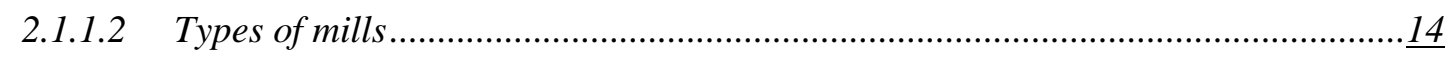

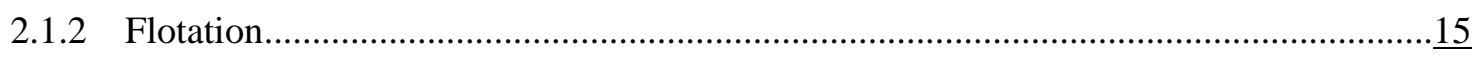

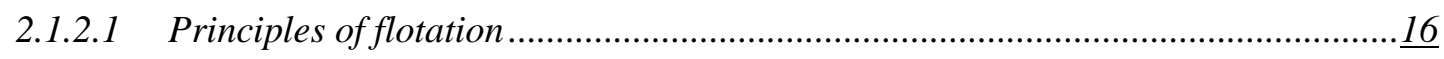


2.1.2.2 Types of flotation cells.

2.2 EXPERIMENTAL MIXTURE DESIGN ..........................................................................18

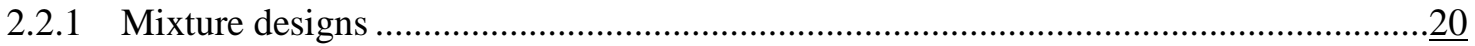

2.2.1.1 Principles of mixture designs ...........................................................

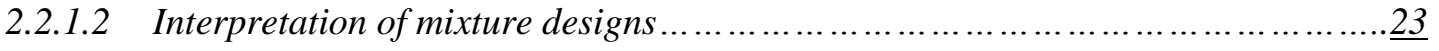

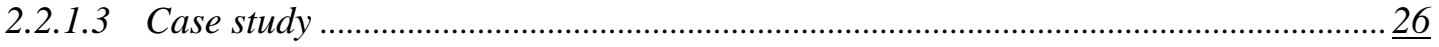

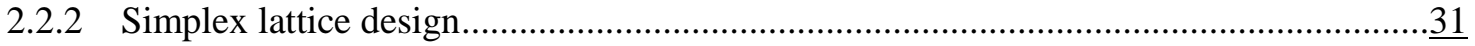

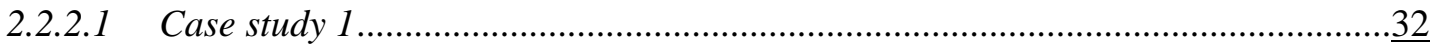

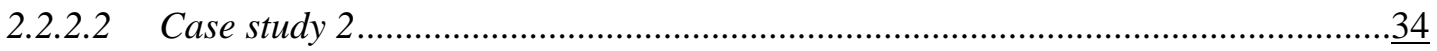

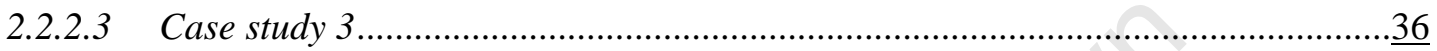

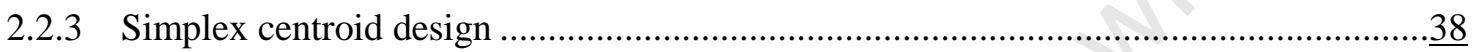

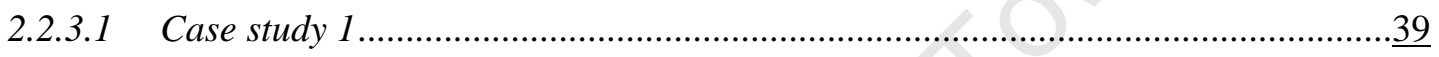

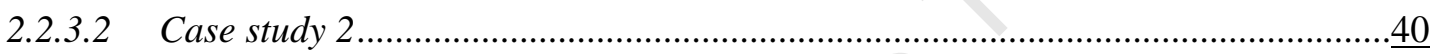

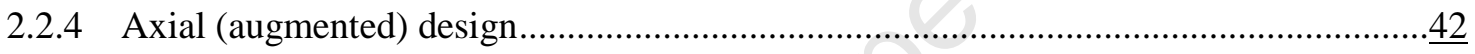

2.3 MIXTURES/BLENDS IN MINERAL PROCESSING ....................................................46

2.3.1 The effect of mixtures on handleability of coal...................................................... 46

2.3.2 The effect of mixtures on milling ....................................................................... 4

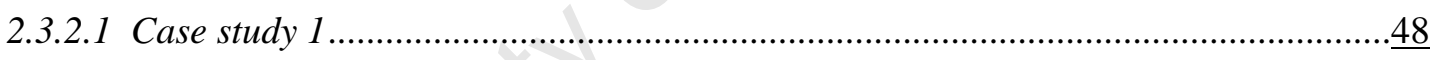

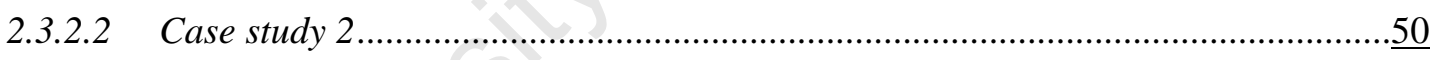

2.3.3 The effect of mixtures on process performance …......................................................

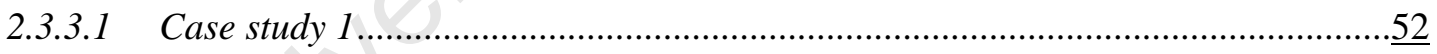

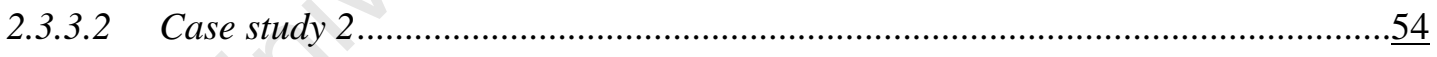

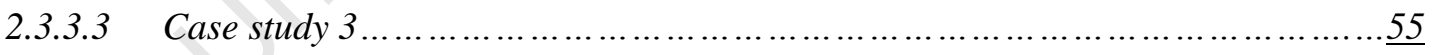

2.3.4 Antagonistic and synergistic effects in mineral processing ..................... $\underline{56}$

2.4 APPLICATION OF THE MIXTURE DESIGN TO THIS PROJECT...............56

CHAPTER 3 EXPERIMENTAL …………………........................................................................... $\underline{\mathbf{5 8}}$

3.1 MINERAL ORES .......................................................................................................................58

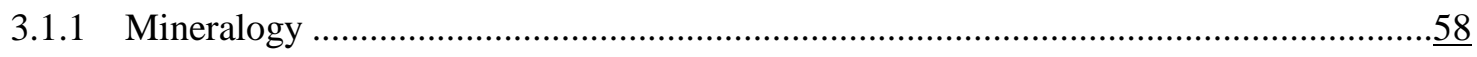

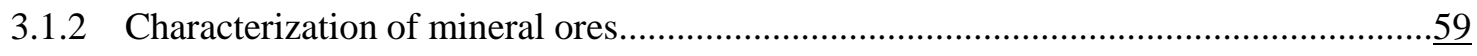

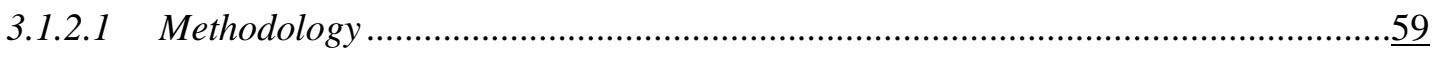

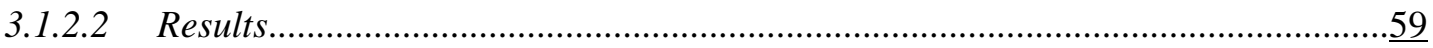


3.1.3 Sampling and sample preparation

3.2 MILLING AND FLOTATION EXPERIMENTS .......................................................63

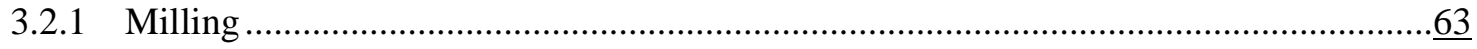

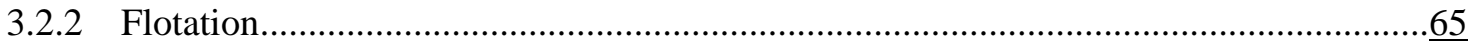

3.2.3 Repeatability and analytical variance ….....................................................................

3.3 SIMPLEX LATTICE DESIGN

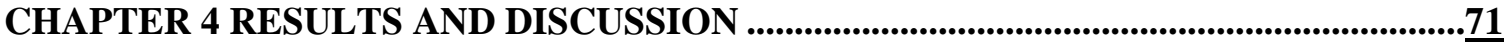

4.1 ANALYSIS OF THE SIMPLEX LATTICE DESIGN ............................................... 11

4.1.1 Methodology for selection of the regression polynomial .......................................

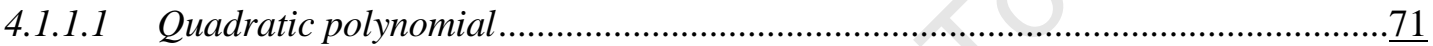

4.1.1.2 Special cubic polynomial.............................................................................

4.1.1.3 Stepwise regression polynomial …………......................................................

4.1.2 Interpretation of the simplex lattice mixture design ..........................................

4.1.2.1 The special cubic regression polynomial …...........................................................

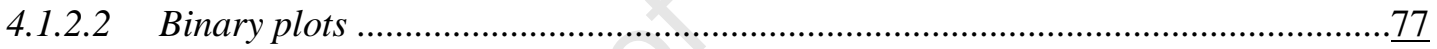

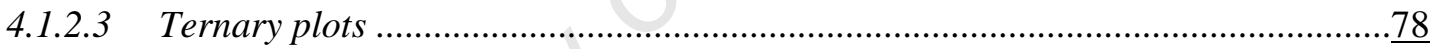

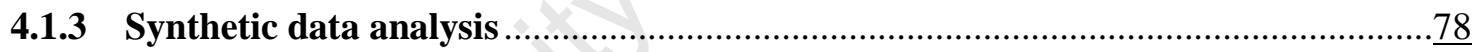

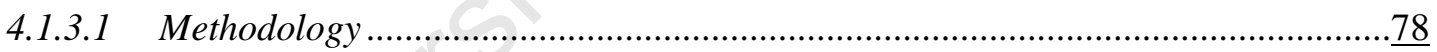

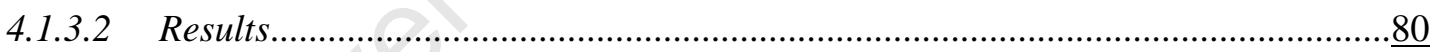

4.2 MILLING AND FLOTATION RESULTS .....................Error! Bookmark not defined.

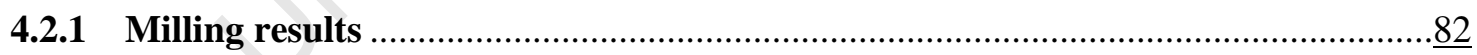

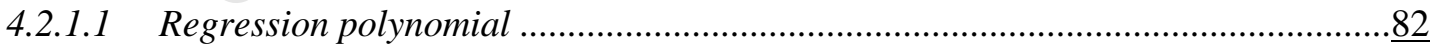

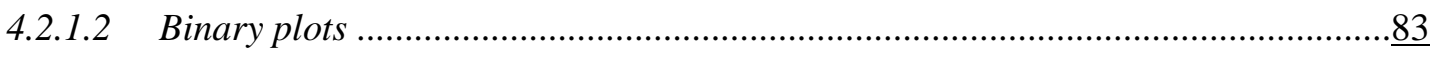

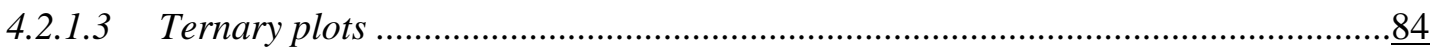

4.2.1.4 Implication for metal accounting ………......................................................

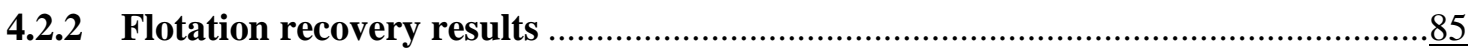

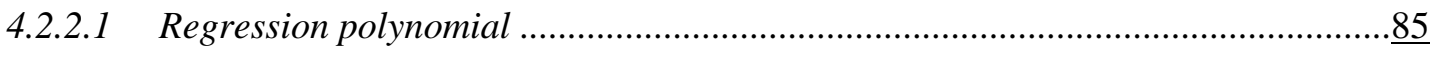

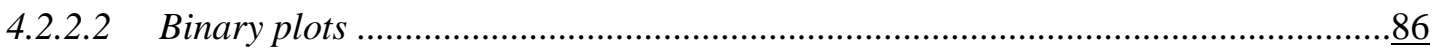

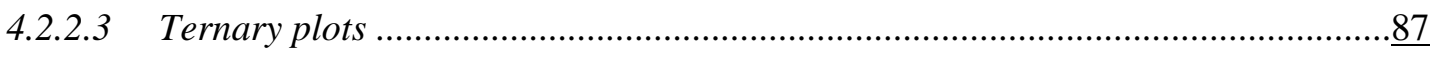

4.2.2.4 Implication for metal accounting ………......................................................... 
4.2.3 Flotation grade results

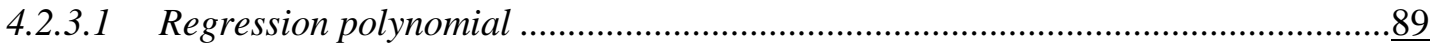

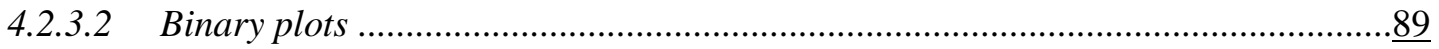

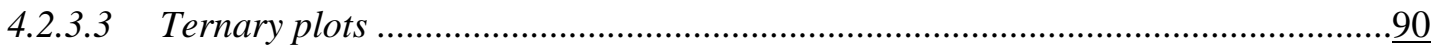

4.2.3.4 Implication for metal accounting ……...............................................................

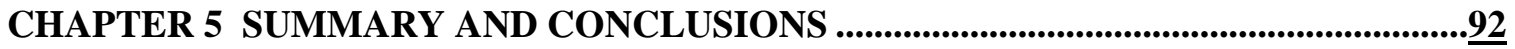

5.1 SUMMARY OF KEY FINDINGS ….................................................................................93

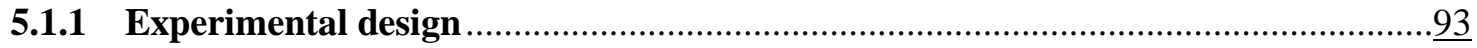

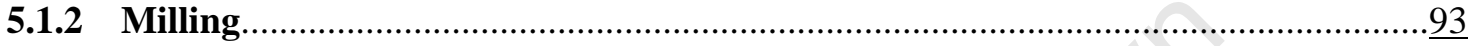

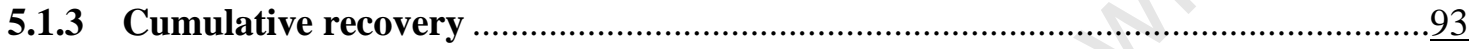

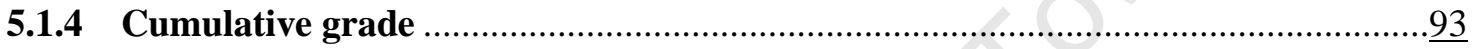

5.2 CONCLUSIONS ..............................................................................................................................

$5.3 \quad$ RECOMMENDATIONS ...................................................................................................... 95

REFERENCES …...................................................................................................................................

APPENDIX A MILLING TEST DATA .....................................................................................102

Table A-1 Salene data ..................................................................................................................................102

Table A-2 Waterval UG2 data........................................................................................................1102

Table A-3 Paardekraal data ............................................................................................................103

Table A-4 Townlands data..........................................................................................................................103

APPENDIX B EXPERIMENTAL DESIGN RESULTS ...........................................................104

Table B-1 Milling results......................................................................................................................................104

Table B-2 Flotation recovery results..................................................................................................105

Table B-3 Flotation grade results....................................................................................................106 


\section{LIST OF FIGURES}

Figure 1.1 Stratigraphic columns of the Bushveld Complex ....................................................

Figure 1.2 Operational map of Anglo Platinum in the Bushveld Complex …............................... 4

Figure 1.3 Schematic of platinum ore from mine to product...............................

Figure 1.4 Coarse ore and fine ore silo at the Waterval UG2 concentrator .................................. $\underline{6}$

Figure 1.5 Flotation cells at the Waterval UG2 concentrator ..................................................

Figure 2.1 Schematic representation of the process of froth flotation.........................................

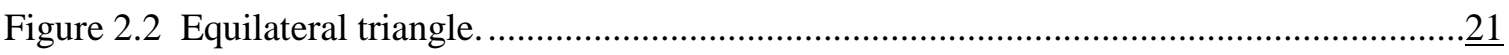

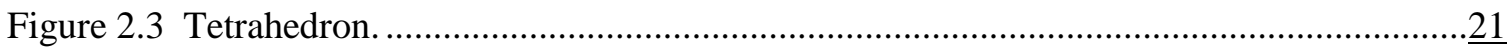

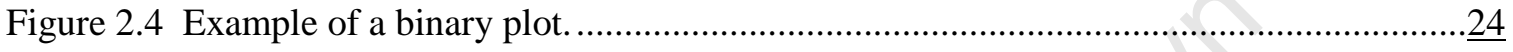

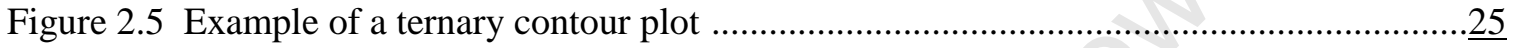

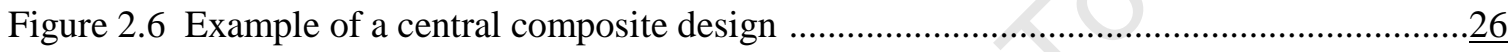

Figure 2.7 Central composite designs of nine different flour blends …......................................

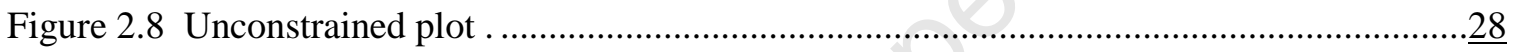

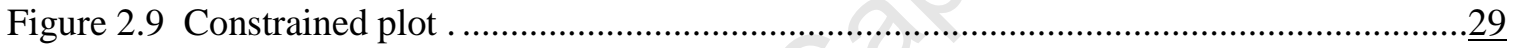

Figure 2.10 General polynomial forms of mixture models ......................................................

Figure 2.11 Contour plots for interfacial tension, viscosity and particle size (D50 $\mu \mathrm{m}) \quad \ldots \ldots \ldots \ldots . . . .34$

Figure 2.12 Experimental design with water constraints (a) and experimental design with water

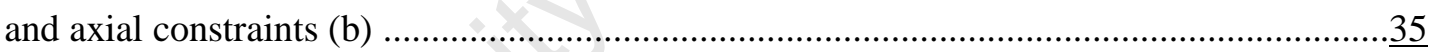

Figure 2.13 Ternary contour plot for (a) protein concentration and (b) $\mathrm{pHe}$...............................

Figure 2.14 Experimental design for gas mixture ...................................................................

Figure 2.15 Contour plots of the mixture effect on the response after 7 days, 10 days and 14 days,

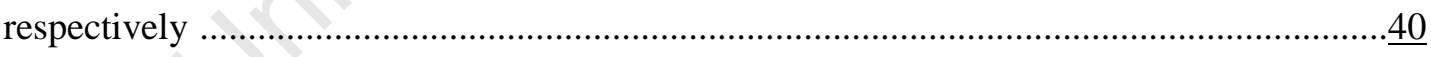

Figure 2.16 Experimental designs for composite mixture ...................................................

Figure 2.17 Contour and surface plot of $\mathrm{a}_{\mathrm{w}}(\mathrm{a}$ and $\mathrm{b})$ and $\boldsymbol{\varepsilon}_{0}(\mathrm{c}$ and $\mathrm{d})$, respectively ....................

Figure 2.18 An example of an axial design ........................................................................

Figure 2.19 Mixture design for the three additives ................................................................

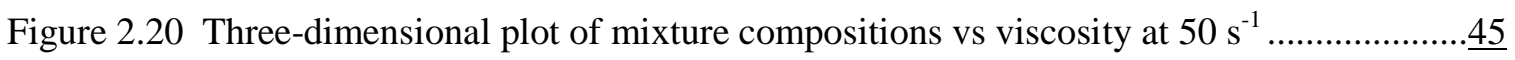

Figure 2.21 The predicted unconfined strengths of different blends of the three coals ............... 48

Figure 2.22 Correlation between the measured HGI and a weighted average HGI for the blend

between Hebe/P4 and Hebe/P2/P4 …..........................................................................

Figure 2.23 Correlation between the measured HGI and a weighted average HGI for the blend between Hebe/P3 
Figure 2.24 Percentage limestone in mixture vs median particle size of product $\underline{51}$

Figure 2.25 Ash deposit layer thickness for binary blends between C and D .$\underline{.52}$

Figure 2.26 TMA percentage of penetration curves for the binary blends between $\mathrm{C}$ and $\mathrm{D} \ldots . . . \underline{53}$

Figure 2.27 Viscosity for the binary blends between C and D ..............................................54

Figure 3.1 Rotary bulk splitter used to split ten ton bulk sample...............................................

Figure 3.2 Rotary splitter used to split $5 \mathrm{~kg}$ sample to $500 \mathrm{~g}$ portions........................................63

Figure 3.3 Rod mill used for laboratory batch milling ............................................................64

Figure 3.4 Milling curve for all ores indicating both $\%$ mass passing $75 \mu \mathrm{m}$ and $\%$ volume

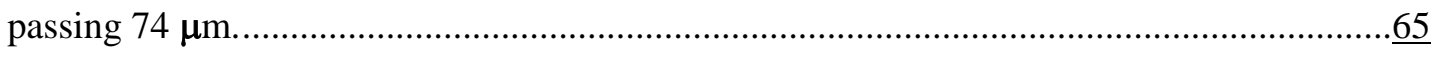

Figure 3.5 Denver flotation cell used for laboratory batch flotation tests.................................. 66

Figure 3.6 Recovery grade curve for the pure ores. ............................................................68

Figure 3.7 Recovery time curve for the pure ores................................................................69

Figure 4.1 Residual plots for the special cubic polynomial for cumulative grade results ..............

Figure 4.2 Binary plot for the overall percentage mass passing $75 \mu \mathrm{m}$ for binary mixtures of the

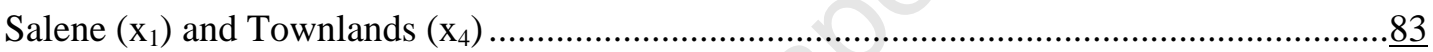

Figure 4.3 Ternary plot for the overall percentage mass passing $75 \mu \mathrm{m}$ for ternary mixtures of the

Salene $\left(\mathrm{x}_{1}\right)$, Paardekraal $\left(\mathrm{x}_{3}\right)$ and Townlands $\left(\mathrm{x}_{4}\right)$ ores.....................................................

Figure 4.4 Binary plot for the cumulative percentage recovery for binary mixtures of the Salene

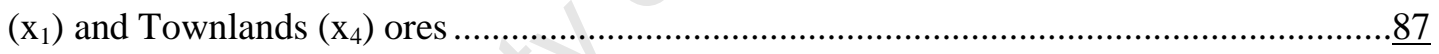

Figure 4.5 Ternary plot for the percentage cumulative recovery for ternary mixtures of the Salene

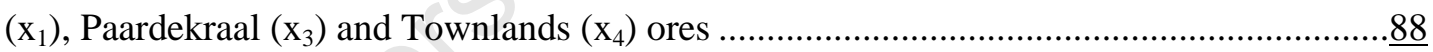

Figure 4.6 Binary plot for the cumulative grade for binary mixtures of the Salene $\left(\mathrm{x}_{1}\right)$ and

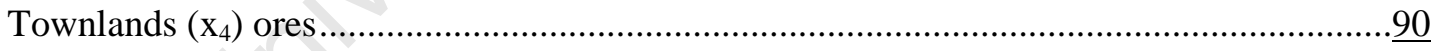

Figure 4.7 Ternary plot for the cumulative grade for ternary mixtures of the Salene $\left(\mathrm{x}_{1}\right)$,

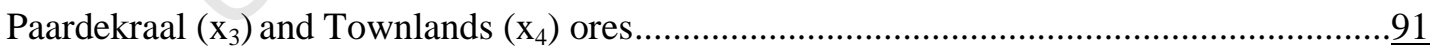




\section{LIST OF TABLES}

Table 2.1 Regression coefficients for the unconstrained model (a) and the constrained model (b)

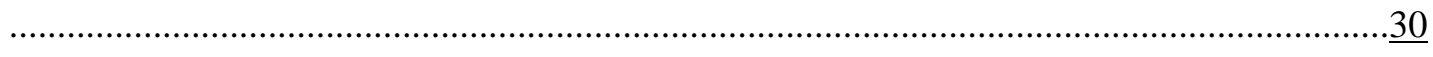

Table 2.2 The $\mathrm{F}$ and $\mathrm{F}_{\text {crit }}$ values for the different complexes and models .....................................

Table 2.3 Design points for the experimental design ............................................................

Table 3.1 Mineralogical results ....................................................................................

Table 3.2 Reagent suite used in flotation tests. ....................................................................

Table 3.3 Design points for simplex lattice mixture design ................................................... 70

Table 4.1 Estimated coefficients for cumulative grade results ...................................................

Table 4.2 ANOVA for cumulative grade results.................................................................

Table 4.3 Estimated coefficients for cumulative grade results ................................................

Table 4.4 ANOVA for cumulative grade results.................................................................. 


\section{NOMENCLATURE}

$\begin{array}{ll}F & \text { Test value for analysis of variance } \\ F_{\text {crit }} & \text { Critical value for analysis of variance } \\ \mathrm{L}_{\mathrm{k}} & \text { Lower bound } \\ \mathrm{m} & \text { Degree of the polynomial } \\ \mathrm{p} & \text { Probability value } \\ \mathrm{q} & \text { Number of components } \\ \mathrm{R}^{2} & \text { Correlation coefficient } \\ \mathrm{R}_{\mathrm{adj}}{ }^{2} & \text { Adjusted correlation coefficient } \\ \mathrm{R}_{\mathrm{k}} & \text { Range } \\ \mathrm{R}_{\mathrm{L}} & \text { Simplex region defined by lower bound } \\ \mathrm{R}_{\mathrm{U}} & \text { Simplex region defined by upper bound } \\ \mathrm{T} & \text { Sum of proportions excluding constant mixture factors } \\ \mathrm{U}_{\mathrm{k}} & \text { Upper bound }\end{array}$




\section{CHAPTER 1 INTRODUCTION}

A short overview is provided in Section 1.1 of Anglo Platinum and the Waterval UG2 concentrator. The main area where platinum is found in South Africa is portrayed, as well as how some of this platinum ore is processed at the concentrator. Section 1.2 is a description of what metal accounting is, its importance in the mining industry and how it is applied at the Waterval UG2 concentrator. The AMIRA P754 research project is described in Section 1.3 and the scope and objectives of this thesis are given in Section 1.4.

\subsection{ANGLO PLATINUM}

South Africa contributes $77 \%$ to the world's primary platinum production. Anglo Platinum is the world's leading producer of platinum and accounts for half of South Africa's supplies. It also produces other platinum group metals like palladium, ruthenium, iridium and osmium. Base metals like nickel and copper are by-products of the refining process for precious group minerals. $48 \%$ of the total platinum consumption is attributed to the manufacture of auto catalysts for both petrol and diesel-engine vehicles. Platinum is also used for jewellery (22\%) and in the chemical, electrical, medical, glass and petroleum industries (28\%).

Anglo Platinum produces all its platinum from the Bushveld Igneous Complex. This complex is a large igneous intrusion within the earth's crust which outcrops around the edge of a geological basin (Schouwstra et al., 2000). As indicated in Figure 1.1 the Bushveld Igneous Complex consists of four layers or zones. They are the upper zone, main zone, critical zone and lower zone. When all the zones are stacked on top of each other, they can be between 7 and $9 \mathrm{~km}$ thick. 


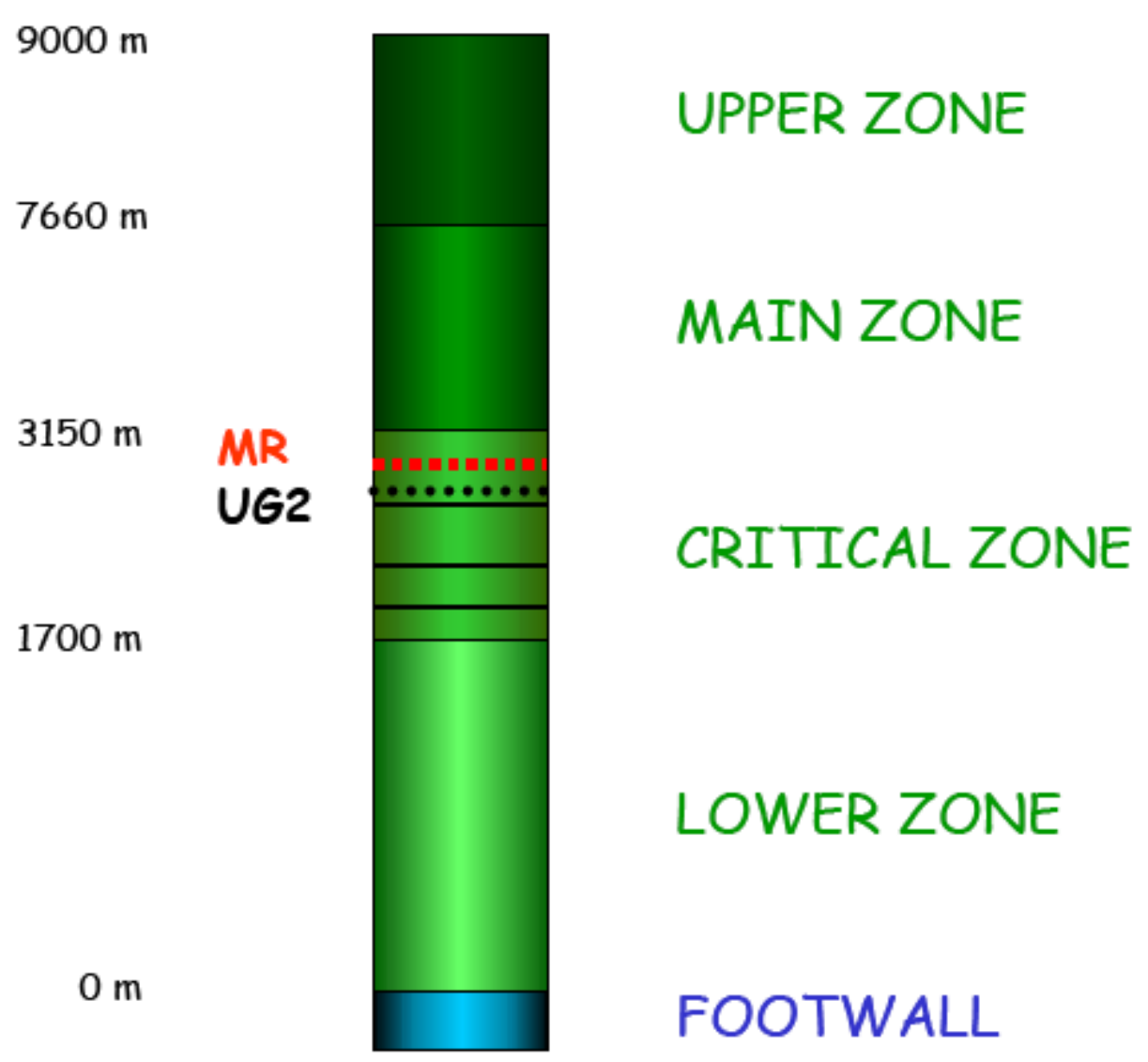

Figure 1.1 Stratigraphic columns of the Bushveld Complex (Rixom, 2004).

The critical zone contains two deposits called the Merensky Reef and the UG2 Reef. These deposits contain most platinum group metals in the form of minerals. The UG2 Reef lies 20 to 400 metres below the Merensky Reef and runs parallel to it. As indicated in Figure 1.2, the Bushveld Igneous Complex is divided into eastern, western and northern sections. Anglo Platinum has various mining operations throughout the Complex, the largest of which is in Rustenburg. Rustenburg section provides most of the platinum ounces produced. 


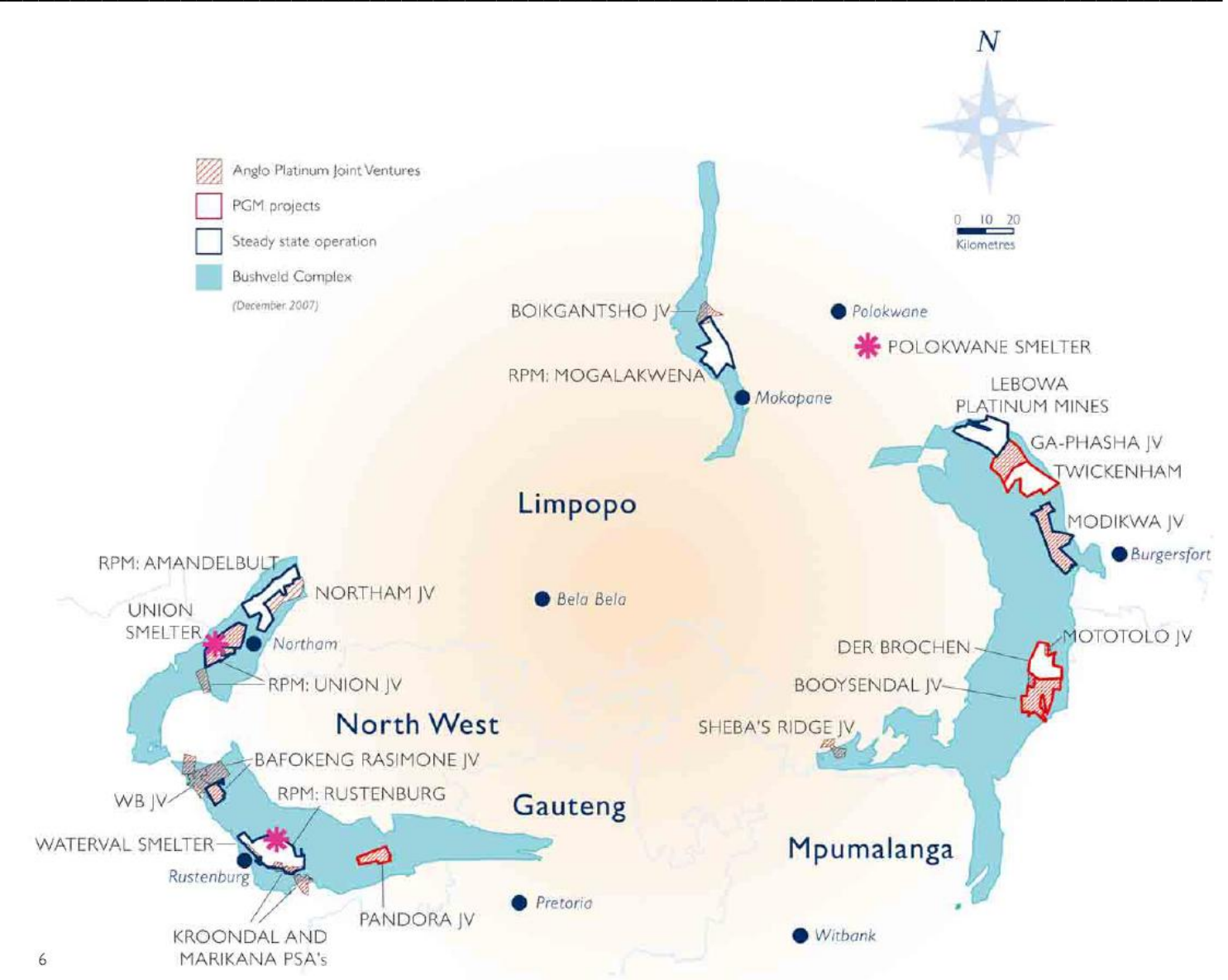

Figure 1.2 Operational map of Anglo Platinum in the Bushveld Complex (http://intranet/angloplatinum/index.aspx).

Figure 1.3 describes the ore flow from mine to product. Ore that is mined from the two reefs is sent to a concentrator for processing. The concentrator uses flotation to concentrate the minerals of interest. The concentrate product is then sent to a smelter for further refining. The smelter recovers the minerals of interest in the form of a matte which is further refined at the Anglo Platinum converting process plant (ACP plant). The converted matte is sent to the Platinum group enrichment plant (MC plant), where the precious metals are separated from the base metals. The base metals are then further refined to a final product at the base metal refinery, while the precious metals are refined to a final product at the precious metal refinery. 


\section{SIMPLIFIED FLOWSHEET}

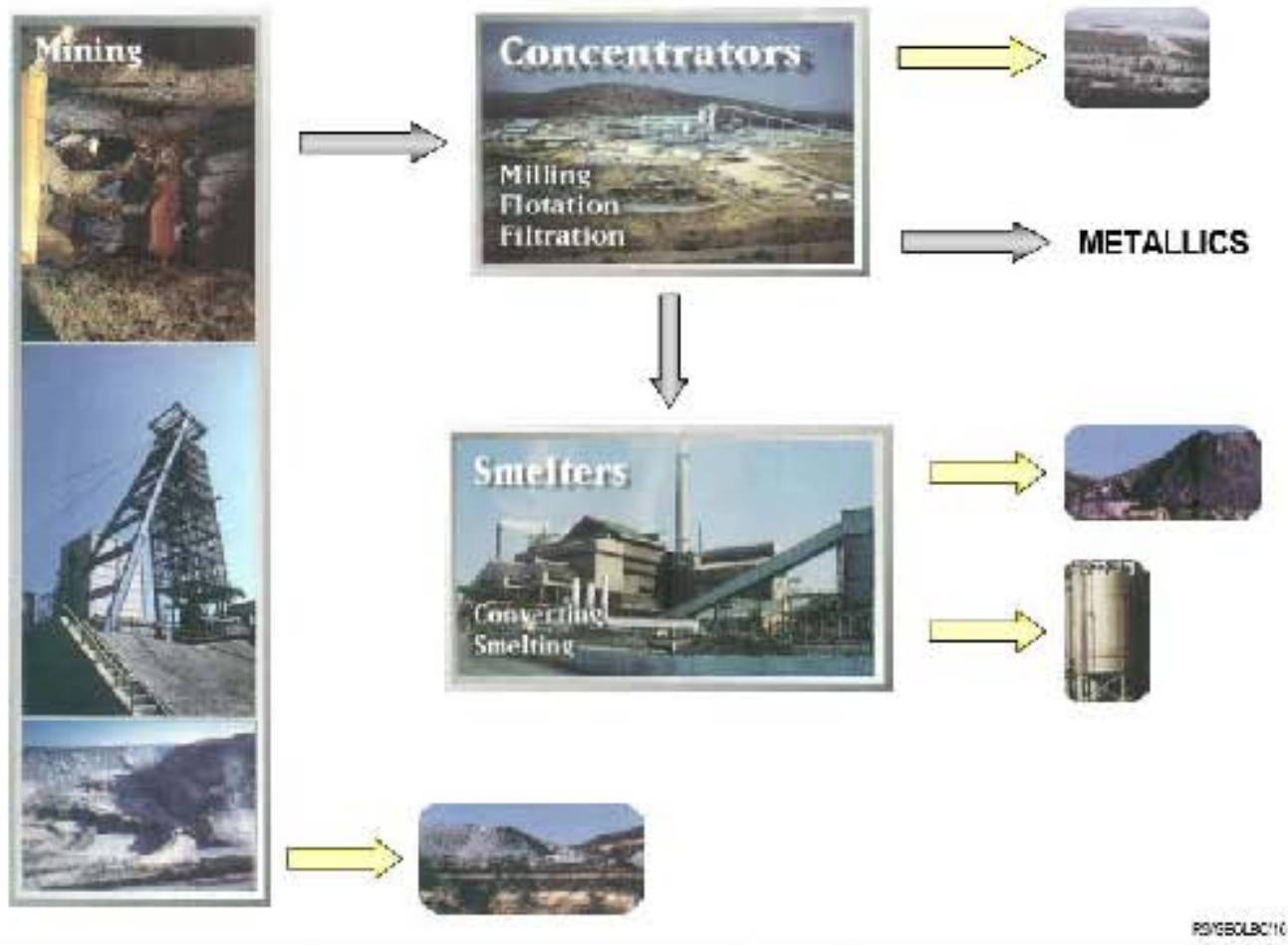

SIMPLIFIED FLOWSHEET: REFINING

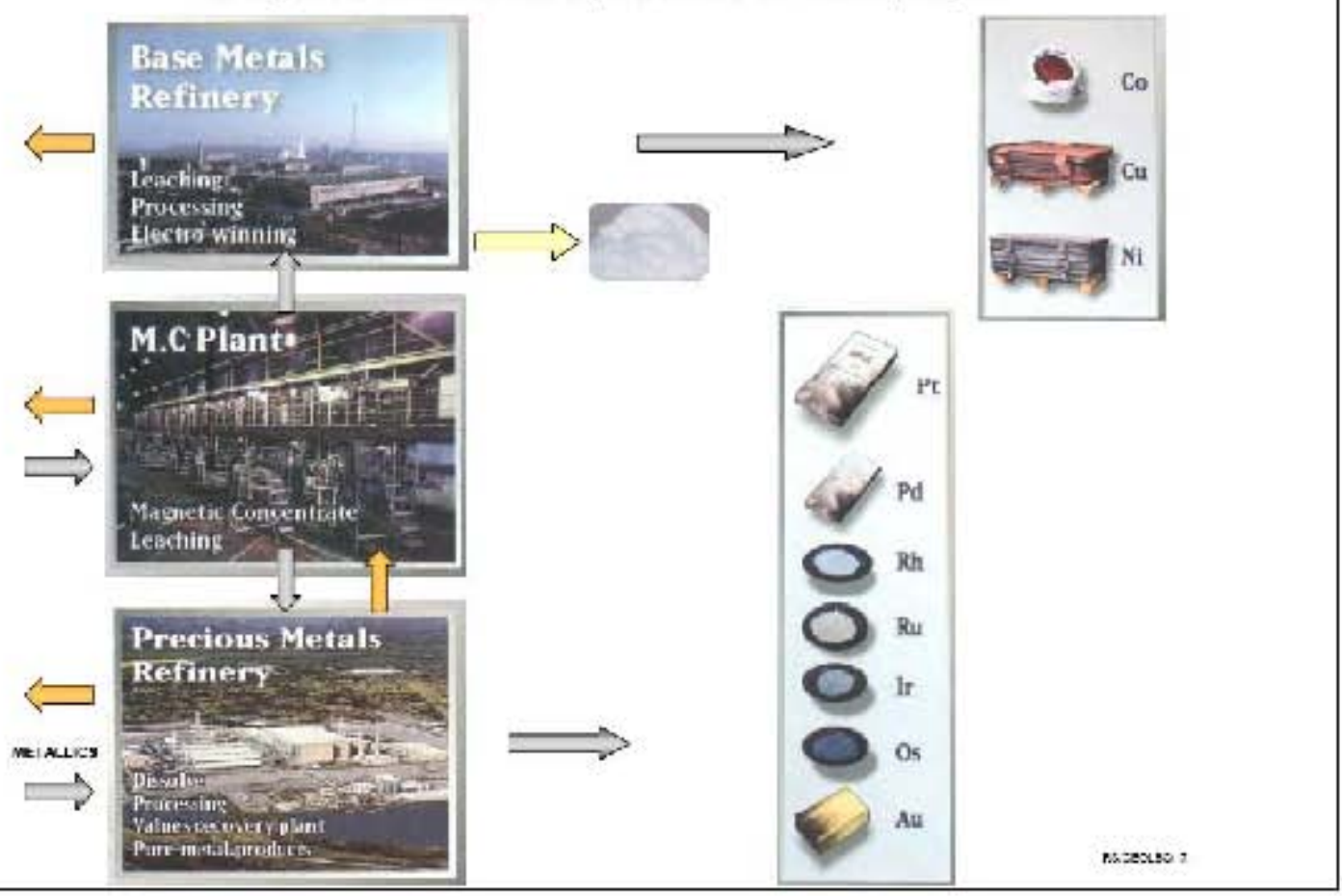

Figure 1.3 Schematic of platinum ore from mine to product (Rixom, 2004). 
In this thesis the Waterval UG2 concentrator in Rustenburg is used as a case study, but the research project is not concentrator specific. The concentrator primarily treats ore which was mined from the UG2 reef, from various shafts in Rustenburg. Ore refers the natural product of mining and crushing, before it is subject to any mineral processing as described by Weiss (1985). The concentrator treats $400 \mathrm{kt}$ of ore per month (Davies, 2002). The ore is delivered from various shafts via a train as well as from the Waterval UG2 shaft, which delivers from two decline shafts by way of a $3 \mathrm{~km}$ overland conveyor.

When the ore is received from the mine the minerals of interest (containing the platinum group metals) are associated or enclosed with other minerals. It must therefore be crushed and milled in order to liberate the minerals of interest. Both ore streams are passed through a primary crushing section to provide a maximum top size of $250 \mathrm{~mm}$. The crushed ores are directed to the mill silo feed belt. The ore that is delivered by rail can also be directed to a $50000 \mathrm{t}$ stockpile. As indicated in Figure 1.4 the combined head feed is conveyed to the top of the mill silos where it passes over a sizing screen. Material bigger than $80 \mathrm{~mm}$ is directed to the coarse ore silo $(7000 \mathrm{t}$ capacity) and the remainder is conveyed to the fine ore silo (11 $000 \mathrm{t}$ capacity). Variable speed feeders under the silos draw the ore onto a mill feed belt at a controlled rate.

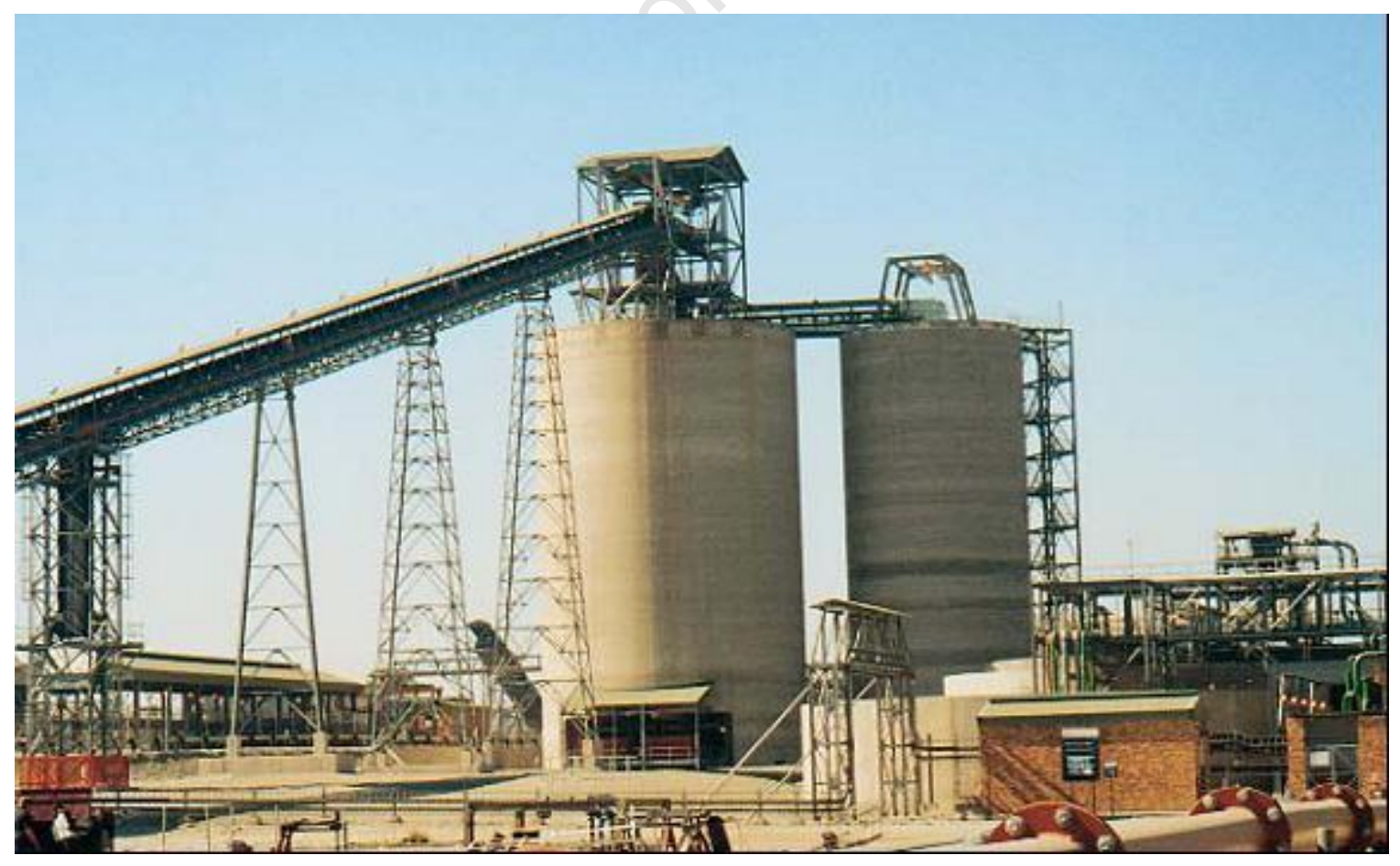

Figure 1.4 Coarse ore and fine ore silos at the Waterval UG2 concentrator (Davies, 2002). 
After milling, the ore (now in slurry form) is sent through various flotation cells and different reagents are added in order to recover the minerals of interest as indicated in Figure 1.5. The product with the minerals of interest is then referred to as concentrate and the remainder reject material is referred to as tails. The flotation process is discussed in more detail in Section 2.1 in the literature review.

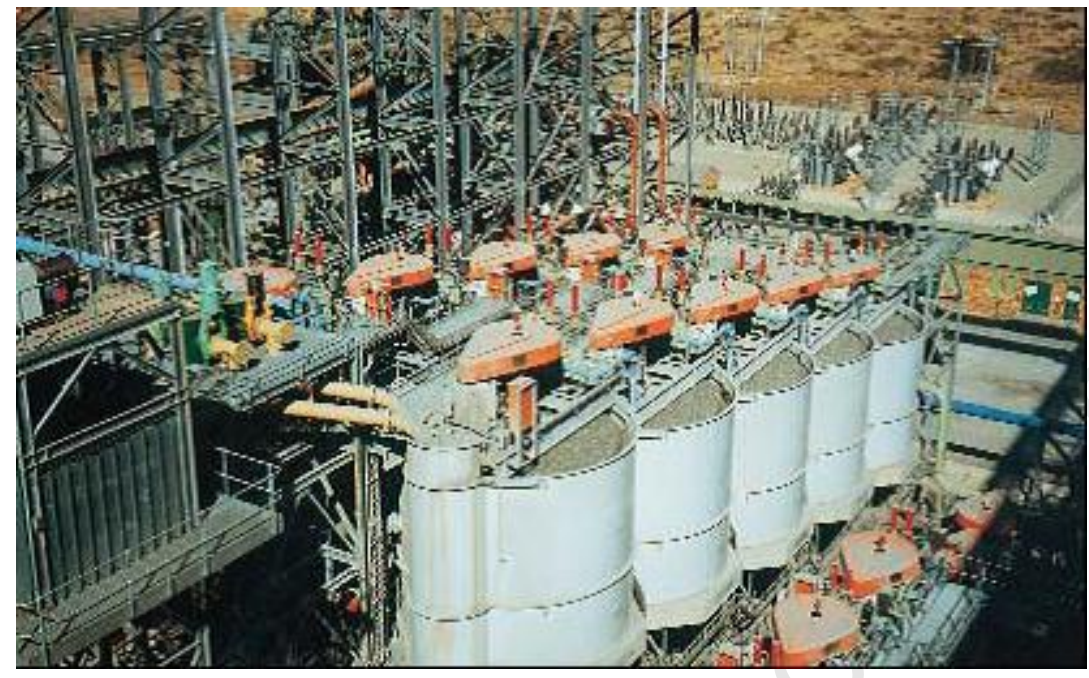

Figure 1.5 Flotation cells at the Waterval UG2 concentrator (Davies, 2002).

Each process (mining, concentrators, smelters, etc.) shown in Figure 1.3 operates as a separate business unit and therefore all ore that is received from the mine must be accounted for in the final concentrate product at the concentrator. Metal accounting is used in order to facilitate this procedure.

The flotation recovery depends not only on control of the process at the plant, but also on the geology of the ore as well as the mining method. The geology of the ore will vary depending on where it was mined from the reef. In mining the reef can be divided into various horizontal sections, for example hanging wall (representing the rock above the mining stope), the foot wall (representing the rock below a mining stope) and a pothole (representing the hanging wall and mining stope that drops into the footwall). Other examples are the transition zone reef (the area where the normal reef changes to a pothole reef) and the iron replacement reef (where discordant veins, pipes and occasionally sub concordant sheets of iron-rich ultramafic pegmatite replace the Merensky Reef). Previous work has shown that when ore from the various sections are blended, they do affect the flotation recovery (Malysiak and Towell, 2004). Factors like mineralogical 
composition, mineral association and valuable mineral grain sizes will affect the lower recovery. The geology of ore retrieved from an open cast mine will also vary significantly from ore retrieved underground, as the former will be weathered and oxidized to a greater extent. Even ore from the same open cast pit can vary extensively as demonstrated by Roberts et al. (1999). Samples were collected from four stockpiles in order to characterize the ore. The stockpiles were identified as: 1) Low-low grade (mostly pyroxenite material); 2) High-low grade (mostly feldspathic pyroxenite); 3) SW extension (serpentinized parapyroxenite) and 4) Calc-silicate. During test work it was found that alteration processes modified the mineralogy and precious metal grade of all the ores and as the degree of alteration increased, the altered silicate increased while the base metal sulphide decreased.

The mining method will also affect milling behaviour of the ore. For example, conventional mining requires blasting and drilling. In contrast to mechanized mining (which makes use of the truck and shovel method), this method generates micro fractures and small particles that will be easier to mill and thus the precious group metals are liberated faster.

\subsection{METAL ACCOUNTING}

\subsubsection{Overview}

According to Girard et al. (2003), metallurgical accounting "is a routine procedure that accounts for the amount of ore and its composition fed to a mineral concentration plant and the amount of products and rejects produced along with its composition". Thus during metal accounting the ore input to the plant and the distribution of the ore input among products of the operation are measured in terms of ore tonnage and metal grade (Weiss, 1985). The products of a mineral concentration plant are normally one or more concentrates and a final tail. By taking these measurements the metal content can be calculated for both the inputs and outputs of a process plant and this data can be used in a metal balance. The metal balance is based on the conservation of mass and thus the input metal content must be the same as the output metal content. Metal balances rely on measurements, which will contain random error and/or bias. A bias is a consistent error that can be caused, for example, by a faulty instrument. Due to the random error and/or bias the metal content within a process plant will not always balance. Thus even when assuming that there are no internal stocks within the process plant, the input content will not always be the same as the output content. The discrepancy can be compensated for by 
either boundary measurements or metal mass balancing. Boundary measurements involve measuring the input and output with high accuracy and recording any discrepancy in the metal balance as an "unaccounted gain or loss". The "unaccounted" balance must then be controlled. Metal mass balancing is used to satisfy the metal balance by using the measured input and output as well as the metal balance constraints (the conservation of mass) to obtain adjusted input and output values.

The current mining industries are affected by various economic factors, for example fluctuations in metal prices, rising operational costs, socio-political trends and technical difficulties in operations (Richardson, 1991). The annual profit which can be made during the life of a mine is determined by the tonnage and grade of an ore body, the recoverable metal and the cost of recovery. Therefore accurate metal accounting plays an imperative part in management to prevent a financial loss. In order to make informed decisions management should have an accurate inventory of how much metal is in the product, how much metal is lost and how much metal is held up in production. Accurate metal accounting also contributes to the technical performance of a concentrator as it is important in production planning, resource allocation and process optimization. Material balances and data reconciliation techniques provide the estimates of production and inventories. The minerals industry normally uses boundary measurements when doing a material balance. To determine an inventory for the boundary measurements the following is required: Bulk mass measurement, sampling, sample preparation and assay. The accuracy of the inventory can be affected by several factors, for example:

i) Uncertainties in mass and analytical measurements due to limitations of instrumentation and calibration.

ii) Uncertainties in sampling and sample preparation.

iii) Unexplained losses/gains in recovery during the plant process.

\subsubsection{Metal accounting at the Waterval UG2 concentrator}

At the Waterval UG2 concentrator ore from the various shafts are the input to the concentrator and the final tails and final concentrate are the output. It is believed that blending ore from various shafts is causing lower recoveries. The input metal content is determined by measuring the amount (dry mass) of ore entering the concentrator and its composition (grade). The output metal content is determined by measuring the amount (dry mass) of concentrate produced as well as its composition (grade), and by calculating the amount (dry mass) of tail produced and measuring its composition (grade). 
As mentioned in Section 1.1 each process (mining, concentrators, smelters, etc.) operates as a separate business unit and therefore all ore received from the mine must be accounted for in the final concentrate product at the concentrator. Thus the concentrator has to allocate all metal in the final concentrate product to the various shafts. The current metal accounting system at the concentrator uses the grade and tonnage provided by each shaft as well as the recovery of ore in their pure form (based on the head grade provided by the shaft) to allocate metals in the final product to the various shafts. The ratio of metal content in ore from the shafts to metal content in the final product is used as a factor to allocate any excess/shortage of metal in the final product to the various shafts. Measurements for metal accounting at the Waterval UG2 concentrator are taken as follows:

\subsubsection{Bulk mass measurement}

At the Waterval UG2 concentrator the total quantity of dry material entering and leaving the plant has to be measured. The mass of ore that enters the plant (plant feed) is measured by a weightometer (belt scale) on the mill feed conveyor belt. A sample is required to determine the moisture content of the ore so the dry mass can be calculated. The mass of the product material is measured by a weighbridge. Again a sample is required to determine the moisture content of the product so the dry mass can be calculated. Once the mass of the material entering the plant (input) and the mass of the product material is known, the mass of the reject material (tail) can be calculated by subtracting the product mass from the feed mass.

\subsubsection{Sampling}

It is not feasible to measure the total moisture content and metal grade of the whole inventory. Therefore a smaller portion of material needs to be obtained from the larger quantity (bulk). This smaller portion is called a sample. A sample is representative if each particle in the bulk has an equal probability of being selected. At the Waterval UG2 concentrator the mill feed sample is obtained with stop belt sampling. The sample is analysed only for moisture in order to determine

dry mass. An additional plant input sample is obtained with a slurry sampler at the mill discharge and this sample is analysed for metal grade. The sample for the product is collected by means of an Auger sampler taken from a truck at the smelter and is analysed both for moisture and metal grade. The tail sample is collected with a slurry sampler before the tails are sent to a tailings dam. 


\subsubsection{Sample preparation and assay}

Usually only a small portion of the initial sample is required to determine the metal grade. Sample preparation involves reducing the sample size (sub sampling) and the particle size (comminution) to obtain a smaller, representative portion. This portion is then analysed in duplicate to minimize uncertainties surrounding the analytical technique.

\subsection{AMIRA P754 RESEARCH PROJECT}

AMIRA is an independent minerals research association. The AMIRA P754 research project is a collaborative research project that aims to develop international standards and tools for metal accounting balancing, reconciliation and reporting from mine resource to final product. The main objective is to improve the credibility and reporting process of mining activities with corporate governance as the driving cause by developing guidelines for data collection, data analysis, reporting and audits, as well as a toolbox for metal balance data. The research presented in this thesis forms part of the AMIRA P754 research project.

\subsection{OBJECTIVES OF THIS RESEARCH THESIS}

As mentioned in Section 1.1 the Waterval UG2 concentrator receives ore from various Anglo Platinum shafts in Rustenburg. In addition, new expansions and ventures throughout Anglo Platinum will generate additional ore sources that contribute to the plant input. The providers of these ores have to be compensated for the ore (either internally or via toll contracts or joint ventures). Compensation is normally based on the recovery of the valued minerals within the ore and the recoveries are determined in advance on only the pure ore. These recoveries are then used for internal allocation of metals to shafts or in a contractual agreement (between Anglo Platinum and the external provider) for payment. It is not always feasible or economical to batch process ore from these different sources. Ore reserves from the various sources are not adequate to satisfy daily output and the process should not be interrupted as this not only decreases process stability but also increases operational cost. The concentrator capacity is not designed to accommodate ore handling for batch processing. The transition from one ore type to another can also create quality and productivity issues in the process (Aaseng and Harrison, 2000).

A second option is to blend ore reserves. In some industries blending of various materials can be quite accurate. For example, in the ceramic industry clay is blended by making use of silos on load cells that are operated according to a computer calculated weight loss system that is accurate 
to $\pm 0.5 \%$ (Canning, 2000). However, in the mining industry the most common method of blending is stockpiles. According to Kumral (2006), the efficiency of a stockpile depends on the following three factors: 1) The stockpiling method, for example Chevron or Windrow; 2) Stockpiling parameters, for example length, width, number of layers and 3) The variability of stockpile input, for example waste, sludge material or fines from de-dusting operations (Bourke et al., 1976). A major contributor to the variability of stockpile input is also the mining operations as variable feed grade will destabilize the process. It has been shown that by implementing selective mining practices and increasing plant capacity, it is possible to improve recoveries (Miller, 2003).

Currently the ores at Waterval UG2 concentrator are blended at random before processing. If, for some reason, blending of these ores causes an unexplained decrease in recovery, the concentrator will run at a loss because it is paying for minerals that it could not recover. The aim of this thesis is to determine the effects of blending on metallurgical performance at the Waterval UG2 concentrator in terms of its impact on milling and flotation behaviour.

The major section in the literature review in Chapter 2 contains an evaluation of various experimental designs that can be used to determine the effects of mixtures on milling and flotation performance. An introductory section of the chapter is devoted to describing the principles of milling and flotation. The review then evaluates possible experimental designs and how current ore blends/mixtures have been assessed in the mineral processing environment. The mixture design selected for this research project is discussed. In Chapter 3 the general mineralogy of UG2 ore and the characterization of UG2 ore (from four shafts) processed at the Waterval UG2 concentrator are described. The sampling and subsampling of the different ores used in the experimental design are also described. The milling and flotation technique is then discussed. Actual experimental data, from the experimental design, is used in Chapter 4 to show the technique used to determine the most efficient model to apply to the experimental design. This chapter also summarizes how results from the experimental design are interpreted and how synthetic data was used to validate the experimental design. The interpretation of the laboratory milling and flotation results and the implication of these results on metal accounting are then discussed. Chapter 5 summarizes the findings and conclusions of this research project and future work in this field is recommended. 


\section{CHAPTER 2 LITERATURE REVIEW}

Section 2.1 covers the introductory part of this review and is devoted to describing the principles of milling and flotation. In the major part of this review in Section 2.2 various experimental designs of relevance to the research presented in this thesis are evaluated, which can, for example, be used to develop a methodology to evaluate the effects of mixtures on milling and flotation performance. In Section 2.3 the review also investigates how blends/mixtures have previously been evaluated in the mineral processing environment. The scope and objective of this thesis are discussed in Section 2.4.

\subsection{MILLING AND FLOTATION}

The aim of flotation is to separate the precious group minerals present in an ore body from the rest of the minerals. Flotation normally involves first milling the ore into a fine powder and mixing it with water so it forms a slurry (Bakker, 2005). The milling section in this review is partially derived from Wills and Napier-Munn (2006). The flotation section in this review is partially derived from reviews done by Bradshaw (1997), Deglon (1998), Lewis (2003) and van der Westhuizen (2004).

\subsubsection{Milling}

\subsubsection{Principles of milling}

According to Wills and Napier-Munn (2006), comminution is the progressive reduction of particle size until the clean mineral particles can be separated. Comminution is a prerequisite for flotation because it liberates the precious group metals to be separated. Minerals normally consist of a crystalline lattice packed with atoms. The bonds between these atoms are only effective over short distances and can be broken by pressure. The addition of water and chemical additives to the grinding process will reduce the energy required for comminution. The mineral particle size is reduced by three different forces: crushing, impact or friction. When mineral particles are broken by crushing, coarse as well as fine material is generated. Impact breaking will generate particles similar in shape and size, while friction will generate a large amount of fine material. Thus comminution will cause physical (for example shape, surface area and size) and chemical (for example lattice distortion and polymorphic) changes in the ore. The extent of these changes depends on the ore and mill type as well as the environmental factors, for example temperature 
and pressure (Ulusoy et al., 2003). These changes will also affect flotation, for example: The

particle shape determines the hydrophobicity and will affect separation and recovery during flotation. A smooth elongated particle will be more hydrophobic than a rough round particle.

\subsubsection{Types of mills}

A grinding mill is normally a rotating, cylindrical, steel vessel containing a grinding medium that can move freely inside. Grinding mills can be classified into tumbling mills and stirring mills. In tumbling mills the grinding media is moved by rotating the mill shell, while stirring mills make use of an internal stirrer to cause motion in the grinding media, while the mill shell is kept stationary. Tumbling mills are normally used in the minerals processing industry. There are three types of tumbling mills; they are the ball mill, the rod mill and the autogenous mill. The ball mill makes use of steel balls as a grinding medium. The milling process is completely random and grinding takes place via point contact between the balls and ore particles. Therefore the probability that a ball will strike a fine particle is the same as for a coarse particle and the product is quite fine. The rod mill uses steel rods with various diameters as grinding media. Grinding takes place via line contact between the rods and the ore. The rods tumble and spin, simulating a set of crushing rolls. As the large particles wedge between the rods they are milled first and this generates a product with a fairly narrow size range. Autogenous milling uses the ore itself as grinding media. The ore is normally run off mine ore, or the product of a primary crusher. The particle size distribution of the product depends on the characteristics of the ore itself.

Each mill exerts a different type of force on the ore and thus the type of mill used may determine the shape of mineral particles in the milled product (Hiçyilmaz et al., 2004). For example, the main mechanism in autogenous mills is abrasion while ball and rod mills use impact crushing. Therefore the autogenous mill generates lesser fines than the ball or rod mill (Ulusoy et al., 2003). The type of mill used is not the only factor that affects the particle shape. There are also centrifugal and frictional forces when the particles are in contact with the liners and lifters (Khanal et al., 2008), and the type of mineral, blasting characteristics under ground, grinding media size etc. also play a role (Salazar et al., 2009). A higher mill load can also increase the wear rate of particles. Even the way the mineral is packed in the ore body can determine the liberation of the precious group metals (Rixom, 2004). 


\subsubsection{Flotation}

Froth flotation is a method used to separate minerals from an unwanted matrix. In 1860 Haynes recognized the difference in the wettability of mineral particles by oil and water. This was the initiate of oil flotation. In 1902 Potter realized the potential for using gas bubbles to carry sulphide mineral particles to the surface of an ore pulp. Nine years later froth flotation was first used commercially at Broken Hill to treat zinc-rich lead tailings. Froth flotation selectively separates minerals by using the differences in their chemical and physical properties. The wanted minerals are conditioned with reagents, making them hydrophobic and adhesive to air bubbles. Froth is generated with a frothing agent and air bubbles and the wanted minerals are extracted from their surrounding matrix due to their affinity to the bubbles. The froth is then removed, rendering what is called the concentrate, leaving the slurry (tails) behind. Besides mineral processing, flotation also has several other uses in industry. It can, for instance, be used for the purification of water or to remove oil from refining waste. It can also be used to remove textile fibres from the process stream and in the separation of dyes. The flow diagram in Figure 2.1 describes the sub processes required for froth flotation. The sub processes are then discussed in Section 2.1.2.1.

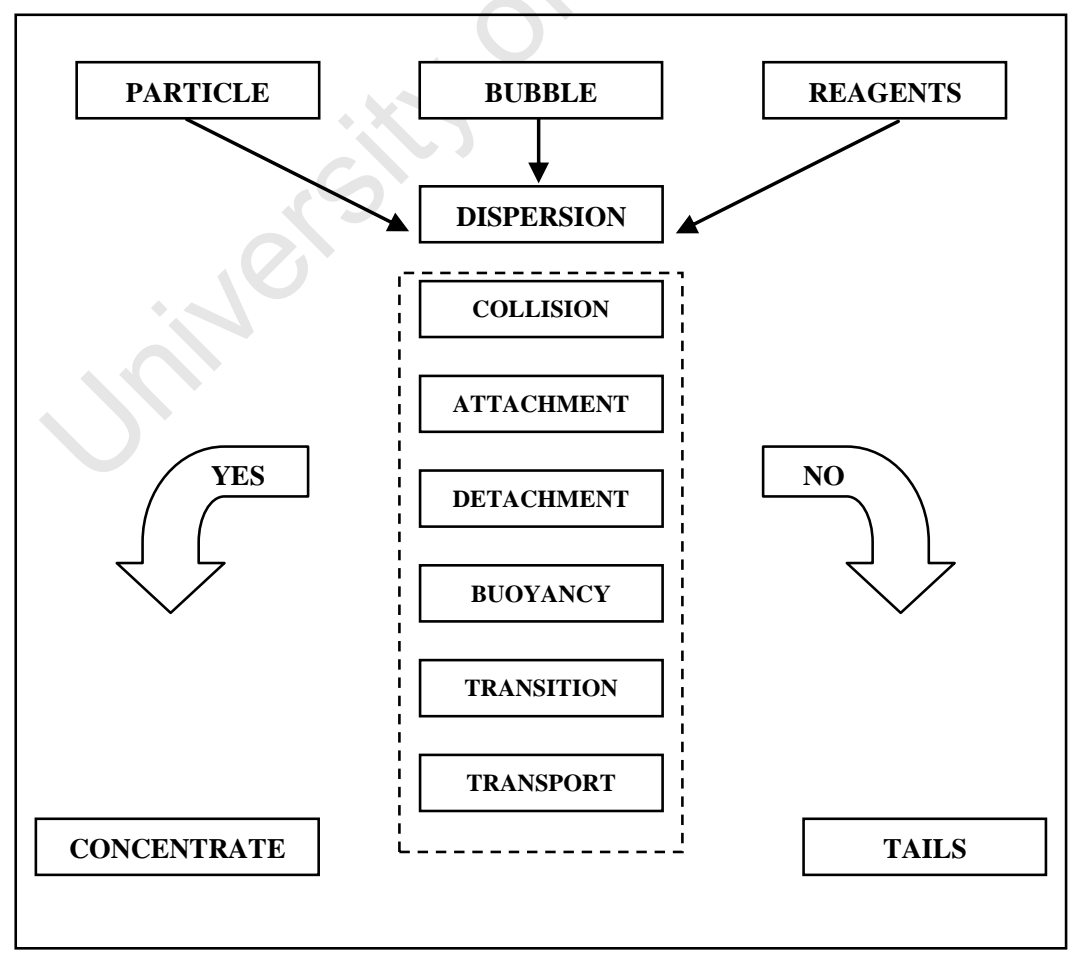

Figure 2.1 Schematic representation of the process of froth flotation. 


\subsubsection{Principles of flotation}

According to Schulze (1984), the sub processes of froth flotation can be divided into three areas, which are conditioning, particle collection and froth removal.

\section{Conditioning}

There are a number of reagents required for conditioning in the flotation process. The main reagents are promoters (also known as activators), collectors, depressants and frothers. Promoters are used to activate certain mineral species in the slurry, to enable the collector to make them hydrophobic. They are generally copper sulphate, sodium sulphide or sodium bisulphide. Collectors are used to selectively make the desired minerals hydrophobic so that they can attach to the bubble surface. Collectors are heteropolar molecules that contain a non-polar hydrocarbon chain and a polar group that interacts with the mineral surface. The non-polar group then creates a hydrophobic surface that is in contact with the water. Depressants are used to suppress the natural floatability of the unwanted (gangue) minerals in the slurry like talc or other oxide minerals. The mechanism used by some depressants is to form large aggregates and complexes of the collector in solution. Frothers are used to promote bubble formation and to stabilize the froth layer on the surface of the flotation cell and to increase the flotation kinetics. They are heteropolar non-ionic molecules. The polar end forms hydrogen bonds with water while the hydrophobic non-polar end concentrates in the air, forming a layer on the water surface.

Besides the above, the $\mathrm{pH}$ and $\mathrm{Eh}$ (measure of the oxidation-reduction potential) can also be conditioned to influence flotation. $\mathrm{pH}$ is the measure of the $\mathrm{H}^{+}$ion concentration and will influence the chemistry of the reagents. Eh is the pulp potential and is measured relative to the standard hydrogen electrode. They are usually controlled by the reagents, but can be modified individually as well. Consequently the water used for the pulp should have a natural $\mathrm{pH}$.

\section{Particle collection (Basics of operation)}

Particle collection can be divided into three secondary processes, which are collision, attachment and detachment. Collision is the contact between the conditioned mineral particles in the slurry and the gas bubbles. The mineral particle attaches itself to the bubble and is conveyed to the froth phase, but not all mineral particles that attach to the bubble are conveyed to the froth phase. Some mineral particles can detach themselves from the bubble 
through various circumstances. The three secondary processes are described in more detail in the subsequent paragraphs.

\section{Collision}

For a particle to collide with a bubble, it should not follow the streamlines around the bubble but rather have enough momentum to resist the streamline (Ahmed and Jameson, 1989). An ideal collision is where the magnitude and velocity of particle are not changed, the particles follow the stream lines of the bubble, the inertial effect of the particle overcomes the stream line effect and increases collision and gravitational forces. Besides the above, collision between the bubble and particle can also be affected by factors like turbulent regions behind the bubble, turbulent particles and bubble cloud formation.

\section{Attachment}

The attachment of a particle to the bubble can be described by the following process (Ahmed and Jameson, 1989): The particle approaches the bubble and the water film between the particle and the bubble is reduced. This is the most important step and depends on the contact between the particle and the bubble (Schulze, 1989), which is characterized by the collision time or the sliding time. The collision time is when the particle impacts on the bubble, thereby deforming the surface. The sliding time is when the particle slides along the bubble, thereby deforming the surface. The water film must diminish to give an interface between the solid phase and the gas phase.

\section{Detachment}

Detachment is an unwanted process that will result in a reduction of recovery. When the bubble with the particle rises to the froth phase, the particle will reside on the bubble, only if the conditions in the cell are stable. According to Ahmed and Jameson (1989), this will only happen if the restoring force for the surface tension on the bubble balances the force associated with the weight of the particle. This balance also determines the maximum particle size that will still float. In some cases the surface hydrophobicity, a larger bubble size and a smaller particle size can also improve retention.

\section{Separation}

With separation the aim is for the bubble with the wanted particle to separate from the liquid film of the slurry and the hydrophilic unwanted (gangue) minerals. The bubble with the 
particle should have enough buoyancy to rise through the pulp and be stable enough to withstand conditions in the pulp. The bubbles that reach the froth phase will remain beneath the froth for a while, until the liquid film drains away. Yet this does not always occur as the bubbles form clusters when moving from the slurry to the froth phase. This will entrain slurry material that will be transported to the froth phase. Conditions in the cell may also affect stability in the cell, thereby causing bubbles to rupture, and wanted minerals to be lost.

\subsubsection{Types of flotation cells}

There are three basic types of flotation cells.

a. Mechanical flotation cells - These cells are the most widely used in the industry. They consist of a tank and an impeller that generates the agitation. Agitation is required for gas dispersion, keeping the solids in suspension and ensuring contact between the bubbles and the particles. A disadvantage of these cells is that the froth level is not very deep and entrainment can cause a lower concentrate grade.

b. Column flotation cells - These cells consist of a long column where fresh slurry is added to the top. Bubbles are generated near the bottom of the cell and as the bubbles flow to the surface they collect particles. The froth phase in this cell is much deeper and will result in a higher concentrate grade.

c. Novel flotation cells - The designs of these cells focus on two areas. Improving gas dispersion by the use of micro bubbles and improving the contact between the bubbles and the particles, by increasing the agitation.

\subsection{EXPERIMENTAL MIXTURE DESIGN}

This section is partially derived from reviews by Lundstedt et al. (1998), Eriksson et al. (1998), Cornell (2002) and the NIST online handbook (SEMATECH). An experimental design is used to systematically investigate problems during research, development and production. During an experimental design the condition and environment can be controlled and the results can assist in optimization of these conditions and/or environment. An experimental design can only be selected once the objective and measurable responses are known. Experiments can then be performed according to the experimental design and the responses can be measured. Thus the information that is required for the investigation determines how the experiments will be designed. The response from the investigation can often be described with an empirical model. 
In other words the response can be described as a function based on some experimental variables as indicated in Equation 2.1. This function can then be used to predict the response under certain experimental conditions. Thus

$$
y=f(x)
$$

With $\mathrm{y}=$ The response value

$f(x)=$ The function based on experimental variable $x$

The objective of an experimental design determines the number of experimental trials and thus the complexity of the empirical model. There are five experimental design objectives:

a. Comparative objective - The comparative design solution enables the researcher to determine if one specific factor (among other factors) has a significant effect on the response.

b. Screening objective - The main purpose of a screening design is to determine what main factors contribute the most to the response relative to all the other less important factors.

c. Response surface objective - The response surface method design enables the researcher to estimate interaction during the process. Its use is threefold:

- It can be used to explain poor results and find weak points in the process.

- It can be used to find and optimize process settings.

- It can be used to make a process more robust against external or uncontrollable influences.

d. Optimizing responses when factors are proportions of a mixture objective - A mixture design is used when the process components are represented as factors of a mixture. The researcher then has to determine what the best proportion of these factors is to maximize or minimize the response.

e. Optimal fitting of a regression model objective - A regression design is used to model a response as a mathematical function and to determine the best model parameter estimates, for example parameters that are unbiased and have the lowest variance.

According to Eriksson et al. (1998), when the objective is screening, fewer experiments are needed than, for example, optimization. The order of the experiments should be random, to 
eliminate the influence of any systematic trends on the response value, for example an improvement in the skills of the experimenter or the degrading of equipment.

\subsubsection{Mixture designs}

According to Cornell (2002), the definition of a mixture experiment is "an experiment in which the response is assumed to depend only on the relative proportions of the ingredients present in the mixture and not the amount of the mixture. In a mixture experiment then, if the total amount is held constant and the value of the response changes when changes are made in the relative proportions of those ingredients making up the mixture, then the behavior of the response is said to be a function of the joint blending property of the ingredients in the mixture". A mixture experiment will have two outcomes. Firstly, by fitting an empirical model, the response value for any combination of ingredients/components can be predicted. Secondly, the influence of each separate component as well as any combination of components on the response value can be evaluated.

\subsubsection{Principles of mixture designs}

When evaluating mixture designs there are two types of factors that can have an effect on the response value:

a. Components (or mixture factors)

The proportions of a component in relation to the other components are used as the experimental variables. The main requirement of a mixture is that the sum of all its components must add up to 1 . This requirement sets a constraint on the empirical model. For these standard mixture designs there are standard models like simplex lattice or simplex centroid (cf. Sections 2.2.2 and 2.2.3, respectively). For further constraints like a maximum or minimum value for each component a constrained mixture design like the extreme vertices design can be used. Some mixture designs may require the presence of a filler. A filler will have no effect on the final response on its own, but its presence is required to obtain the response and thus it will always be present in the mixture - usually in a large amount. Only one component can be identified as a filler.

Mixture factors cannot be random variables. They have to be systematically controlled numbers or constants. If they are constants they are kept unchanged throughout the 
whole experimental design. The mixture factors then add up to $\mathrm{T}$, as indicated in Equation 2.2:

$$
\mathrm{T}=1-\sum \text { (constant mixture factors) }
$$

b. Process factors

Process variables are factors that contribute to an experiment but they do not form part of the mixture proportions. Yet when their level changes they do affect the blending properties of the ingredients. "A process factor is an experimental parameter that is not part of the actual mixture" (Lundstedt et al., 1998); rather, it controls the experimental conditions, for example pressure or temperature. It can either be quantitative or qualitative.

The experimental region is the area that is described by the experimental variables in the empirical model and it can be represented by means of geometry. "When mixture factors vary from 0 up to $\mathrm{T}$ (the mixture total), the shape of the experimental region is a simplex. A simplex is a geometric figure with $n+1$ corners in an n-dimensional space" (Lundstedt et al., 1998). For example: If the region is regular a simplex in two dimensions $(n=2)$ will be an equilateral triangle as indicated in Figure 2.2.

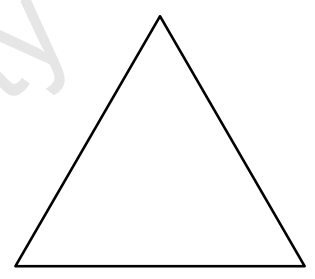

Figure 2.2 Equilateral triangle.

In three dimensions $(\mathrm{n}=3)$ it becomes a tetrahedron as indicated in Figure 2.3.

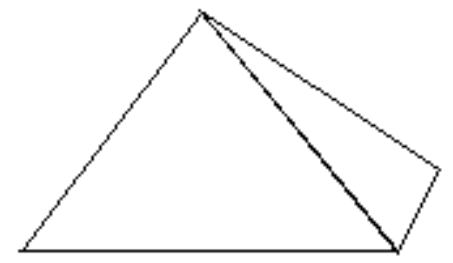

Figure 2.3 Tetrahedron. 
The range of any mixture component can be defined by its upper and lower bounds expressed by means of Equation 2.3:

$$
\mathrm{R}_{\mathrm{k}}=\mathrm{U}_{\mathrm{k}}-\mathrm{L}_{\mathrm{k}}
$$

$$
\text { With } \begin{aligned}
\mathrm{R}_{\mathrm{k}} & =\text { Range } \\
\mathrm{U}_{\mathrm{k}} & =\text { Upper bound } \\
\mathrm{L}_{\mathrm{k}} & =\text { Lower bound }
\end{aligned}
$$

A simplex region can be identified mathematically. When the region is a regular simplex it is defined by either the upper bound, rendering $R_{U}$ as indicated in Equation 2.4, or the lower bound, rendering $\mathrm{R}_{\mathrm{L}}$ as indicated in Equation 2.5:

$$
\begin{aligned}
& \mathrm{R}_{\mathrm{U}}=\sum \mathrm{U}_{\mathrm{k}}-1 \\
& \mathrm{R}_{\mathrm{L}}=1-\sum \mathrm{L}_{\mathrm{k}}
\end{aligned}
$$

A bound is inconsistent if $\mathrm{U}_{\mathrm{k}}>\mathrm{U}_{\mathrm{k}} *$ as indicated in Equation 2.6 or if $\mathrm{L}_{\mathrm{k}}<\mathrm{L}_{\mathrm{k}} *$ as indicated in Equation 2.7:

$$
\begin{aligned}
& \mathrm{U}_{\mathrm{k}} *=\mathrm{L}_{\mathrm{k}}+\mathrm{R}_{\mathrm{L}} \\
& \mathrm{L}_{\mathrm{k}} *=\mathrm{U}_{\mathrm{k}}-\mathrm{R}_{\mathrm{U}}
\end{aligned}
$$

When a bound is inconsistent it is replaced by $\mathrm{U}_{\mathrm{k}} *$ or $\mathrm{L}_{\mathrm{k}} *$ and $\mathrm{R}_{\mathrm{L}}$ and $\mathrm{R}_{\mathrm{U}}$ are recalculated and the following applies:

$$
\text { If } \mathrm{R}_{\mathrm{U}}=\mathrm{R}_{\mathrm{L}} \text { the region is not a simplex }
$$

If $\mathrm{R}_{\mathrm{L}}<\mathrm{R}_{\mathrm{U}}$ the region is an $\mathrm{L}$-simplex if $\mathrm{R}_{\mathrm{k}}=\mathrm{R}_{\mathrm{L}}$ for all values of $\mathrm{k}$ If $R_{U}<R_{L}$ the region is a $U$-simplex if $R_{k}=R_{U}$ for all values of $k$

However, some mixture factors may be constrained, thus having bounds before 0 or $\mathrm{T}$ is reached. This results in some of the simplex region not being explored. If there is only one similar bound per factor, the restricted experimental region will be a smaller simplex within the original 0 to $\mathrm{T}$ simplex. But if the factors have several constraints, the experimental region will be an irregular polyhedron within the original 0 to $\mathrm{T}$ simplex. 


\subsubsection{Interpretation of mixture designs}

The following section describes how results from a mixture experiment are interpreted. As mentioned before, by fitting an empirical model to an experimental mixture design, the response value for any combination of ingredients/components can be predicted. For mixture designs a regression polynomial equation can be generated. This polynomial equation can have linear terms, quadratic terms, cubic terms etc. An example of a polynomial equation is given in Equation 2.8. For all non-linear terms each term in the equation will have a coefficient with a positive or negative sign. If the sign is positive the interaction between the components in the term is synergistic, and if the sign is negative the interaction between the components in that term is antagonistic. Coefficient $\mathrm{d}$ has a negative sign and thus the binary interaction between components $\mathrm{x}_{1}$ and $\mathrm{x}_{2}$ is antagonistic. Coefficient $\mathrm{e}$ has a positive sign and thus the binary interaction between components $\mathrm{x}_{1}$ and $\mathrm{x}_{3}$ is synergistic.

$$
\mathrm{y}=\mathrm{ax}_{1}+\mathrm{bx}_{2}+\mathrm{cx}_{3}-\mathrm{dx}_{1} \mathrm{x}_{2}+\mathrm{ex}_{1} \mathrm{x}_{3}
$$

The quality of the mixture design and the resulting polynomial equation can be evaluated according to the following:

a. The coefficient of determination $\left(\mathrm{R}^{2}\right)$ or the adjusted coefficient of determination $\left(\mathrm{R}_{\mathrm{adj}}{ }^{2}\right)$ - The coefficient of determination $\mathrm{R}^{2}$ measures the correlation between the experimental data and the data calculated using the regression polynomial (Romagnoli and Rivasi, 2007). The closer this is to 1 , the better the correlation and the more reliable the regression polynomial. The coefficient of determination $\left(\mathrm{R}^{2}\right)$ will increase as the number of terms (whether they are significant or not) in the polynomial equation increases. The adjusted $\mathrm{R}^{2}$ disregards the effect of the number of terms (Cornell, 2002).

b. ANOVA (F-test) - The F-test hypothesizes that at least one of the coefficients in the polynomial is non-zero. If the p-value (probability) is less than, say, 0.05 then at least one coefficient is non-zero (Bruns et al., 1996).

c. Parameter estimates - Parameter estimates indicate the significance of the coefficient before each term in the polynomial equation. A t-test is performed on each term and if the p-value (probability) is less than, say, 0.05 then the coefficient is non-zero, i.e. the interaction is significant (Naes et al., 1999). 
Binary and ternary contour plots may also be used to graphically identify antagonistic (or synergistic) effects. These plots show the response value as a function of the relative proportion of either two (binary) or three (ternary) components in the mixture. Figure 2.4 gives an example of a binary plot. The $\mathrm{x}$-axis presents component $\mathrm{x}_{1}$ in increasing proportion from left to right and component $\mathrm{x}_{2}$ in decreasing proportion from left to right. The $\mathrm{y}$-axis represents the response value. The straight black line indicates a linear (or additive) effect between component $\mathrm{x}_{1}$ and component $\mathrm{x}_{2}$. The curved blue line below the straight black line indicates an antagonistic effect between the two components (concave). If there were a synergistic interaction between the two components it would be presented by a curved line above the linear line (convex).

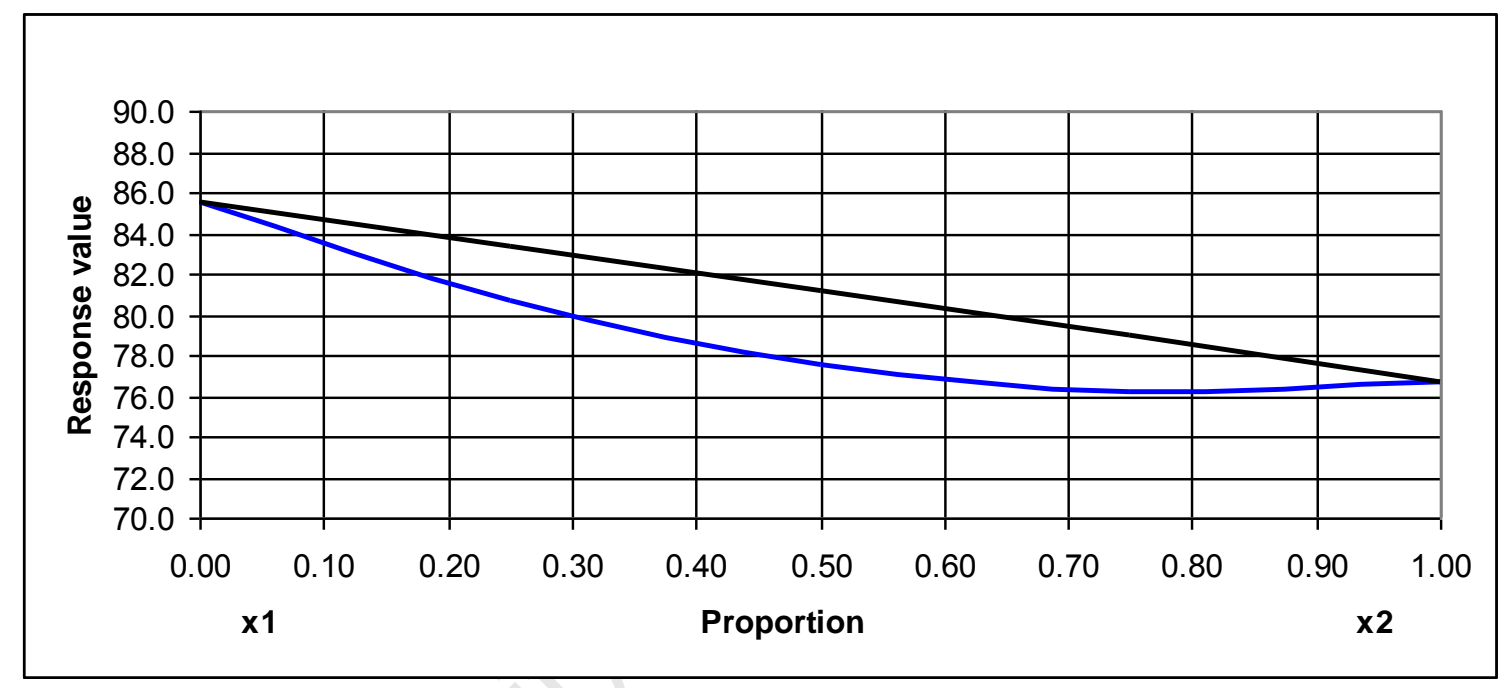

Figure 2.4 Example of a binary plot.

Figure 2.5 gives an example of a ternary contour plot between three components, namely $\mathrm{x}_{1}, \mathrm{x}_{2}$ and $\mathrm{x}_{3}$. In Figure 2.5a each component in its pure form is represented at a corner of the triangle. The proportion of each component in the mixture varies as it moves along the sides of the triangle. For example, the bottom left-hand corner represents $100 \%$ of $x_{2}$ in the mixture. Then as you move away from this corner (either along the sides of the triangle or to a space within the triangle), the proportion of $\mathrm{x}_{2}$ decreases. In Figure 2.5a the contour lines are curved indicating binary/ternary/cubic etc. interactions between components. Any point on the triangle will represent a certain combination of the three components with a contour line indicating the associated response value. The contour lines in Figure 2.5a show that as the proportion of $\mathrm{x}_{1}$ increases, the values on the contour lines (and thus the response value) will increase, rendering a synergistic effect. On the other hand, as the proportion of $\mathrm{x}_{2}$ increases, the response value will decrease, rendering an antagonistic effect. The contour lines in Figure 2.5b are linear indicating 
no binary/ternary/cubic etc. interactions between components. Here $\mathrm{x}_{3}$ will have a synergistic effect and $\mathrm{x}_{1}$ an antagonistic effect.

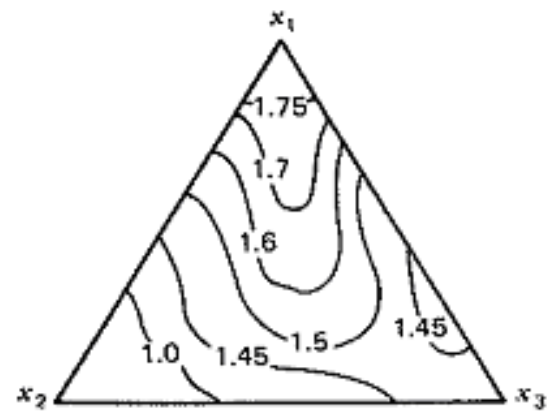

a

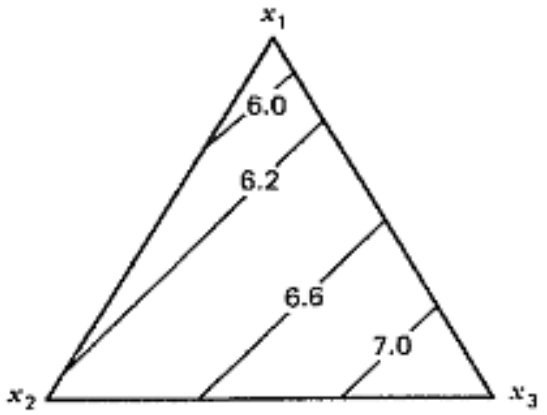

b

Figure 2.5 Example of a ternary contour plot (Cornell, 2002).

\section{Factorial experimental design vs mixture designs}

The factorial experimental design is well known and widely applied. The mixture design is an application of the normal factorial design. The following section reviews why a mixture design (as opposed to the normal factorial deign) is used when evaluating mixture experiments. Naes et al. (1999) conducted test work and compared the results obtained with a factorial design with results obtained with a mixture design. They used a central composite design for a factorial design (also referred to as the unconstrained approach) and independent variables in a constraint region for a classical mixture design (also referred to as the constrained approach).

A factorial design evaluates all experimental variables, factors and interaction effects on the response value. For example, if the combinations of $\mathrm{k}$ factors have to be investigated at two levels, the factorial designs will consist of $2^{\mathrm{k}}$ levels. The levels are represented by a minus sign (-) for a low level and plus sign (+) for a high level, as well as a zero level where all variables are set at the mid value. As with a mixture design, the factorial design can also be presented by a function or equation. For a linear function only two levels (low and high) of each factor are required to describe the behaviour of the response value. For a quadratic function at least three levels of each factor are required to describe the response value. For a cubic function at least four levels of each factor are required to describe the response value. Quadratic functions are nearly always adequate for industrial applications. A central composite design is a classical quadratic design that is often used for response surface designs. An equation for a quadratic model is given in Equation 2.9. 


$$
y=b_{0}+b_{1} x_{1}+b_{2} x_{2}+b_{3} x_{3}+b_{12} x_{1} x_{2}+b_{13} x_{1} x_{3}+b_{23} x_{2} x_{3}+b_{11} x_{1}^{2}+b_{22} x_{2}^{2}+b_{33} x_{3}^{2} \text { (Eq. 2.9) }
$$

In a fractional factorial design only a fraction of the experiments required by a full factorial design are conducted. This is due to the fact that the number of experiments will increase with the number of variables. For example, if the number of variables/factors is 7 , at least $2^{7}=128$ experiments will be required and this is not always possible. Thus with a fractional factorial experiment a fraction like $1 / 2$ or $1 / 4$, of the total experiments required, are conducted.

Figure 2.6 represents a Box-Wilson central composite design (also known as a central composite design). This design contains an imbedded factorial or fractional factorial design with centre points that are amplified with a group of star points that enable the estimation of the curve.

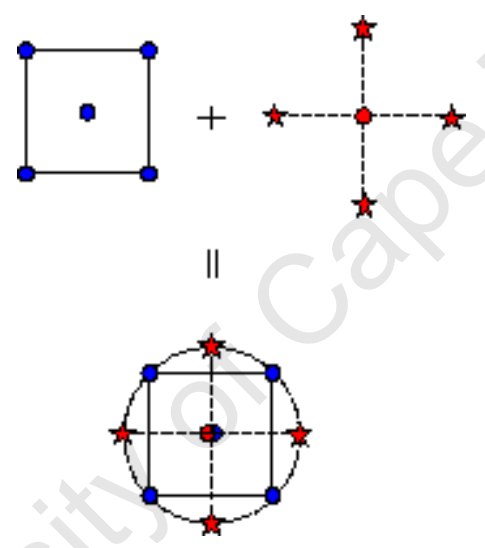

Figure 2.6 Example of a central composite design (NIST/SEMATECH).

\subsubsection{Case study}

As discussed previously, the purpose of this case study is to illustrate the difference between a normal factorial design and a mixture design. Naes et al. (1999) used three different flours to bake bread. The three flours were mixed into nine different blends (indicated in Figure 2.7). Three centre samples were produced and three mixing times of each blend were evaluated as a process factor. Each experiment was conducted twice, rendering 66 experiments in total. The form ratio (loaf width:loaf length) was used as a measured response. The greater the ratio, the better the bread. 


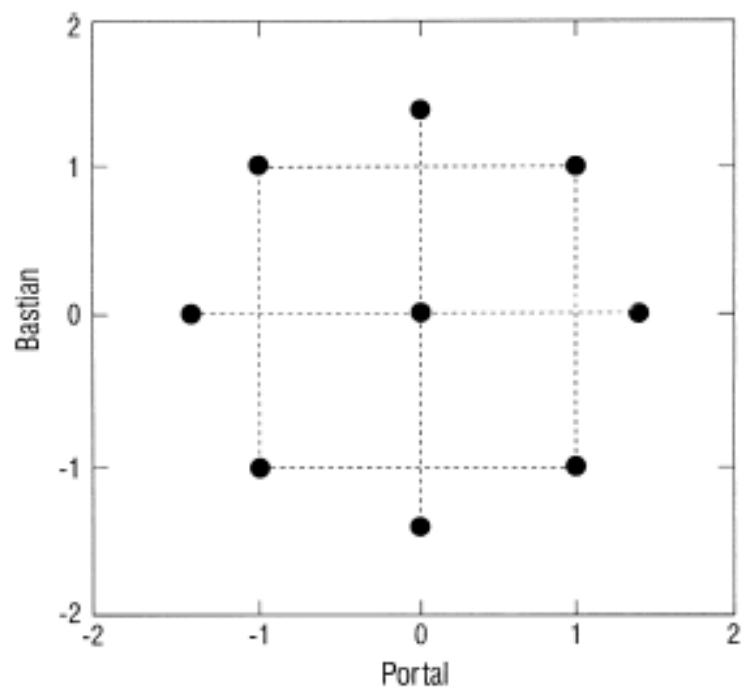

Figure 2.7 Central composite designs of nine different flour blends (Naes et al., 1999).

The respective models used for the unconstrained (Equation 2.10) and constrained (Equation 2.11) approach were as follows:

Unconstrained:

$$
\begin{aligned}
& \mathrm{y}=\mathrm{b}_{0}+\mathrm{b}_{1} \mathrm{x}_{1}+\mathrm{b}_{2} \mathrm{x}_{2}+\mathrm{b}_{11} \mathrm{x}_{1}{ }^{2}+\mathrm{b}_{22} \mathrm{x}_{2}{ }^{2}+\mathrm{b}_{12} \mathrm{x}_{1} \mathrm{x}_{2}+\mathrm{a}_{1} \mathrm{z}+\mathrm{a}_{2} \mathrm{z}^{2}+\mathrm{c}_{1} \mathrm{x}_{1} \mathrm{z}+\mathrm{c}_{2} \mathrm{x}_{2} \mathrm{z}+\mathrm{c}_{11 \mathrm{z}} \mathrm{x}^{2} \mathrm{z}+\mathrm{c}_{22 \mathrm{z}} \mathrm{x}_{2}{ }_{2} \mathrm{z} \\
& +c_{1 z z} x_{1} z^{2}+c_{2 z z} x_{2} z^{2}+d_{12 z} x_{1} x_{2} z+e
\end{aligned}
$$

\section{Constrained:}

$$
\begin{aligned}
y= & b_{1} x_{1}+b_{2} x_{2}+b_{3} x_{3}+b_{12} x_{1} x_{2}+b_{13} x_{1} x_{3}+b_{23} x_{2} x_{3}+c_{1} x_{1} z+c_{2} x_{2} z+c_{3} x_{3} z+c_{12} x_{1} x_{2} z+c_{13} x_{1} x_{3} z \\
& +c_{23} x_{2} x_{3} z+d_{1} x_{1} z^{2}+d_{2} x_{2} z^{2}+d_{3} x_{3} z^{2}+e
\end{aligned}
$$

With $\mathrm{x}_{\mathrm{i}}=$ Component (mixture) factor

$\mathrm{z}=$ Process factor (mixing time)

The two models indicated different parameters of the same model. The residuals and fitted values were identical. From the results the following were found:

Figures 2.8 and 2.9 show unconstrained and constrained contour plots of the results, respectively. When looking at the figures below it is evident that as the amount of Folke flour increases, the form ratio decreases. Thus when evaluating the two figures it is clear that the effect of $x_{3}$ (Folke flour) is the main cause for a reduction in the form ratio. Yet this is much more visible for the 
constrained model than for the unconstrained model as the unconstrained model in Figure 2.8 does not show the simultaneous effect of all three flours on the form ratio. Thus the factorial design does not cover the experimental region properly.
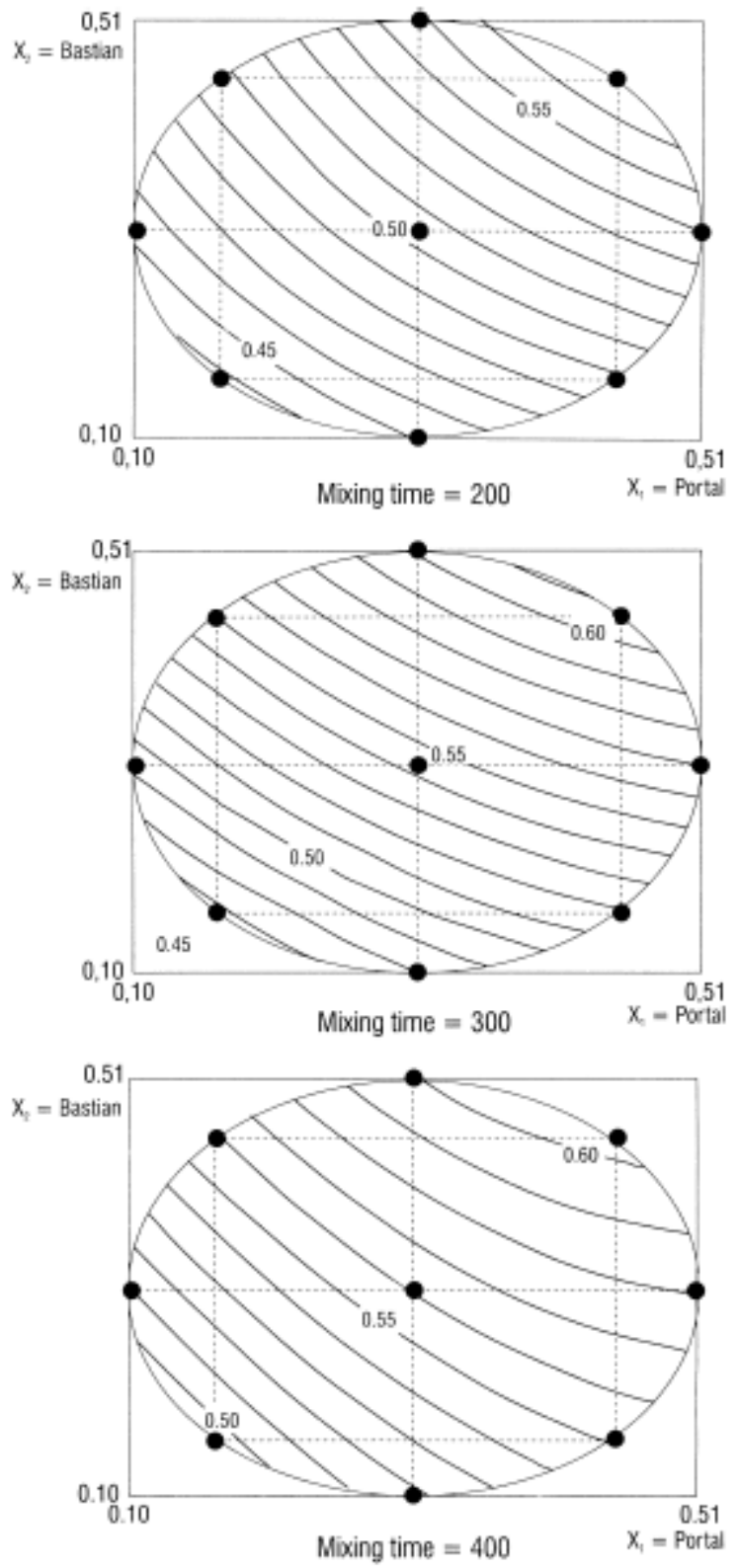

Figure 2.8 Unconstrained plot (Naes et al., 1999). 

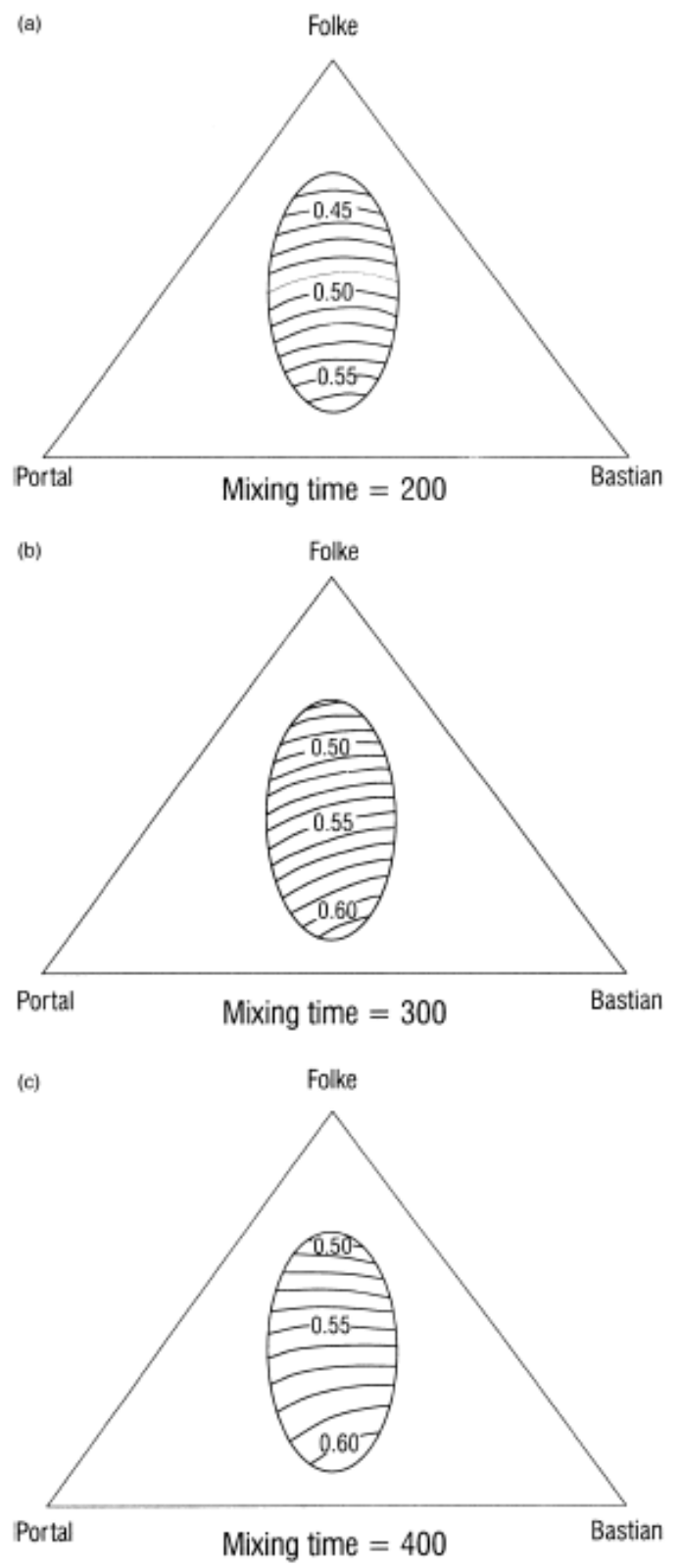

Figure 2.9 Constrained plot (Naes et al., 1999).

Table 2.1 shows the regression coefficients for both models. $\mathrm{R}^{2}$ was 0.9 for both models, which indicates a good fit for experimental results. The coefficients were evaluated at a $95 \%$ significance. The constrained model indicates a significant non-linearity related to the product of $\mathrm{x}_{1}$ and $\mathrm{x}_{3}$, which is not visible in the unconstrained model. 
Table 2.1 Regression coefficients for the unconstrained model (a) and the constrained model (b) (Naes et al., 1999).

\begin{tabular}{|c|c|c|}
\hline Model term & Coefficient & $p$-value \\
\hline \multicolumn{3}{|l|}{ (a) } \\
\hline$x_{1}$ & 0.347 & 0.0014 \\
\hline$x_{2}$ & 0.339 & 0.0017 \\
\hline$x_{1} \times x_{1}$ & -0.293 & 0.0395 \\
\hline$x_{2} \times x_{2}$ & -0.096 & 0.4895 \\
\hline$x_{1} \times x_{2}$ & 0.072 & 0.6634 \\
\hline$z$ & 0.017 & 0.5776 \\
\hline$z \times z$ & 0.010 & 0.5275 \\
\hline$z \times x_{1}$ & 0.098 & 0.4272 \\
\hline$z \times x_{2}$ & 0.018 & 0.8850 \\
\hline$z \times x_{1} \times x_{1}$ & -0.094 & 0.5806 \\
\hline$z \times x_{2} \times x_{2}$ & 0.038 & 0.8255 \\
\hline$z \times x_{1} \times x_{2}$ & -0.206 & 0.3116 \\
\hline$z^{2} \times x_{1}$ & 0.006 & 0.8764 \\
\hline$z^{2} \times x_{2}$ & -0.078 & 0.0337 \\
\hline \multicolumn{3}{|l|}{ (b) } \\
\hline$x_{1}$ & 0.422 & 0.0001 \\
\hline$x_{2}$ & 0.610 & 0.0001 \\
\hline$x_{3}$ & 0.367 & 0.0001 \\
\hline$x_{1} \times x_{2}$ & 0.462 & 0.1013 \\
\hline$x_{1} \times x_{3}$ & 0.294 & 0.0390 \\
\hline$x_{2} \times x_{3}$ & 0.097 & 0.4855 \\
\hline$z \times x_{1}$ & 0.020 & 0.8329 \\
\hline$z \times x_{2}$ & 0.072 & 0.4542 \\
\hline$z \times x_{3}$ & 0.017 & 0.5772 \\
\hline$z \times x_{1} \times x_{2}$ & -0.150 & 0.6607 \\
\hline$z \times x_{1} \times x_{3}$ & 0.094 & 0.5819 \\
\hline$z \times x_{2} \times x_{3}$ & -0.038 & 0.8245 \\
\hline$z^{2} \times x_{1}$ & 0.016 & 0.5681 \\
\hline$z^{2} \times x_{2}$ & -0.068 & 0.0170 \\
\hline$z^{2} \times x_{3}$ & 0.010 & 0.5277 \\
\hline
\end{tabular}

a Regression coefficients significant at $5 \%$ level are shown in bold $\left(R^{2}=0.90\right)$.

Thus even though the design and polynomials are nearly identical, the mixture design has more flexible strategies to cover the design region, and the factorial design did not detect all significant interactions between the components. Even though the predicted values are identical, the contour plot of the mixture design is more informative for visual inspection. Thus for accurate/more relevant results it is better to use a mixture design when evaluating mixture experiments. 


\subsubsection{Simplex lattice design}

The simplex lattice design has wide applications in industry. It has contributed to the pharmaceutical industry regarding the formation of lipid emulations, which have growing importance as they act as an ideal delivery system for drugs that are insoluble in water (Jumaa et al., 1998). This design has also been used to model chemical systems and to predict the spectrophotometric responses of chemical complexes. It has been used in the food industry when evaluating various properties of emulsion in a mixture of chicken, beef and turkey.

A lattice is an array of points. A simplex lattice is an arrangement of equally spaced points on a simplex. When described by a polynomial equation the lattice can be referred to as

$$
\{\mathrm{q}, \mathrm{m}\}
$$

With $\mathrm{q}=$ Number of components

$\mathrm{m}=$ Degree of the polynomial, or in other words, the number of proportions assumed by each component

For example:

The simplex lattice $\{4,2\}$ will have the following points as indicated in Equation 2.12:

$$
\begin{aligned}
\left(\mathrm{x}_{1} \mathrm{x}_{2} \mathrm{x}_{3} \mathrm{x}_{4}\right)= & (1,0,0,0) ;(0,1,0,0) ;(0,0,1,0) ;(0,0,0,1) ;(1 / 2,1 / 2,0,0) ;(1 / 2,0,1 / 2,0) ;(1 / 2,0,0,1 / 2) ; \\
& (0,1 / 2,1 / 2,0) \text { and }(0,0,1 / 2,1 / 2)
\end{aligned}
$$

Because there is always a 0 present, these points exist on the boundary of the tetrahedron. The number of design points for the simplex lattice design $\{\mathrm{q}, \mathrm{m}\}$ can be calculated by using the following permutation as indicated in Equation 2.13:

$$
\frac{\mathrm{q}+\mathrm{m}-1}{\mathrm{~m}}=\frac{(\mathrm{q}+\mathrm{m}-1) !}{\mathrm{m} !(\mathrm{q}-1) !}
$$

Once the design points have been determined an empirical model that will fit the experimental design is postulated. The model can be described by means of Equation 2.14 (Brandvik, 1998):

$$
\mathrm{y}=f(\beta, x)+\varepsilon
$$

With $y=$ The response value describing the variable that the experimenter wants to predict $\beta=$ The vector of constants for the model 


$$
\begin{aligned}
& x=\text { The vector of input variables for the model } \\
& \varepsilon=\text { The vector of residuals }
\end{aligned}
$$

In mixture designs the empirical model is normally a polynomial equation. The polynomial will have different forms, depending on the experimental response obtained. If the polynomial is linear the effect of the mixture on the response value has only additive properties, while with a cubic polynomial the contribution of interactions between the various components on the response value is considered. This can even include self-interaction terms (for example $\mathrm{x}^{2}$ ). As described in Section 2.2.1.2, the effect of each term in the polynomial on the response value is determined by its coefficient and it is evaluated statistically to be significant or not. The model is also tested for fit or lack thereof by comparing the response obtained experimentally with the response predicted by the model. If the difference is statistically significant a different model has to be applied. Figure 2.10 gives the general polynomial forms of mixture models.

$$
\begin{aligned}
& \text { Linear } \quad E(Y)=\sum_{i=1}^{q} \beta_{i} x_{i} \\
& \text { Quadratic } \quad E(Y)=\sum_{i=1}^{q} \beta_{i} x_{i}+\sum \sum_{i<j}^{q} \beta_{i j} x_{i} x_{j} \\
& \text { Cubic } \quad E(Y)=\sum_{i=1}^{q} \beta_{i} x_{i}+\sum \sum_{i<j}^{q} \beta_{i j} x_{i} x_{j} \\
& +\sum \sum_{i<j}^{q} \delta_{i j} x_{i} x_{j}\left(x_{i}-x_{j}\right)+\sum \sum_{i<j<k}^{q} \sum \beta_{i j k} x_{i} x_{j} x_{k} \\
& \text { Special Cubic } E(Y)=\sum_{i=1}^{q} \beta_{i} x_{i}+\sum \sum_{i<j}^{q} \beta_{i j} x_{i} x_{j}+\sum \sum_{i<j<k}^{q} \sum \beta_{i j k} x_{i} x_{j} x_{k}
\end{aligned}
$$

Figure 2.10 General polynomial forms of mixture models

\subsubsection{Case study 1}

The following case study shows how the simplex lattice design was applied to experimental work in the pharmaceutical industry. The emulsification process of lipids and the effect of three components in an oil mixture were investigated. The three components were oleic acid oleyester, castor oil and medium-chain triglycerides (MCT). The three components were varied in different ratios and the emulsification process was evaluated in terms of interfacial tension, viscosity and 
particle size. The simplex lattice design was applied to find the most suitable oil ratio for emulsification.

The four general polynomial forms (given in Figure 2.10) were used to analyse the results. They were linear, quadratic, cubic and special cubic models. A stepwise regression was used to fit all four models to the results. The cubic and quadratic models were found to be significant and were used to plot ternary contour plots. In the contour plot (cf. Figure 2.11) each corner of the triangle indicates a component in the mixture. The component proportion in the mixture varies from 0 to 1. The associated response value (depending on the varying component proportions in the mixture) is indicated by the contour lines in the triangle. The plot showed that as castor oil is increased the particle size and viscosity increase. Even though the interfacial tension decreased with an increase in castor oil, viscosity was identified as the dominating factor in emulsification. Thus the more castor oil is added to the mixture, the better the emulsification, and castor oil has a synergistic effect on emulsification. The high $\mathrm{R}_{\mathrm{adj}}{ }^{2}$ values (close to 1 ) indicate a good fit of experimental results. Thus this case study shows that the simplex lattice design can be applied successfully to a mixture experiment in the pharmaceutical industry. By making use of a polynomial model a ternary contour plot can be constructed. The ternary plot then assists in interpreting synergistic and antagonistic effects between three components in a mixture. 

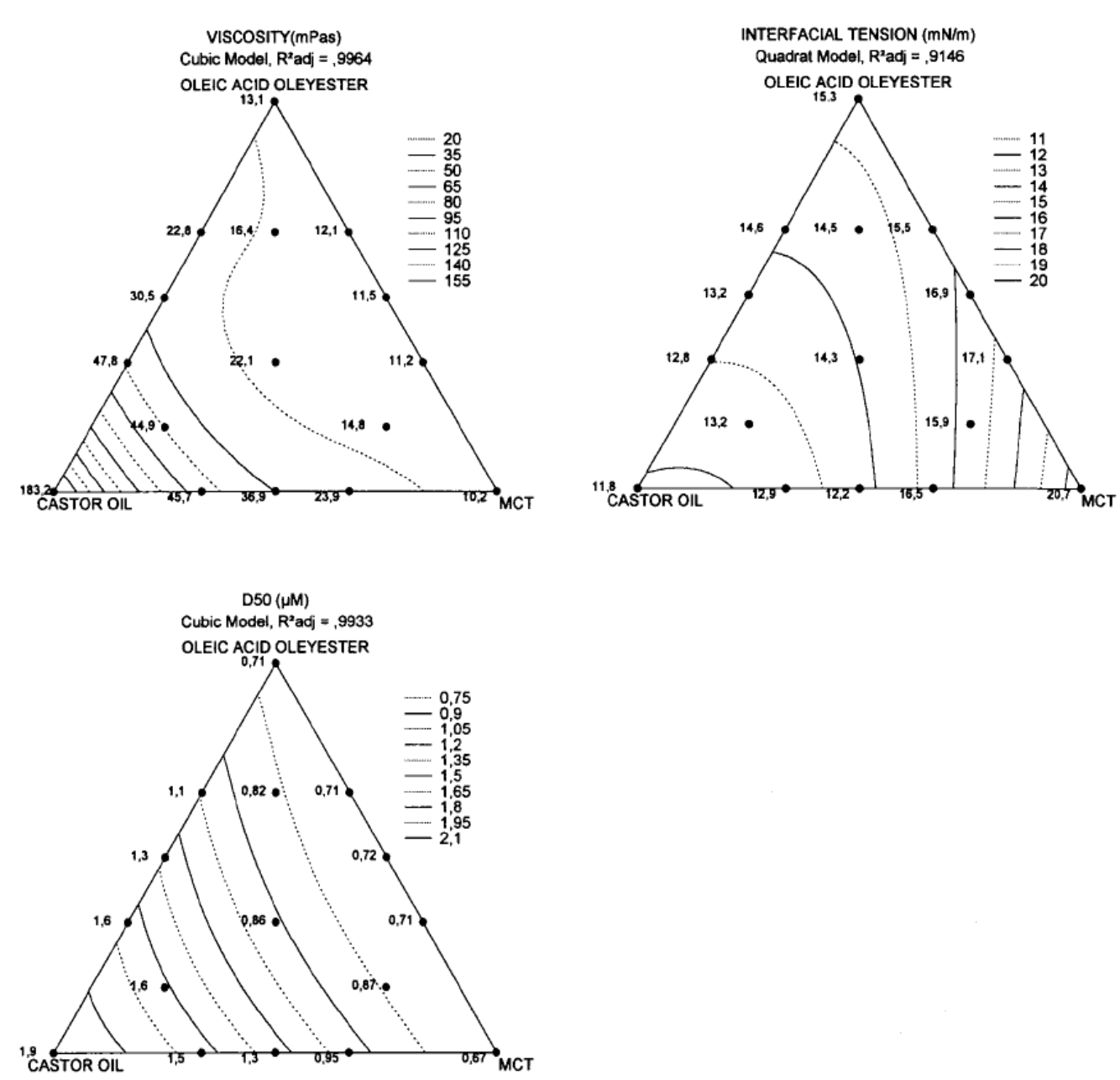

Figure 2.11 Contour plots for interfacial tension, viscosity and particle size (D50 $\mu \mathrm{m})$ (Jumaa et al., 1998).

\subsubsection{Case study 2}

Bruns et al. (1995) applied the simplex lattice design to predict the spectrophotometric response of $\mathrm{Co}^{\mathrm{II}}$ and $\mathrm{Fe}^{\mathrm{III}}$ thiocyanate complexes. The composition of three components (water $-\mathrm{x}_{1}$, ethanol $-\mathrm{x}_{3}$ and acetone $-\mathrm{x}_{4}$ ) in the complex solvent was varied within a constrained region. The reason for the constraint was that the water component was never allowed to decrease to below $30 \%$. Nor could the complex develop completely in pure water $\left(\mathrm{x}_{1}\right)$, thus a second constraint was placed before the extreme vertice $\left(\mathrm{x}_{1}=1\right)$. Three axial points (cf. Section 2.2.4) were also included to assist in the lack of fit for the entrained model. The experimental design is represented in Figure 2.12. The sides of the triangle indicate a fraction of each component in the 
mixture, varying from 0 to 1 . Figure 2.12 a indicates a simplex design with the two constraints on the water component $\left(\mathrm{x}_{1}\right)$ and Figure $2.12 \mathrm{~b}$ indicates a hexagonal design with the axial points.

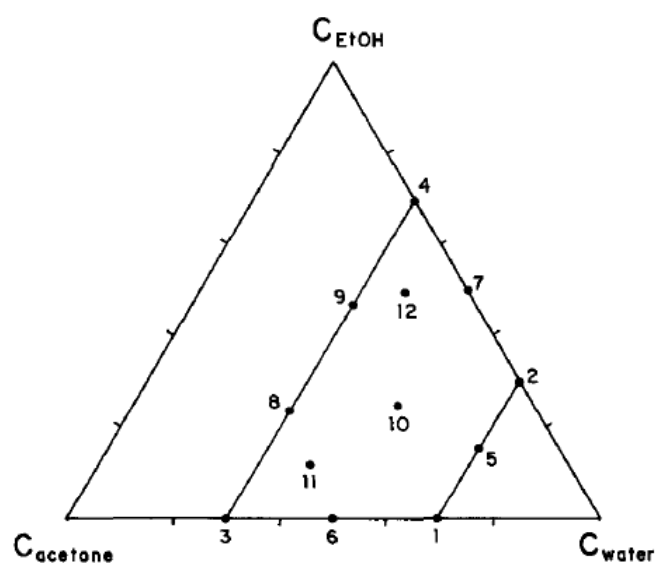

(a)

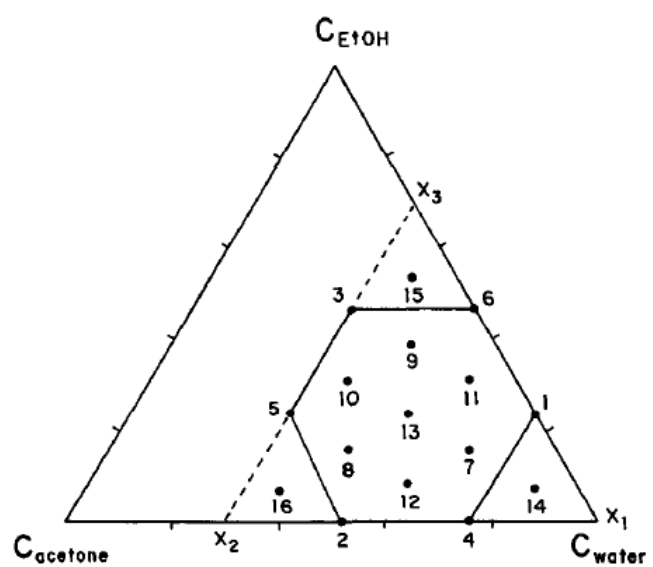

(b)

Figure 2.12 Experimental design with water constraints (a) and experimental design with water and axial constraints (b) (Bruns et al., 1995).

The full cubic model is given by Equation 2.15:

$$
\begin{gathered}
\hat{y}=b_{1} x_{1}+b_{2} x_{2}+b_{3} x_{3}+b_{12} x_{1} x_{2}+b_{13} x_{1} x_{3}+b_{23} x_{2} x_{3}+b_{123} x_{1} x_{2} x_{3}+d_{12} x_{1} x_{2}\left(x_{1}-x_{2}\right)+ \\
d_{13} x_{1} x_{3}\left(x_{1}-x_{3}\right)+d_{23} x_{2} x_{3}\left(x_{2}-x_{3}\right)
\end{gathered}
$$

The full cubic model was then broken up in the linear model, quadratic model and special cubic model (given in Figure 2.10) and each model was evaluated separately. Both the simplex lattice and hexagonal experimental designs indicated the same results and thus only the results for the hexagonal design are reported.

An analysis of variance (ANOVA) was conducted on each model. An F-test was used as the deciding factor on the significance of the model. If the F-value exceeded the $F_{\text {crit }}$ value, the model was deemed as a poor fit. The F-values and the $\mathrm{F}_{\text {crit }}$ values for the different models for both complexes are summarized in Table 2.2. 
Table 2.2 The $\mathrm{F}$ and $\mathrm{F}_{\text {crit }}$ values for the different complexes and models.

\begin{tabular}{|l|c|c|}
\hline $\begin{array}{l}\text { Complex and } \\
\text { model }\end{array}$ & F-value & $\mathbf{F}_{\text {crit }}$ \\
\hline Fe $^{\text {III }}$ & 7.6 & 2.4 \\
\hline Linear model & 1.7 & 2.49 \\
\hline Quadratic model & 43.3 & 2.6 \\
\hline Co & 16.1 & 2.8 \\
\hline $\begin{array}{l}\text { Special cubic } \\
\text { model }\end{array}$ & & \\
\hline Full cubic model & & \\
\hline
\end{tabular}

With the ANOVA test it was found that although the response of the $\mathrm{Fe}^{\mathrm{III}}$ complex could accurately be described by the quadratic model, the $\mathrm{Co}^{\mathrm{II}}$ complex could not be described sufficiently by the full cubic model and a more advanced model was required. Equation 2.16 gives the quadratic model for the $\mathbf{F e}^{\mathrm{III}}$ complex. From this equation it is evident that all binary interactions are antagonistic.

$$
\hat{y}=0.357 x_{1}+0.791 x_{2}+0.518 x_{3}-0.205 x_{1} x_{2}-0.012 x_{1} x_{3}-0.018 x_{2} x_{3}
$$

Equation 2.17 gives the full cubic model for the $\mathbf{C o}^{\mathbf{I I}}$ complex. No accurate conclusions can be made from this equation as the ANOVA showed that the full cubic model is not adequate to describe the data.

$$
\begin{aligned}
& \hat{y}=4.817 x_{1}+1.252 x_{2}+0.264 x_{3}-11.247 x_{1} x_{2}-9.624 x_{1} x_{3}+2.737 x_{2} x_{3}+8.436 x_{1} x_{2} x_{3}- \\
& 12.567 x_{1} x_{2}\left(x_{1}-x_{2}\right)-5.968 x_{1} x_{3}\left(x_{1}-x_{3}\right)-0.611 x_{2} x_{3}\left(x_{2}-x_{3}\right)
\end{aligned}
$$

Thus, this case study shows how the ANOVA is used to decide if a polynomial equation of the simplex lattice design is sufficient to describe experimental results. The polynomial equation is then also used to interpret interactions between components in the mixture experiment.

\subsubsection{Case study 3}

Zorba et al. (2006) used the simplex lattice design to evaluate various properties of emulsion (for example protein concentration, emulsion $\mathrm{pH}$, emulsion stability, emulsion density) in a 
mixture of beef, chicken and turkey. Fifteen combinations of the three meat sources were evaluated and the design points for the experimental design are given in Table 2.3.

Table 2.3 Design points for the experimental design (Zorba et al., 2006).

\begin{tabular}{|c|c|c|c|c|c|c|}
\hline \multirow[t]{2}{*}{ Mixture } & \multicolumn{3}{|c|}{ Level } & \multirow[t]{2}{*}{ Beef $(\%)$} & \multirow[t]{2}{*}{ Chicken (\%) } & \multirow[t]{2}{*}{ Turkey $(\%)$} \\
\hline & $\mathrm{X}_{1}$ & $\mathrm{X}_{2}$ & $\mathrm{X}_{3}$ & & & \\
\hline 1 & 0 & 0 & 1 & 0 & 0 & 100 \\
\hline 2 & 0 & 0.25 & 0.75 & 0 & 25 & 75 \\
\hline 3 & 0 & 0.5 & 0.5 & 0 & 50 & 50 \\
\hline 4 & 0 & 0.75 & 0.25 & 0 & 75 & 25 \\
\hline 5 & 0 & 1 & 0 & 0 & 100 & 0 \\
\hline 6 & 0.25 & 0 & 0.75 & 25 & 0 & 75 \\
\hline 7 & 0.25 & 0.25 & 0.5 & 25 & 25 & 50 \\
\hline 8 & 0.25 & 0.5 & 0.25 & 25 & 50 & 25 \\
\hline 9 & 0.25 & 0.75 & 0 & 25 & 75 & 0 \\
\hline 10 & 0.5 & 0 & 0.5 & 50 & 0 & 50 \\
\hline 11 & 0.5 & 0.25 & 0.25 & 50 & 25 & 25 \\
\hline 12 & 0.5 & 0.5 & 0 & 50 & 50 & 0 \\
\hline 13 & 0.75 & 0 & 0.25 & 75 & 0 & 25 \\
\hline 14 & 0.75 & 0.25 & 0 & 75 & 25 & 0 \\
\hline 15 & 1 & 0 & 0 & 100 & 0 & 0 \\
\hline
\end{tabular}

Equations 2.18 and 2.19 show the prediction model of two of the emulsion properties investigated and Figure 2.13 shows the ternary contour plot for a) protein concentration and b) pHe. Equation 2.18 shows that (based on the size of the coefficients) there is less protein in beef than in turkey. The signs of the coefficients before binary terms also show that there is an antagonistic interaction between beef and chicken as well as chicken and turkey (negative sign) and a synergistic interaction between beef and turkey (positive sign). The negative effect of beef is also evident in Figure 2.13a where the protein content (indicated by the value on the contour line) decreases as the proportion of beef in the mixture increases from right to left on the horizontal axis. Equation 2.19 shows that (based on the size of the coefficients) chicken has the highest and beef the lowest pHe. The signs of the coefficients before binary terms also show that there is an antagonistic interaction between beef and chicken as well as chicken and turkey (negative sign) and a synergistic interaction between beef and turkey (positive sign). The higher pHe of chicken is also evident in Figure 2.13b where the pHe (indicated by the value on the contour line) 
increases as the proportion of chicken in the mixture increases from bottom to top on the lefthand side of the triangle.

$$
\begin{aligned}
& \mathrm{y}_{\text {protein }}=4.08 \mathrm{x}_{1}+4.51 \mathrm{x}_{2}+4.84 \mathrm{x}_{3}-0.32 \mathrm{x}_{1} \mathrm{x}_{2}+0.16 \mathrm{x}_{1} \mathrm{x}_{3}-0.3 \mathrm{x}_{2} \mathrm{x}_{3} \\
& \mathrm{y}_{\mathrm{pHe}}=5.56 \mathrm{x}_{1}+5.96 \mathrm{x}_{2}+5.84 \mathrm{x}_{3}-0.07 \mathrm{x}_{1} \mathrm{x}_{2}+0.07 \mathrm{x}_{1} \mathrm{x}_{3}-0.13 \mathrm{x}_{2} \mathrm{x}_{3}
\end{aligned}
$$
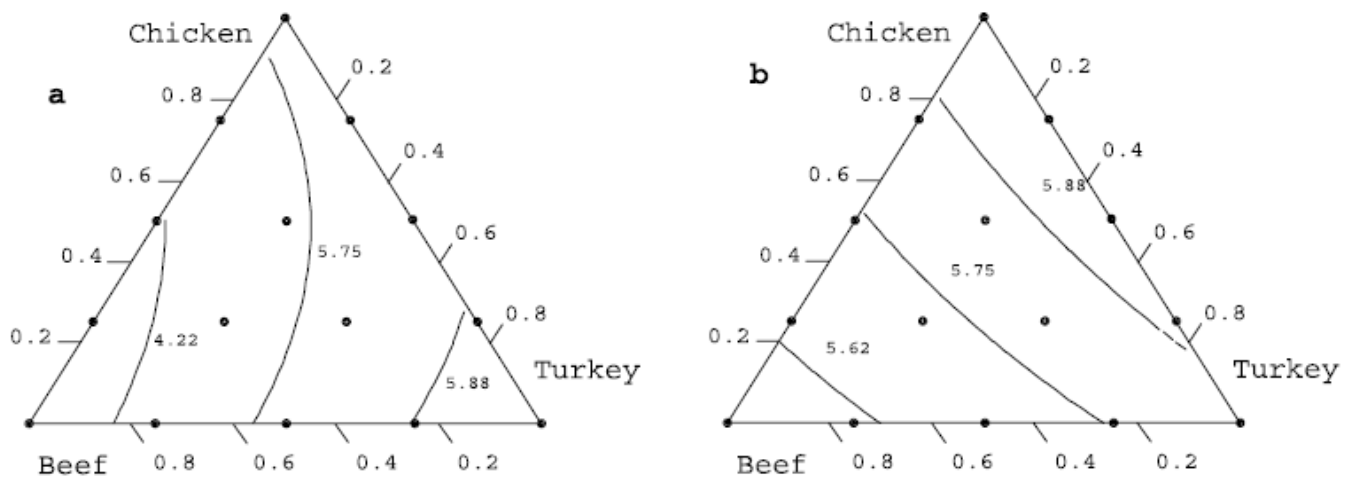

Figure 2.13 Ternary contour plot for (a) protein concentration and (b) pHe (Zorba et al., 2006).

Thus this case study shows that the simplex lattice design has been applied to a mixture experiment in the food industry. Using a polynomial prediction model, a ternary contour plot was constructed. The ternary plot assists in interpreting synergistic and antagonistic effects between three components in a mixture.

\subsubsection{Simplex centroid design}

The simplex centroid design is based on the same principles as the simplex lattice design, with the exception that the design points are not only equally spaced but now also appear either in equal proportions or zero (on the boundaries). The number of design points is determined by $2^{\mathrm{q}}-1$. The design also has an overall centroid containing equal proportions, equally spaced.

The simplex centroid design can be expanded by adding design points inside the simplex region. These points do not have to be equal or equally spaced. The design is then called an augmented simplex centroid design. 


\subsubsection{Case study 1}

This design has been applied to determine the optimal gas composition to maintain the quality of modified atmosphere packaged filleted Atlantic cod (fish) at $0{ }^{\circ} \mathrm{C}$. The effect of the three major packing gases $\left(\mathrm{CO}_{2}, \mathrm{O}_{2}\right.$ and $\left.\mathrm{N}_{2}\right)$ was evaluated throughout the complete simplex region (Sivertsvik, 2007). Three proportions of each gas $(0,1 / 2$ and 1$)$ as well as three replicates of the overall centroid $(1 / 3,1 / 3,1 / 3)$ were evaluated. Microbiological analysis was used as one of the response values. The microbiological analysis involved a psychrotrophic plate of cod fillets as affected by a gas mixture after 7 days, 10 days and 14 days of storage. The experimental design is given in Figure 2.14. The sides of the triangle indicate a fraction of each component in the mixture, varying from 0 to 1 .

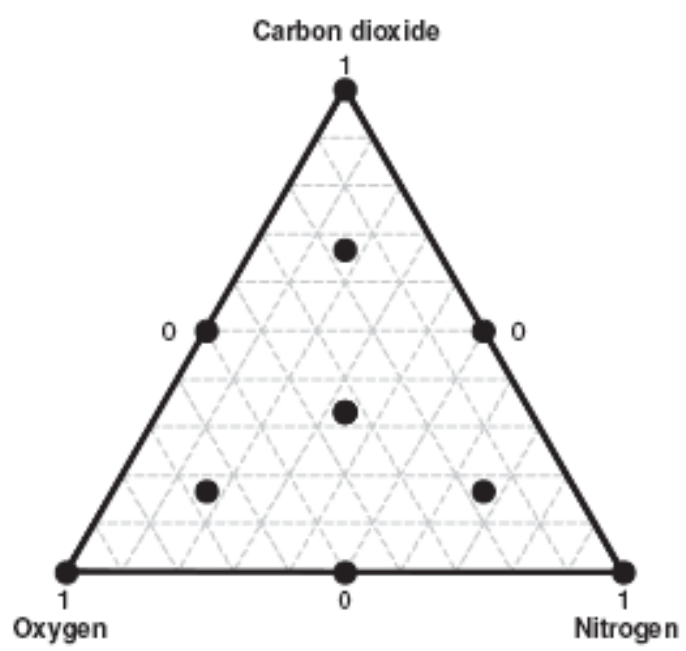

Figure 2.14 Experimental design for gas mixture (Sivertsvik, 2007).

Design of experiments (DOE) with a statistical software program Minitab was used to determine the optimum gas mixture after 7,10 and 14 days. Contour plots were used to evaluate the effect on the response value. They are indicated in Figure 2.15. The lighter the shade of grey, the less unwanted bacteria were present in the sample. As can been seen from the contour plots, an increase in the level of $\mathrm{CO}_{2}$ inhibited the growth of bacteria after 7 days as the grey level turns lighter as you move from the left-hand corner to the top (and thus the unwanted bacteria are less). After 10 days the presence of $\mathrm{O}_{2}$ also became important with an optimum blend of $50 \% \mathrm{CO}_{2}$ and $50 \% \mathrm{O}_{2}$ after 14 days. 


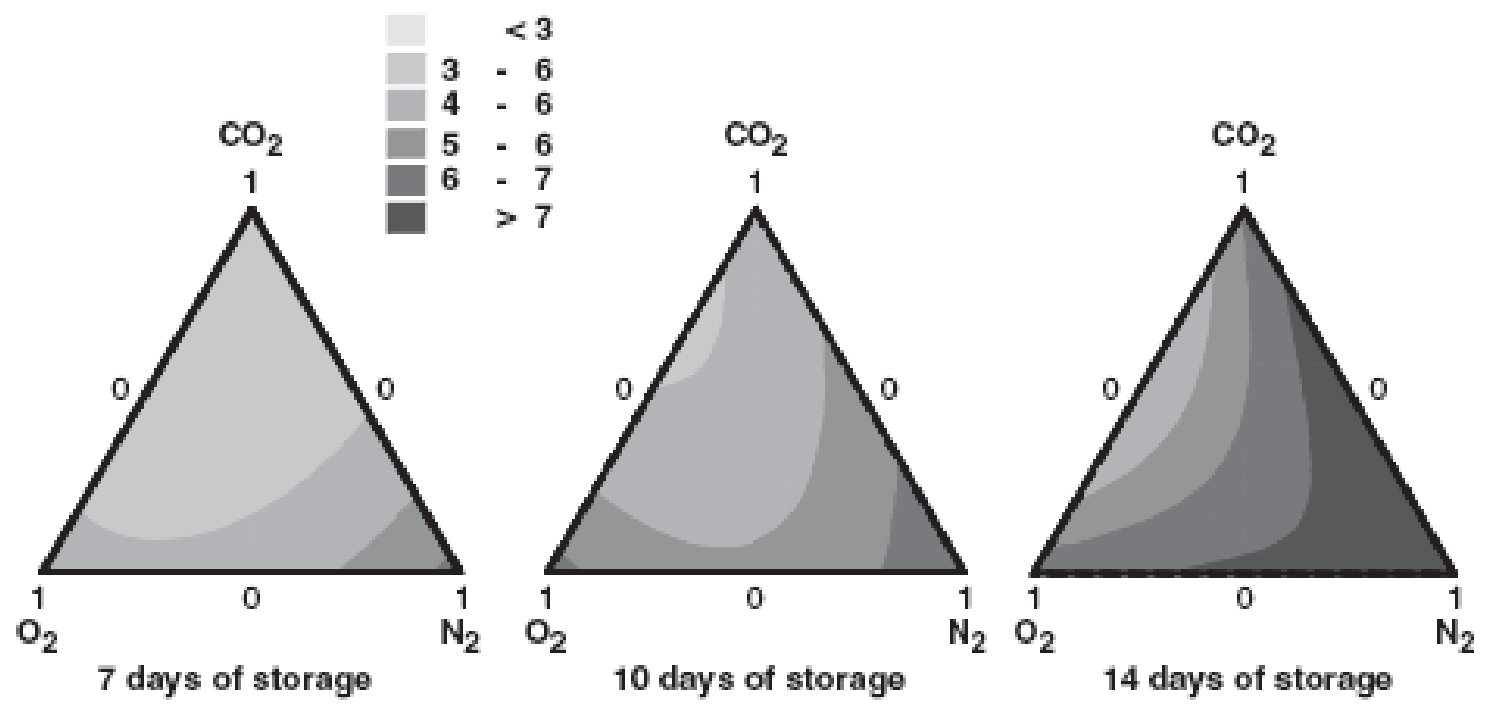

Figure 2.15 Contour plots of the mixture effect on the response after 7 days, 10 days and 14 days, respectively (Sivertsvik, 2007).

Thus this case study shows that the simplex centroid design can be applied successfully to a mixture experiment in the food industry. The response value in the ternary contour plot can also be presented with colour instead of values on the contour line. The ternary plot for the simplex centroid design can therefore assist in interpreting synergistic and antagonistic effects between three components in a mixture.

\subsubsection{Case study 2}

The simplex centroid design was also used to model a co-compositing system in a bioreactor with soil containing hydrocarbons, sugarcane bagasse pith (SBP) and water (Aguilera-Vázquez et al., 2001). The three mixture variables used were water, contaminated soil and SBP. The experimental design is indicated in Figure 2.16. The sides of the triangle indicate a fraction of each component in the mixture, varying from 0 to 1 . A certain amount of each component was required to ensure that biodegrading took place. Therefore the components had the following restrictions:

a) $\mathrm{f}_{\mathrm{s}}\left(\right.$ also denoted as $\left.\mathrm{x}_{\mathrm{s}}\right)=$ Soil fraction $-(0$ to 0.4$)$

b) $\mathrm{f}_{\mathrm{b}}\left(\right.$ also denoted as $\left.\mathrm{x}_{\mathrm{b}}\right)=\mathrm{SBP}$ fraction $-(0.2$ to 0.6$)$ 
c) $\mathrm{f}_{\mathrm{w}}$ (also denoted as $\left.\mathrm{x}_{\mathrm{w}}\right)=$ Water fraction $-(0.4$ to 0.8$)$

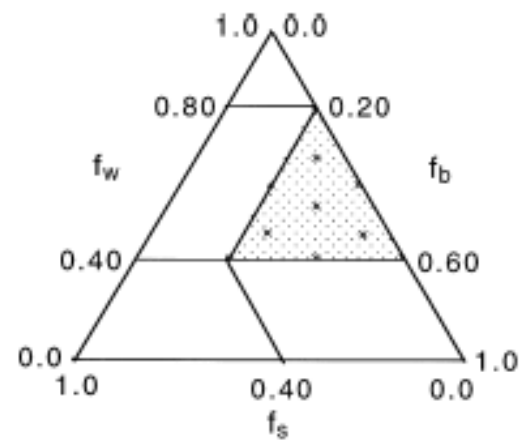

Figure 2.16 Experimental designs for composite mixture (Aguilera-Vázquez et al., 2001).

The free water activity and porosity were used for response values. The best fit to determine both response values were found to be the special cubic model describing the additive nature of the mixture as well as synergistic/antagonistic effects in binary and ternary interactions. After data analysis the models for free water activity $\left(\mathrm{a}_{\mathrm{w}}\right)$ and porosity $\left(\varepsilon_{0}\right)$ were found to be:

$$
\begin{aligned}
& a_{w}=0.99 x_{w}+0.71 x_{b}+1.25 x_{s}+0.32 x_{w} x_{b}-0.5 x_{w} x_{s}-1.05 x_{b} x_{s}+2.01 x_{w} x_{b} x_{s} \\
& \varepsilon_{0}=0.54 x_{w}+0.26 x_{b}+2.26 x_{s}+1.03 x_{w} x_{b}-2.73 x_{w} x_{s}-5.26 x_{b} x_{s}+11.64 x_{w} x_{b} x_{s}
\end{aligned}
$$

The $\mathrm{R}^{2}$ value was used as an indication of model significance. The $\mathrm{R}^{2}$ value was 0.999 for both models, indicating that the models explain the response adequately for both variables. As indicated in the contour and surface plots ( $a$ and $b$ ) in Figure 2.17, $a_{w}$ decreases as the water fraction decreases. This is evident as the water fraction $\mathrm{f}_{\mathrm{w}}$ decreases from the top of the triangle (in Figure 2.17a) to the bottom left-hand corner of the triangle, while the response value $a_{w}$, indicated on each contour, also decreases from the top of the triangle to the bottom left-hand corner. The effect is amplified with a decrease in contaminated soil. This is evident as the soil fraction $\mathrm{f}_{\mathrm{s}}$ decreases from left to right of the triangle, while the response value $\mathrm{a}_{\mathrm{w}}$ indicated on each contour also decreases from left to right. Based on the same interpretation, Figure 2.17 (c and d) shows that as the fraction of water decreases $\varepsilon_{0}$ increases. $\varepsilon_{0}$ also increases as the fraction of soil increases. 
a)

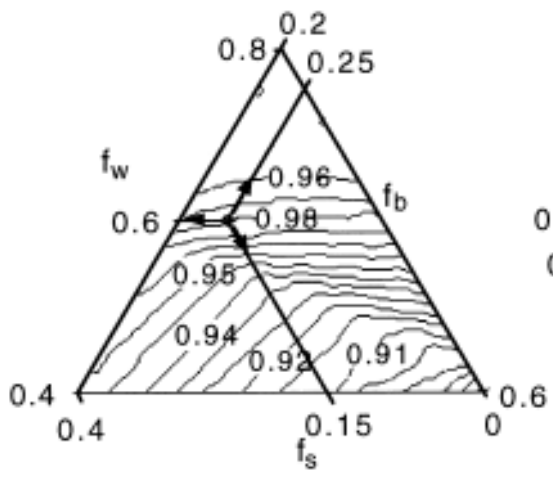

c)

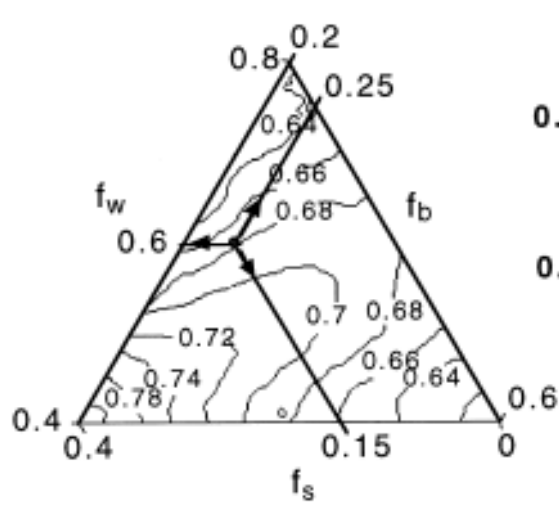

b)

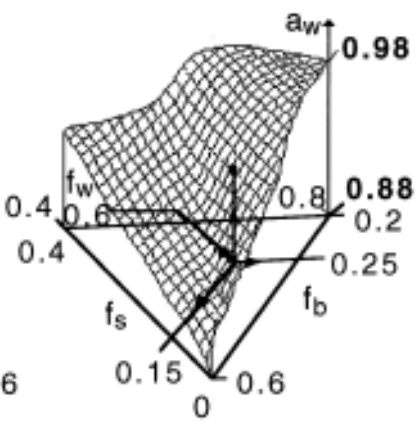

d)

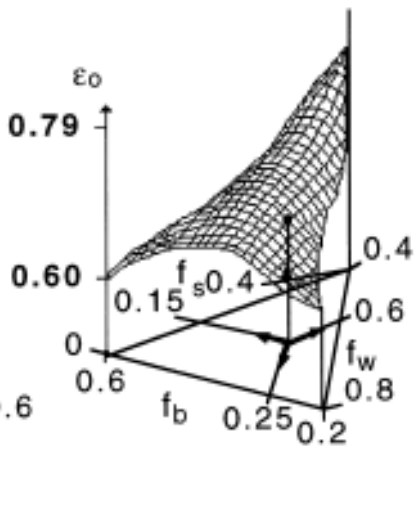

Figure 2.17 Contour and surface plot of $\mathrm{a}_{\mathrm{w}}\left(\mathrm{a}\right.$ and $\mathrm{b}$ ) and $\varepsilon_{0}$ (c and d), respectively (AguileraVázquez et al., 2001).

Thus this case study shows that the simplex centroid design can be applied successfully to a mixture experiment in chemical engineering. The response value in the ternary contour plot was presented by values on the contour line. The ternary plot for the simplex centroid design again assists in interpreting synergistic and antagonistic effects between three components in a mixture.

\subsubsection{Axial (augmented) design}

According to Cornell (2002), the axial design differs from the two designs discussed previously in that they are boundary designs. Thus except for the overall centroid all design points are stationed on the axes of the simplex region. For a three-component system the axial design enables the experimenter to focus more on the effect of all three components in the inner simplex region and it enables the experimenter to explore a wider region within the simplex as opposed to only evaluating the binary effect on the boundaries as with the simplex lattice design. Thus the 
simplex lattice design will provide more information than the axial design on how the response will behave for blends on the boundaries of the triangle, while the axial design will provide more information on how the response will behave for blends inside the triangle. The axial design is a more complex model and evaluates each component at more levels. Depending on the application, this may result in fitting a more complex polynomial with higher order terms to the model.

"The axis of a component $i$ is the imaginary line extending from the base point $x_{i}=0, x_{j}=1 /(q-1)$ for all $j \neq i$, to the vertex where $x_{i}=1, x_{j}=0$ all $j \neq i$ " (Cornell, 2002). When referring to Figure 2.18 the base point opposite the vertex $\left(\mathrm{x}_{1}=1\right)$ is $\mathrm{x}_{1}=0$ and is the centroid of the dimensional boundary referred to as (q-2)-flat. The axis length is the shortest distance between the vertex $\left(\mathrm{x}_{1}\right.$ $=1)$ and the base point $\left(\mathrm{x}_{1}=0\right)$.

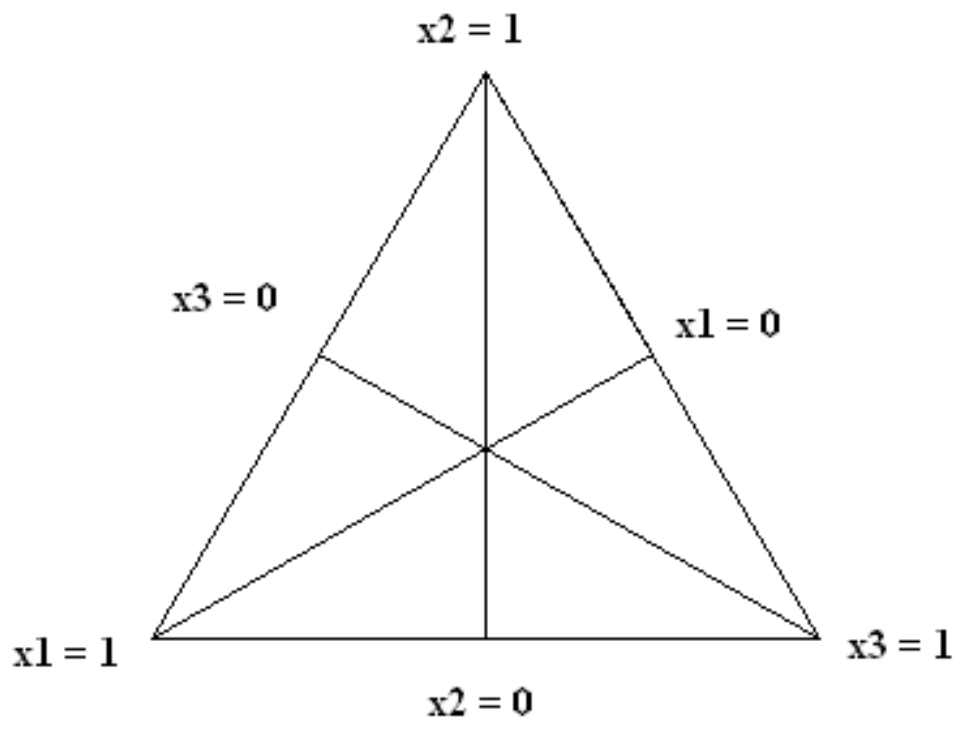

Figure 2.18 An example of an axial design (Cornell, 2002).

Case study 1 Romagnoli and Andreola (2007) used the axial design to expand/augment the simplex centroid design. The proportion of a mixture of additives, used to deflocculate three different types of clay for tile production, was varied in order to obtain the minimum viscosity as a response value. This case study focuses only on results obtained with the Kaolinitic clay. 
The mixture design chosen for the test work is indicated in Figure 2.19. The mixture design used was an augmented simplex centroid design. The three additives were added as a total weight percentage of $0.3 \%$ to a mixture of water and solids to obtain the viscosity. They were:

$$
\begin{aligned}
& \mathrm{x}_{1}=\text { sodium polyacrylate } \\
& \mathrm{x}_{2}=\text { sodium tripolyphosphate } \\
& \mathrm{x}_{3}=\text { anhydrous sodium metasilicate }
\end{aligned}
$$

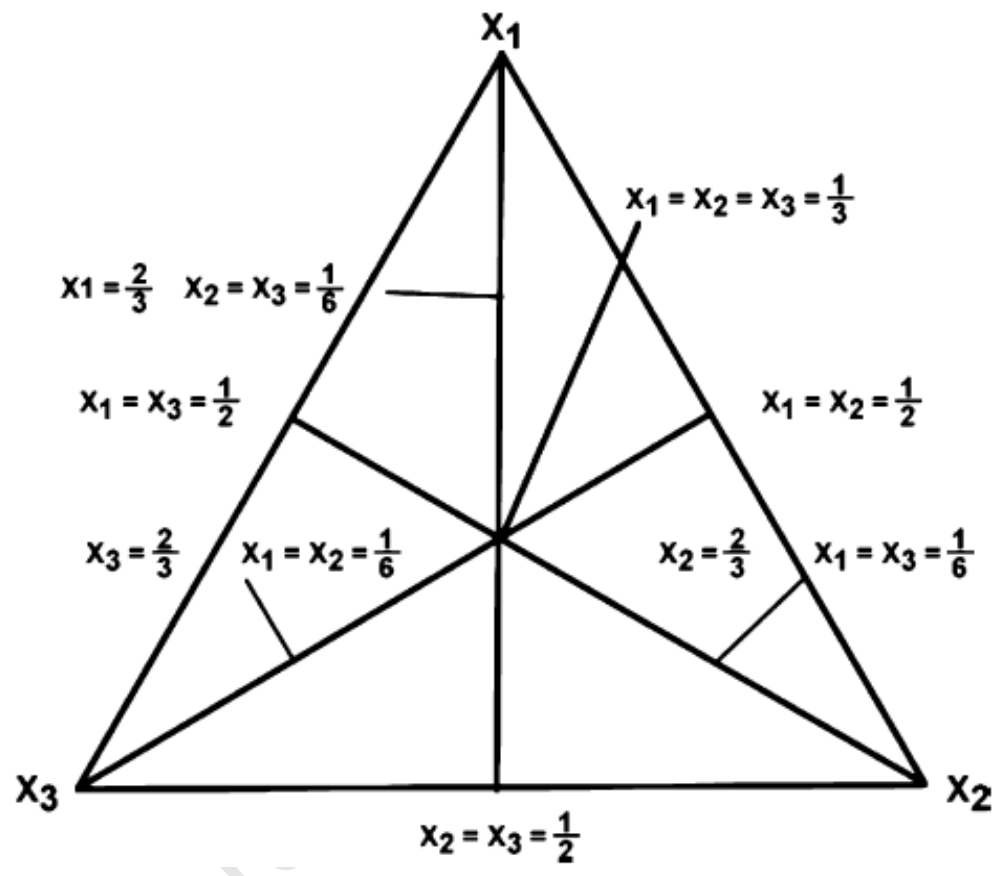

Figure 2.19 Mixture design for the three additives (Romagnoli and Andreola, 2007).

Figure 2.20 shows a three-dimensional plot of mixture compositions vs viscosity at a shear rate of $50 \mathrm{~s}^{-1}$. As the proportion of $\mathrm{x}_{3}$ increased (left to right from the remainder corners of the triangle), the viscosity increased. Therefore the plot indicates that $\mathrm{x}_{3}$ is less efficient in lowering the viscosity than $\mathrm{x}_{1}$ and $\mathrm{x}_{2}$. 


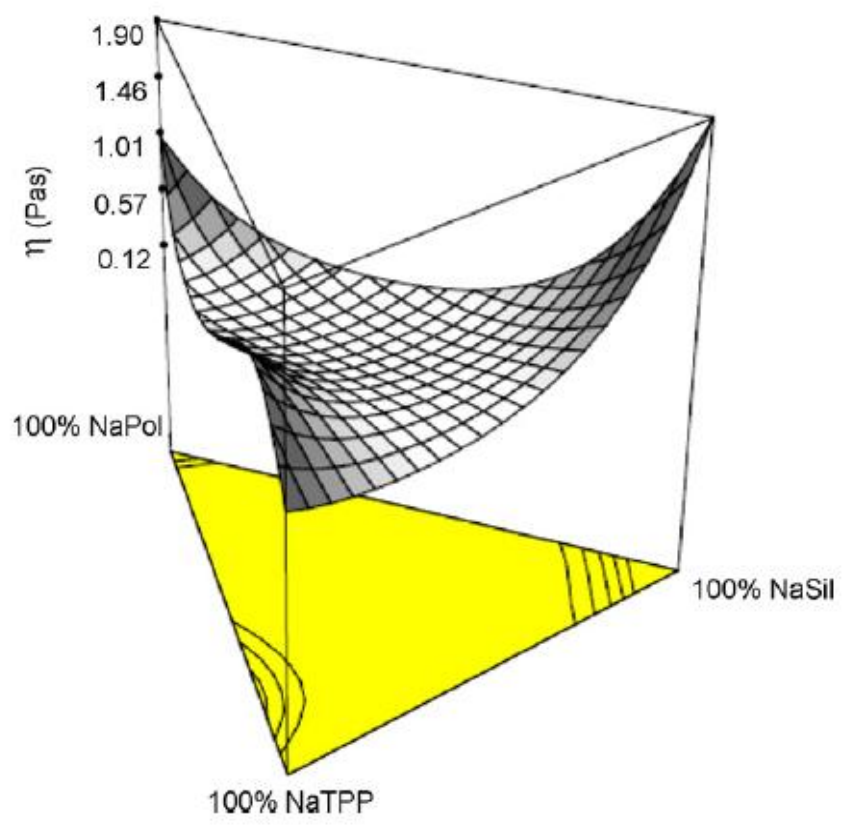

Figure 2.20 Three-dimensional plot of mixture compositions vs viscosity at $50 \mathrm{~s}^{-1}$ (Romagnoli and Andreola, 2007).

The empirical models for three viscosity measurements and three different shear rates are given in Equations 2.22 to 2.24 .

$$
\begin{aligned}
& \eta_{50 \mathrm{~s}}^{0.38}=3.33 \mathrm{x}_{1}+2.27 \mathrm{x}_{2}+4.25 \mathrm{x}_{3}-4.62 \mathrm{x}_{1} \mathrm{x}_{2}-25.79 \mathrm{x}_{1} \mathrm{x}_{3}-15.87 \mathrm{x}_{2} \mathrm{x}_{3}-111.06 \mathrm{x}_{1} \mathrm{x}_{2}\left(\mathrm{x}_{1}-\mathrm{x}_{2}\right) \\
& \sqrt{\eta_{100 \mathrm{~s}}{ }^{-1}}=2.79 \mathrm{x}_{1}+1.71 \mathrm{x}_{2}+3.40 \mathrm{x}_{3}-2.27 \mathrm{x}_{1} \mathrm{x}_{2}-24.02 \mathrm{x}_{1} \mathrm{x}_{3}-14.81 \mathrm{x}_{2} \mathrm{x}_{3}-88.98 \mathrm{x}_{1} \mathrm{x}_{2}\left(\mathrm{x}_{1}-\mathrm{x}_{2}\right) \\
& \eta^{0.22}{ }_{200 \mathrm{~s}}^{-1}=2.80 \mathrm{x}_{1}+2.35 \mathrm{x}_{2}+3.02 \mathrm{x}_{3}-0.81 \mathrm{x}_{1} \mathrm{x}_{2}-11.17 \mathrm{x}_{1} \mathrm{x}_{3}-7.13 \mathrm{x}_{2} \mathrm{x}_{3}-37.09 \mathrm{x}_{1} \mathrm{x}_{2}\left(\mathrm{x}_{1}-\mathrm{x}_{2}\right)
\end{aligned}
$$

From the models it is evident that the coefficient for $x_{3}$ is higher than for $x_{1}$ and $x_{2}$. This highlights an increase in viscosity with $\mathrm{x}_{3}$ as seen in Figure 2.20. $\mathrm{x}_{2}$ indicates the lowest viscosity. Coefficients for the binary interactions between the additives are negative, indicating a reduction in viscosity. Thus the binary mixture between $\mathrm{x}_{1} \mathrm{x}_{2} ; \mathrm{x}_{1} \mathrm{x}_{3}$ and $\mathrm{x}_{2} \mathrm{x}_{3}$ all show antagonistic effects as the coefficients are negative. Thus this case study shows that the augmented/axial simplex centroid design can be applied successfully to a mixture experiment. The polynomial 
prediction model was used to interpret interactions between components, although the polynomial prediction equation now has complex terms (in comparison with the previous case studies mentioned in this literature review), for example $\mathrm{x}_{2}\left(\mathrm{x}_{1}-\mathrm{x}_{2}\right)$. Although these terms do perhaps assist in creating a model that generates a more comprehensive three-dimensional plot, they complicate direct interpretation of interactions between components.

\subsection{MIXTURES/BLENDS IN MINERAL PROCESSING}

There is no evidence in current literature that experimental mixture designs have been applied to mineral processing. However, some experiments have been done in order to evaluate the effect of mixtures on certain aspects of mineral processing. The following examples are found in the literature:

\subsubsection{The effect of mixtures on handleability of coal}

Zhong et al. (2005) postulate that blending affects the handleability of coal. Handleability is defined as the ability of coal to pass through bunkers and other facilities without blockages. The major concern with blending is the effect of fines on the handleability due to the high clay content. Several different source coal materials (washed coarse sizes, unwashed fines, stockpiled materials and recovered slurry) are usually blended before further process and until recently trial and error has been used to determine the handleability of the blended material.

Flow blockages and static occurrences depend on the coal cohesion and thus handleability is measured by cohesion strength. This is combined to a particular stress level known as the consolidation pressure. The unconfined compression strength fluctuates non-linearly with the moisture content and the critical moisture content varies with blends. The critical moisture is where the unconfined cohesion strength is at its maximum. The addition of coarse coal particles can reduce the unconfined strength of coal.

The following experimental test work was conducted:

1) The same coal was blended with varying moisture contents.

2) A coarse coal (with varying moisture content) was blended with a cohesive coal.

3) Two cohesive coals (with varying moisture contents) were blended. 
Zhong et al. (2005) found that by using measurements of the pure source coal the unconfined strength of a coal blend can be predicted with an algorithm. This creates a possible method of producing handleable coals while minimizing wastage of combustible material. The predicted unconfined strength of the blend is given by Equation 2.25:

$$
\sigma_{\mathrm{b}}=\sigma_{\mathrm{r}}(1+\lambda)-\sigma_{1} \lambda
$$

Where $\sigma_{\mathrm{r}}$ is given by Equation 2.26

$$
\sigma_{\mathrm{r}}=\sigma_{2}\left[\frac{\mathrm{X}_{2}}{1-\mathrm{x}_{1}}\right]+\sigma_{3}\left[\frac{\mathrm{X}_{3}}{1-\mathrm{x}_{1}}\right]
$$

and $\mathrm{x}_{1}, \mathrm{x}_{2}$ and $\mathrm{x}_{3}$ are the proportion of each coal type with $\Sigma_{\mathrm{xi}}=1$ and $\mathrm{x}_{1}$ represents a coarse ore used to decrease the cohesive strength of ore $x_{2}$ and $x_{3} . \sigma_{r}$ represents the unconfined strength of the blend while $\sigma_{2}$ and $\sigma_{3}$ are the unconfined strength of ore $\mathrm{x}_{2}$ and $\mathrm{x}_{3}$, respectively.

$\lambda$ is the relative change in the unconfined strength and is a function of the coarse ore $x_{1}$ and is expressed as a cubic function by Equation 2.27:

$$
\lambda=\mathrm{ax}_{1}+\mathrm{bx}_{1}^{3}+\mathrm{cx}_{1}^{3}
$$

With $\mathrm{a}=0, \mathrm{~b}=1.65$ and $\mathrm{c}=0.65$ and $\mathrm{a}, \mathrm{b}$ and $\mathrm{c}$ were derived as the best fit to the measurements.

Equation 2.25 was then used to draw a chart that can be used to predict the unconfined strength of the coal blend as indicated in Figure 2.21 or to determine the maximum proportion of a coal that can be used in the blend to obtain a specified unconfined strength. For example, if the unconfined strength must not exceed $\sigma_{\mathrm{b}}=2.6 \mathrm{kPa}$, then only $26 \%$ of coal 2 (on the y-axis) can be used (if none of coal 1 is added to the blend). If, however, the maximum amount of coal 2 must be used in a blend, then a maximum of $45 \%$ of coal 2 (on the y-axis) can be added as long as $43 \%$ of coal 1 (on the $\mathrm{x}$-axis) is also added to the blend. Figure 2.21 shows a synergistic interaction for $\mathrm{x}_{1}$; as the proportion of $x_{1}$ increases, the unconfined strength decreases and the handleability of coal will improve. Thus this case study shows how an algorithm is used to draw a chart that can predict the handleability of a ternary coal blend. Based on the literature the mathematical model was developed for only three source coals as this is common practice in the industry. Thus if more than three components contribute to a blend, a new algorithm would have to be devised to predict/explain the effect on the handleability. 


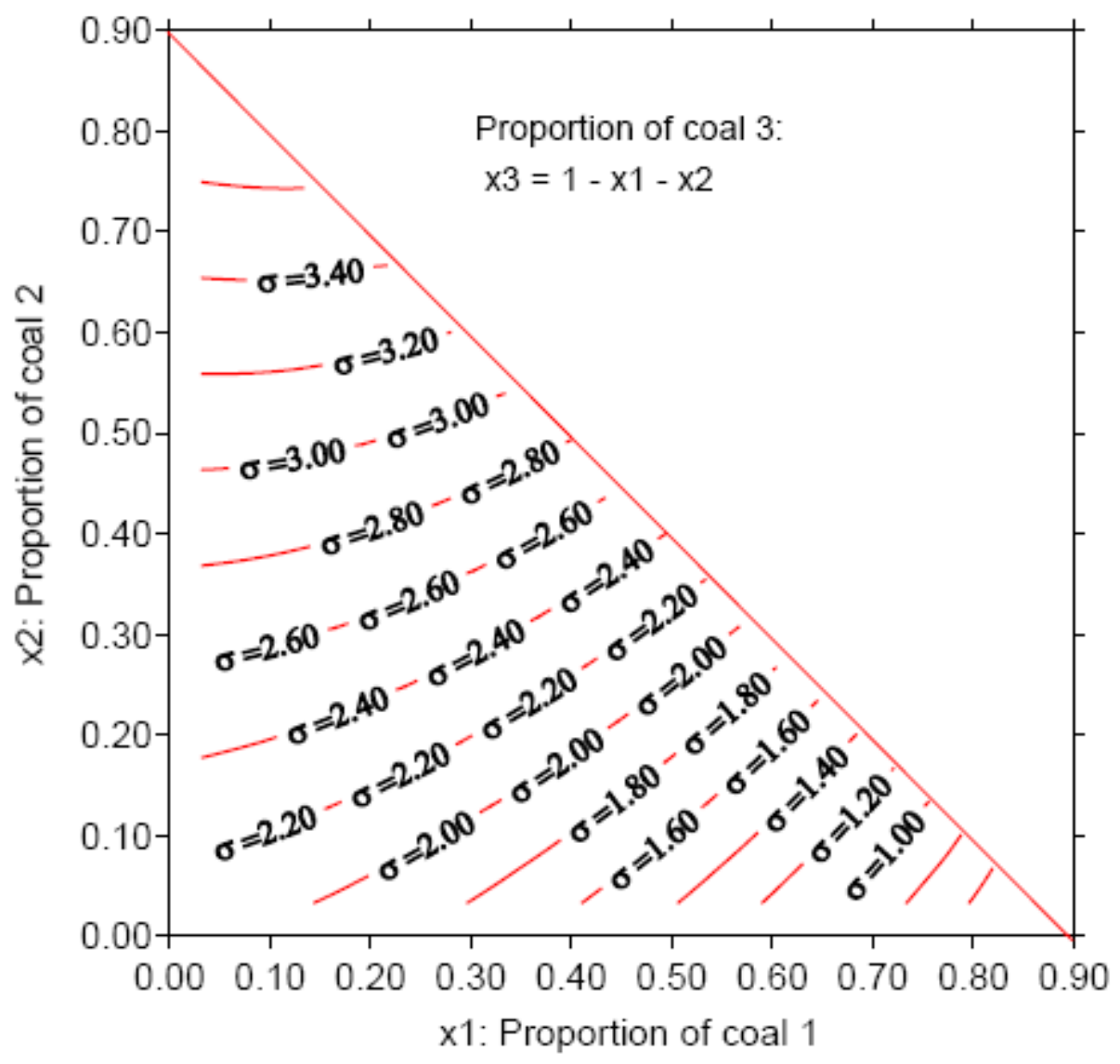

Figure 2.21 The predicted unconfined strengths of different blends of the three coals (Zhong et al., 2005).

\subsubsection{The effect of mixtures on milling}

\subsubsection{Case study 1}

Vuthaluru et al. (2003) investigated the effect of Western Australian coal blending on the Hardgrove grindability index (HGI), which measures coal grindability. The coal grindability reflects coal hardness, tenacity and fracture. Although some coal shows that the HGI is additive during blending, this is not the usual tendency. Vuthaluru et al. (2003) refer to a study on blending Indonesian coals with Australian thermal coals, which determined that the HGI of all coal blends was lower than the calculated weighted composite value and sometimes even lower than the components in their pure form. 
While blends from different portions in the same seam of the Premier mine (Western Australia) do have some additive properties, different seams render a different result. The effect of the following four seams: P2, P3, P4 and Hebe, were investigated. They were blended as binary blends (between Hebe and P4 or P3) as well as ternary blends (between Hebe, P2 and P4). Figure 2.22 indicates the correlation between the measured HGI and a weighted average HGI for the blend between Hebe and P4 and Hebe, P2 and P4. Figure 2.23 indicates the correlation between the measured HGI and a weighted average HGI for the blend between Hebe and P3.

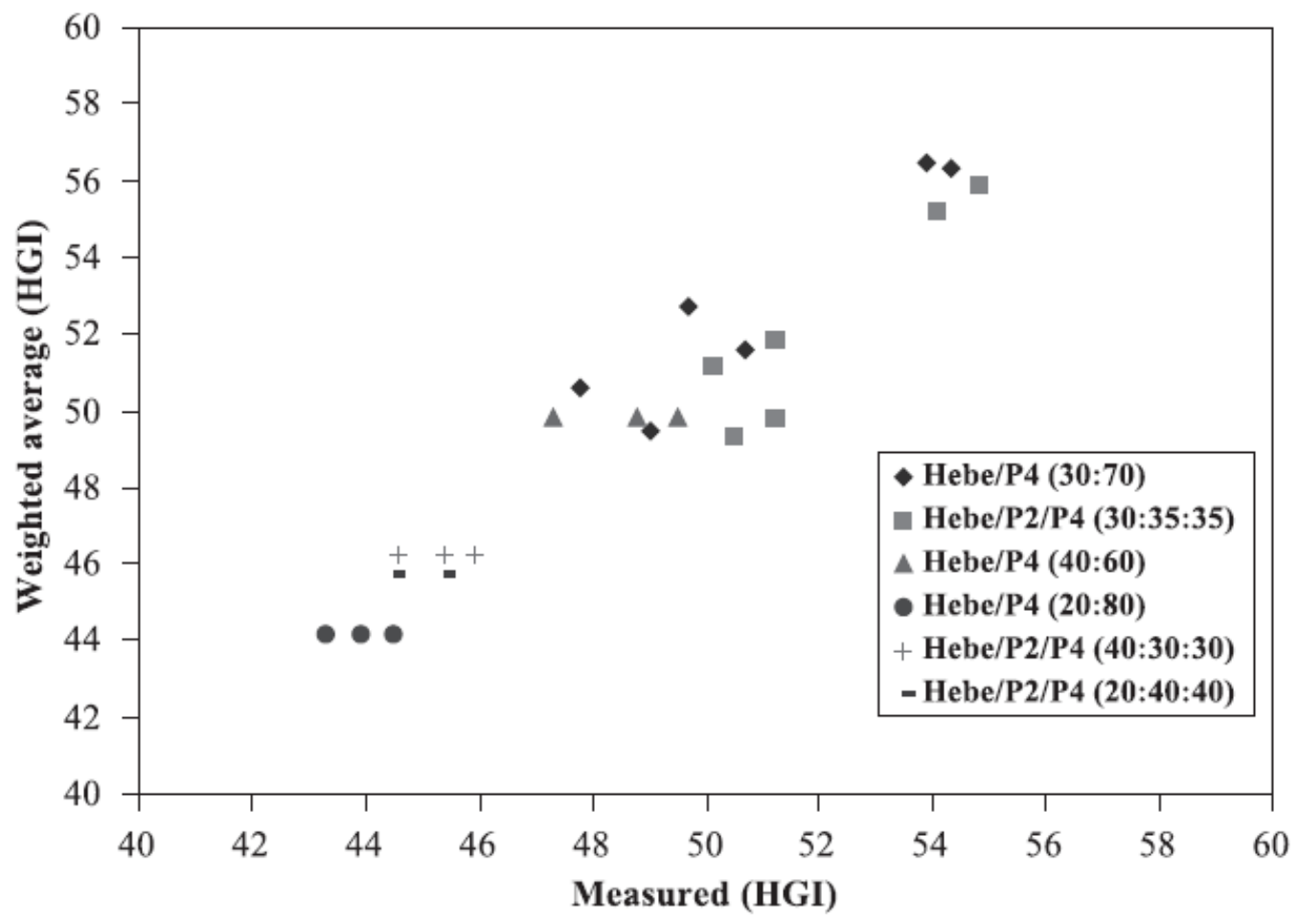

Figure 2.22 Correlation between the measured HGI and a weighted average HGI for the blend between Hebe and P4 and Hebe, P2 and P4 (Vuthaluru et al., 2003). 


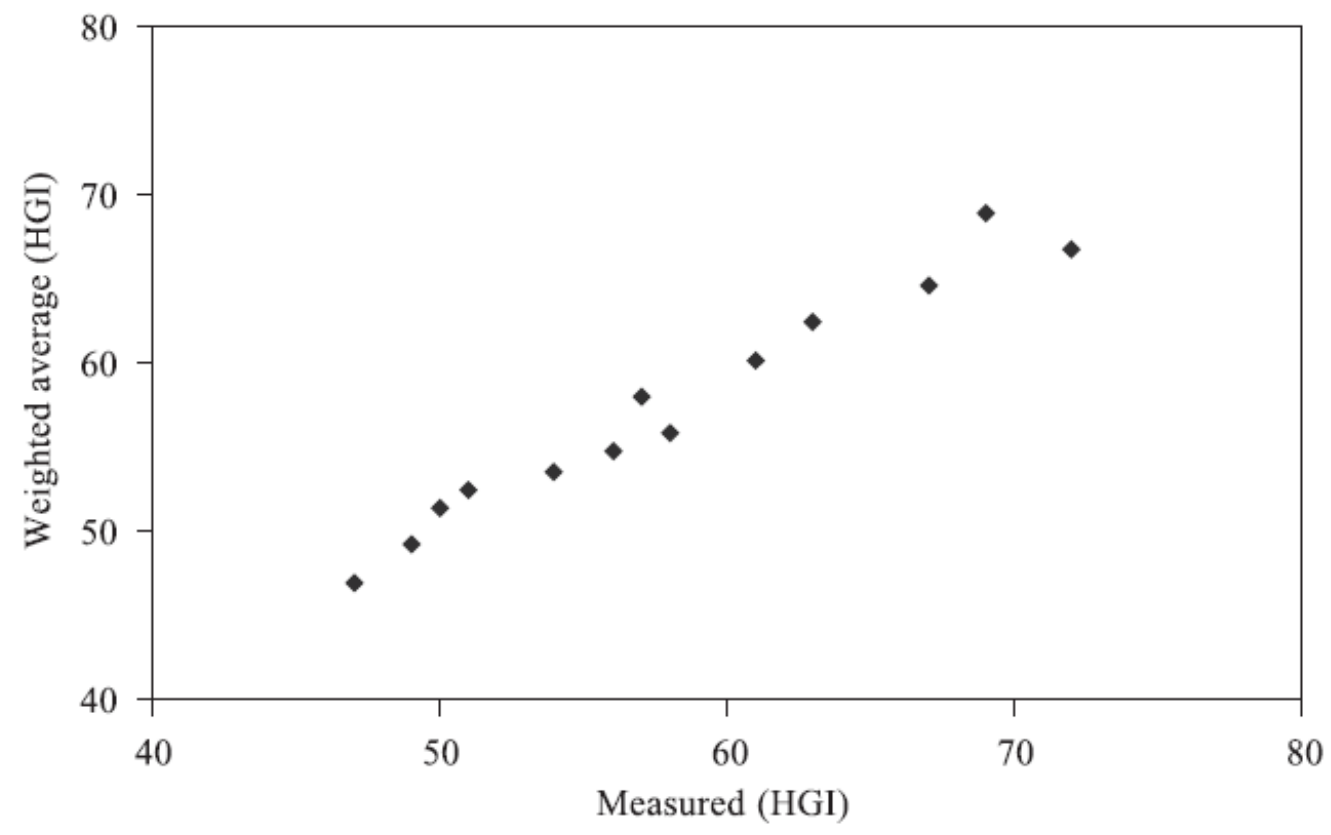

Figure 2.23 Correlation between the measured HGI and a weighted average HGI for the blend between Hebe and P3 (Vuthaluru et al., 2003).

From Figures 2.22 and 2.23, it is evident that the blending effects on Collie coals from Western Australian coal from several coal seams were additive and thus linear. The measured values of each blend corresponded within +2 HGI units with the calculated weighted average value for three binary and three ternary blends. The HGI of the coal blend only showed the weighted average of the coal in its pure form. Thus this case study shows how experimental/measured data of binary and ternary blends was plotted against a calculated weighted average (thus assuming a linear effect). The graph showed a linear correlation between the weighted average and the measured data and it was therefore concluded that the effect of the blend is linear. If the effect of the blends were not linear, a different method would have to be devised in order to predict the grindability.

\subsubsection{Case study 2}

Abouzeid and Fuerstenau (2000) wanted to determine the effect of an ore blend on grinding in a high pressure roll mill (HPRM). Quartz and limestone were used for comminution in the HPRM. The minerals were ground individually and as a mixture in $10 \%, 25 \%, 50 \%, 75 \%$ and $90 \%$ proportions. After comminution the product was sieved, each size fraction was weighed and the 
limestone of each size fraction was dissolved in HCL. The size distribution of both materials in the mixture could then be determined.

It was found that even though the feed size distribution of the two minerals was the same, the product size distribution for the two minerals in the mixture was quite different. As can be seen from Figure 2.24, as the percentage limestone in the feed increased, the particle size for both quartz and limestone increased, but the effect was much greater on quartz than on limestone. There was a $400 \mu \mathrm{m}$ increase in $\mathrm{X}_{50 \mathrm{P}}$ for quartz (when its feed decreased from $90 \%$ to $10 \%$ ), while the change for limestone (when its feed increased from $90 \%$ to $10 \%$ ) increased by only 120 $\mu \mathrm{m}$.

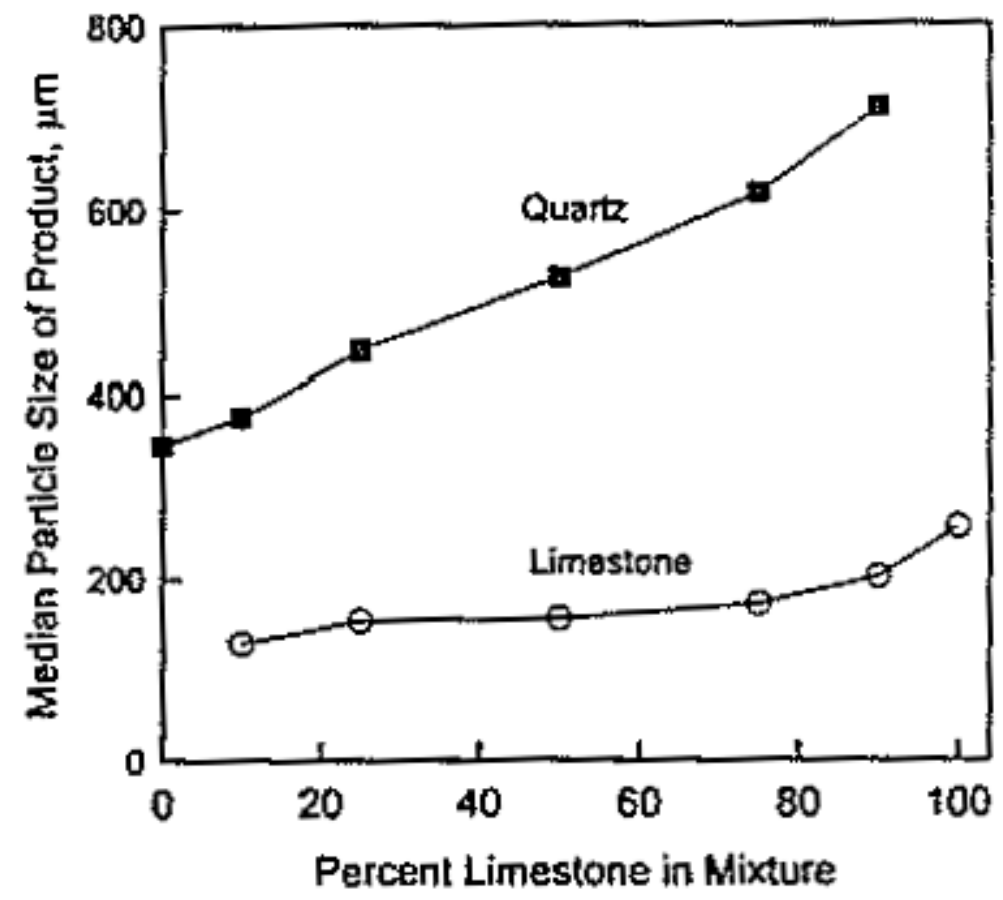

Figure 2.24 Percentage limestone in mixture vs median particle size of product (Abouzeid and Fuerstenau, 2000)

Figure 2.24 shows that the addition of limestone has an antagonistic effect on the median particle size of the product and the effect on quartz is much higher than on limestone. It was concluded that the quartz is more sensitive to the feed composition than the limestone, but no attempt was made to predict the grind of a mixture with an empirical model. This case study shows how the effect of a binary mixture on the response value (product particle size) is graphically evaluated by 
using a binary plot. The $\mathrm{x}$-axis represents the composition of the blend and the y-axis represents the product response value.

\subsubsection{The effect of mixtures on process performance}

\subsubsection{Case study 1}

The effect of coal blending on ash deposition was investigated by Rushdi et al. (2004). The effect of binary blends of various coal sets was evaluated by means of their slag viscosity and thermo mechanical analysis (TMA). The TMA is based on heating the sample and then measuring the penetration of a ram into the sample. It measures the potential of a sample to form deposits. The slag viscosity was calculated by using a standard viscosity curve for the pure coal compounds and an empirical model to determine the viscosity of the blends. The coals used were nominated as A, B, C, D, E, F and G. Various binary blends were evaluated. For the purpose of this study only the results of the binary blend between coal $\mathrm{C}$ and $\mathrm{D}$ will be discussed.

Figure 2.25 presents the graph for the ash deposit layer thickness for the binary blends between C and D.

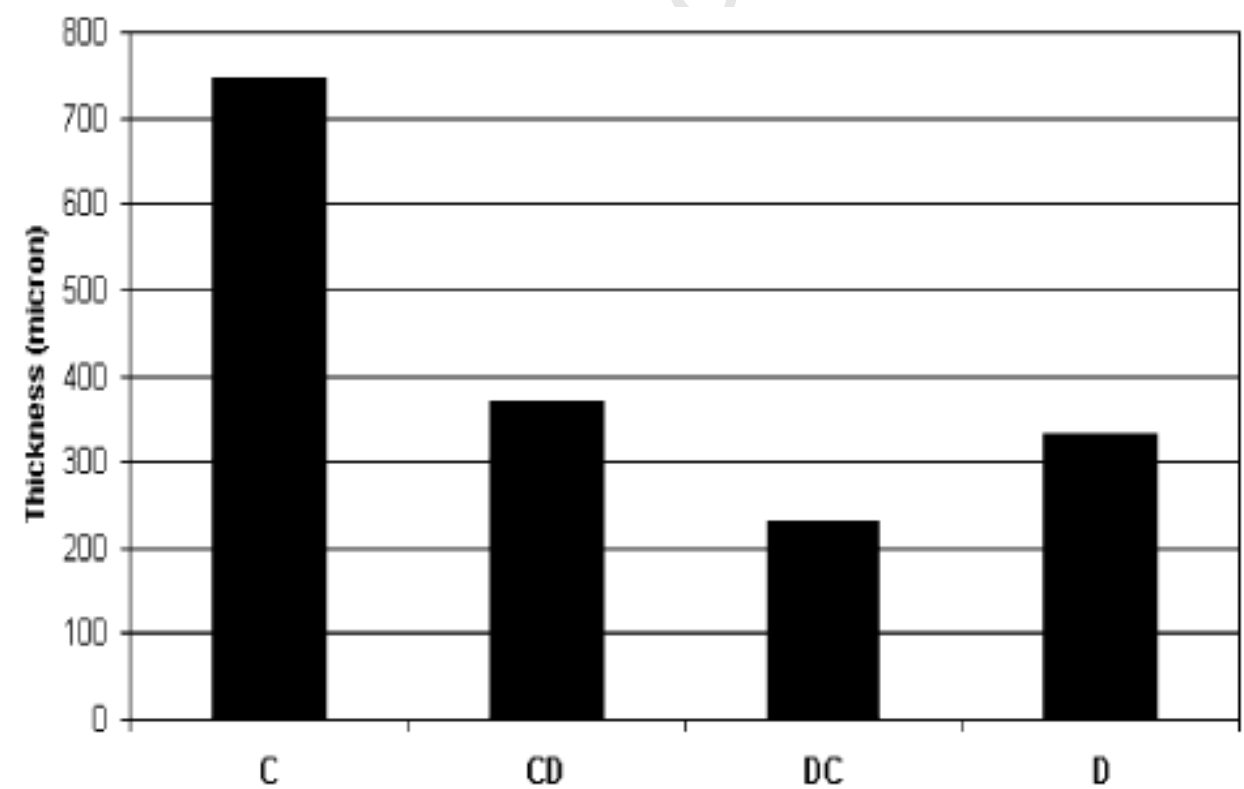

Figure 2.25 Ash deposit layer thickness for binary blends between C and D (Rushdi et al., 2004). 
From the graph it is evident that the coal blends showed non-additive behaviour; therefore the coal blends' performance may not be the same as that of the pure coals. Figure 2.26 indicates the TMA percentage of penetration curves for the binary blends between $\mathrm{C}$ and $\mathrm{D}$.

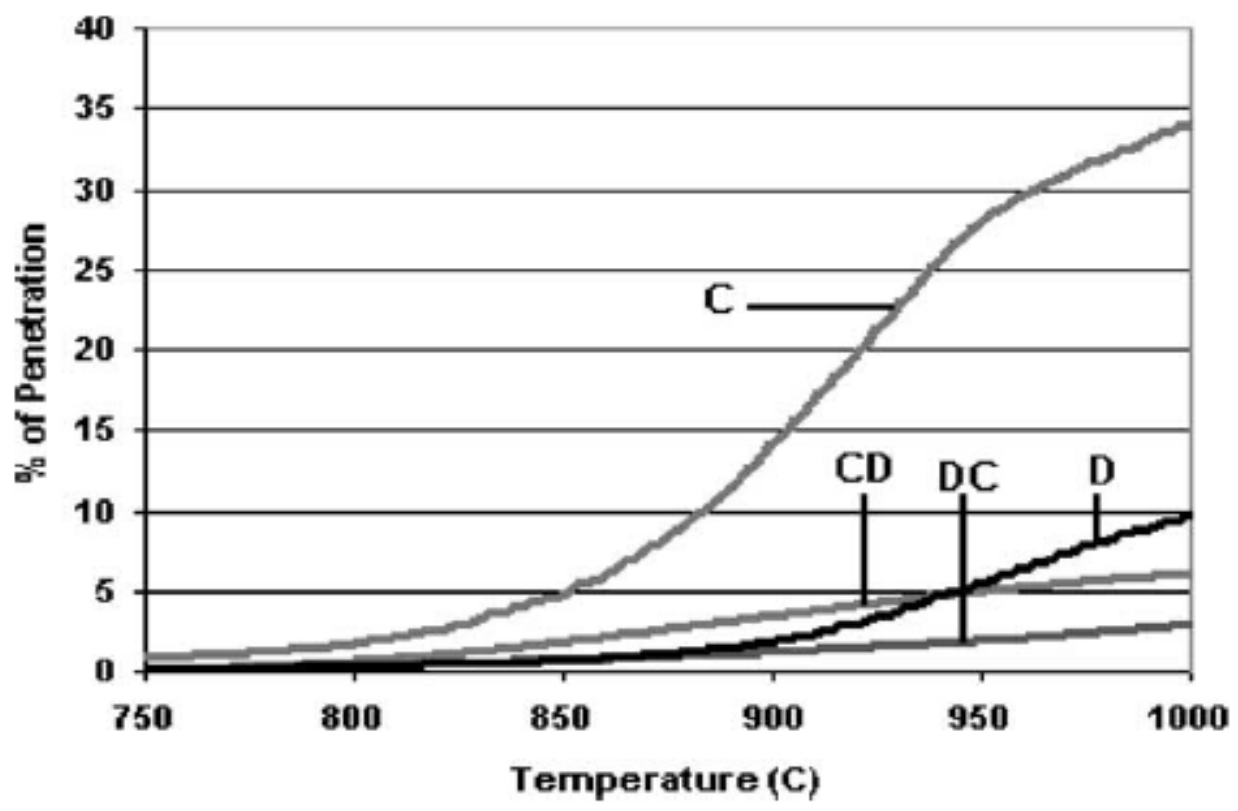

Figure 2.26 TMA percentage of penetration curves for the binary blends between C and D (Rushdi et al., 2004).

From the graph it is evident that coal $\mathrm{C}$ had the highest potential for ash deposits, with coal $\mathrm{D}$ the second highest at a temperature of $1000{ }^{\circ} \mathrm{C}$. The values show nearly the same trend as with the ash deposit layer thickness in Figure 2.25. Figure 2.27 shows the viscosity. This graph indicates that the blend behaviour is between the pure coals. Therefore it was concluded that the slag viscosity model cannot be used as an indicator to predict the slagging behaviour of coal blends. 


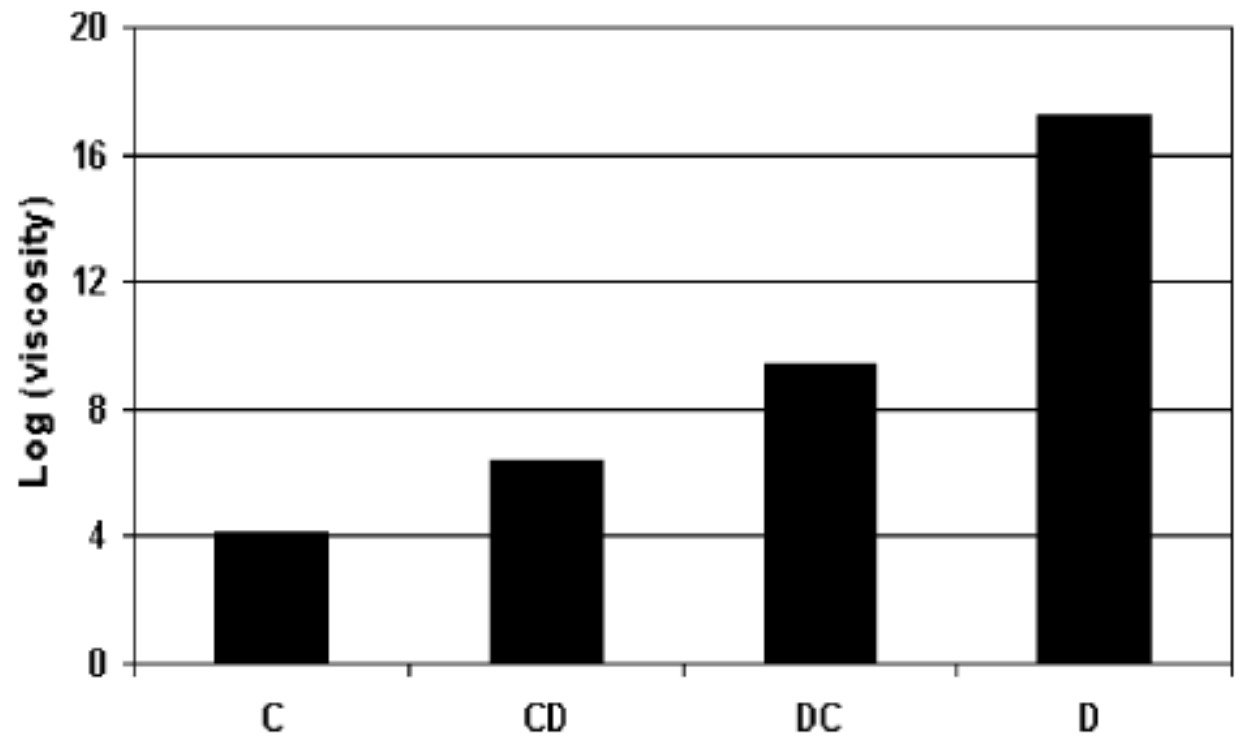

Figure 2.27 Viscosity for the binary blends between C and D (Rushdi et al., 2004).

This case study shows how an experimental measured characteristic of the source coals (the thermal behaviour) and the blends was used to predict the potential to form ash deposits. However, results for the use of an empirical model to determine the viscosity of coal blends and predict ash deposition were inconclusive.

\subsubsection{Case study 2}

A fuzzy programming approach was used by Chakraborty and Chandra (2005) in order to achieve three objectives when producing a washed coal product from the raw blended components. The aim of the research was as follows:

a) To obtain the optimal blend that would render a desired amount of ash percentage in the washed coal $\left(\mathrm{y}_{1}\right)$,

b) To obtain a desired amount of yield $\left(\mathrm{y}_{2}\right)$ and

c) To meet the input cost of raw coal within the desired budget $\left(y_{3}\right)$.

The effect of six coals $\left(\mathrm{x}_{1}\right.$ to $\left.\mathrm{x}_{6}\right)$ was evaluated. Due to limited stocks, upper and lower limits were placed on the amount of each coal that could be used in the blend. An original set of polynomials to predict each of the objectives was derived from data of the last 12 months and with multiple linear regression analysis. They were as follows: 


$$
\begin{aligned}
& \mathrm{y}_{1}=6.701-4.115 \mathrm{x}_{1}+2.819 \mathrm{x}_{2}-0.986 \mathrm{x}_{3}+0.231 \mathrm{x}_{4}+0.373 \mathrm{x}_{5}+0.126 \mathrm{x}_{6} \\
& \mathrm{y}_{2}=6.803+0.252 \mathrm{x}_{1}+1.381 \mathrm{x}_{2}+0.843 \mathrm{x}_{3}+0.444 \mathrm{x}_{4}+0.436 \mathrm{x}_{5}+0.580 \mathrm{x}_{6} \\
& \mathrm{y}_{3}=357.563+2.084 \mathrm{x}_{1}+2.856 \mathrm{x}_{2}+1.7886 \mathrm{x}_{3}+0.976 \mathrm{x}_{4}-0.341 \mathrm{x}_{5}-3.774 \mathrm{x}_{6}
\end{aligned}
$$

An estimate (fuzzy data) of each of the desired objectives was then assigned. By using the "crisp" mathematical model the required proportion of each of the coals was determined in order to achieve all three objectives. This case study shows how linear regression is applied in order to create a prediction model for various objectives and then optimize the blend in order to achieve those objectives. However, the model does not make use of higher order terms (binary or ternary) and thus does not give any insight into the interaction between components/coals within the blend.

\subsubsection{Case study 3}

An investigation was done by Hey and Malysiak (2003) to characterize different sections of a reef at an Anglo Platinum mine. The effect on flotation recovery (when these sections are blended) was also evaluated. The aim was to determine if the mining cut of the reef can be expanded without decreasing productivity. Thus during mining the material would be blended at random with little or no control. The blend consisted of hanging wall reef, a mixture of pothole and normal reef, and two sections of the footwall reef. During characterization of the pure ore it was found that there was a large difference in the mineralogy of the hanging wall and foot wall sections. The foot wall reef was harzburgitic and was also affected by serpentinization processes. Serpentinization decreases the liberation of base metal sulphides and precious group minerals and increases association of precious group metals with silicates.

When ore from the different reefs was blended, the platinum ounces in the concentrate product reduced by up to $16.8 \%$. Therefore widening the mining cut and blending this material at random will have a significant effect on contractual recoveries. However, additional test work was conducted to determine if the reduction in platinum content was due to a drop in head grade (from blending) or to antagonistic effects between the footwall reef and the other ore. It was found that the drop in platinum content in the product was due to a linear effect through poorer recoveries of the footwall material caused by the serpentinization. 


\subsubsection{Antagonistic and synergistic effects in mineral processing}

Although the cause of synergistic and antagonistic interactions is uncertain, some attempts have been made to explain them. Papini et al. (2001) investigated how to blend silicate-carbonate ore with oxidized ore without decreasing the flotation performance. After characterization of six ore types as well as some microflotation experiments, they found that the intergrowth of different minerals interfered with the zeta potential and thus the selectivity of the ore during flotation. Minerals from one ore source will interfere with another mineral's association with the flotation reagents.

Yan and Eaton (1994) also argue that when ore of different grindabilities is blended before grinding, it does not result in the average of the component grindabilities. They found that the Bond work index is not linear with blend composition but is weighted towards the harder component. Thus the harder component creates antagonistic effects. Qualitative analysis of the breakage properties showed an interaction between the components of the blend which affected the individual breakage rates. The breakage properties of the harder material have a greater effect on the overall breakage properties of the Bond work index of the blend than the softer material. A possible cause for the antagonistic effect is that the harder particles shield the softer particles during milling. Parameters like power to the mill and grinding time cannot be used to predict final grind.

\subsection{APPLICATION OF THE MIXTURE DESIGN TO THIS PROJECT}

In summary the objective of this thesis is to investigate the effect of blends on milling and flotation performance and to (dis)prove significant linear/antagonistic/synergistic effects. From the reviews presented in Section 2.3 it is evident that, although some research has been done on the effect of ore blends in mineral processing, none of the research conducted made use of a mixture design as described in Section 2.2. The reviews in Section 2.3 used empirical models or graphical evaluation in order to evaluate the effect of blends. The reviews in Section 2.3 were found to be case specific and limiting with regard to: a) The number of components in the blend (cf. Sections 2.3.1 and 2.3.2.2) b) the relationship between the measured and predicted results (cf. Section 2.3.2.1) and c) the type of empirical model (cf. Section 2.3.3.2). 
The mixture designs that were most evident in the literature were the simplex centroid design, the simplex lattice design and the axial (augmented) design. The literature shows that the axial design is more complex and will fit higher order polynomials that would complicate interpretation of interactions between the components of the blend. As the objective of this research is to evaluate the effect of blends, this design was not considered. The major difference between the simplex lattice and simplex centroid design is how the proportions of the components are spaced along the boundaries of the simplex. The simplex centroid design renders not only equally spaced proportions but also equal proportions of each component. This reduces the number of component combinations and thus design points. Although it makes this design more cost effective than the simplex lattice design, there is a risk involved as the design must still consist of a greater number of design points than terms in the fitted polynomial model (Cornell, 2002). The simplex lattice design was selected for this research. The design is commonly used in the literature and has the added advantage that it enables the researcher to obtain representative proportions for the blends.

As indicated, the objective of this research is to investigate the effect of blends on milling and flotation performance. This is relevant to metal accounting as current resources are calculated based on pure component recovery and the effect of blends is not considered. This thesis will provide a methodology for evaluating the effect of blends using a statistical mixture design. To the author's knowledge this is the first time such a study has been undertaken. 


\section{CHAPTER 3 EXPERIMENTAL}

This chapter addresses the general mineralogy of UG2 ore as well as the mineralogical results for the ores used in the experimental design. The method used to sample and subsample material from the ore sources is then discussed. The milling and flotation technique used are described and the design points for the simplex lattice mixture design are given.

\subsection{MINERAL ORES}

\subsubsection{Mineralogy}

$70 \%$ of the UG2 reef consists of the chromite mineral $(\mathrm{Mg}, \mathrm{Fe}) \cdot(\mathrm{Cr}, \mathrm{Al}, \mathrm{Fe})_{2} \mathrm{O}_{3}$ (Ekmekçi et al., 2003). Silicate gangue minerals like pyroxene and feldspar are normally also attached to the chromite crystals. The chromite crystal lattice also contains oxide nickel, only $15 \%$ of which is in the form of a recoverable sulphide. The size of the chromite grains vary between $0.1 \mathrm{~mm}$ and 4 $\mathrm{mm}$, with an average of $0.5 \mathrm{~mm}$ (Rixom, 2004). The base metal sulphide (BMS) and platinum group minerals (PGM) are mostly attached to the silicate gangue between the harder chromite grains. Therefore the mining and crushing operations will generate natural fines. During processing the grinding of UG2 ore must be well controlled as inadequate grinding will cause poor liberation of the BMS and PGM as well as sanding in the flotation cells. Yet excessive grinding will cause sliming of the sulphides containing the PGM and BMS, which will render poor recoveries during flotation. Flotation normally takes place at a natural $\mathrm{pH}$ of 7 and collector like isobutyl xanthate (SIBX) is used (Xiao et al., 2004).

According to Xiao et al. (2004), there are 109 species of PGMs recognized by the International Mineralogical Association. They include sulphides, tellurides, antimonides, arsenides, alloys and native species, for example platinum nuggets. In UG2 ore from the Bushveld Complex the PGMs are associated primarily with the BMSs (Miller et al., 2005). Most platinum minerals are associated with copper sulphides and palladium minerals with nickel sulphides. The PGMs are also associated with oxides and silicate minerals to a minor degree. The nature of the PGM association will determine the flotation recovery. The three primary base metal sulphides in the UG2 reef are pentlandite, chalcopyrite and pyrrhotite. 


\subsubsection{Characterization of mineral ores}

Ore from the following four shafts was selected for this research: Waterval UG2, Paardekraal, Townlands and Salene. The first three shafts were selected as they are main feeds to the Waterval UG2 concentrator. Salene ore was added to the experimental design as it is known that this is a poor quality ore, of different origin and characteristics, and it was used to test the experimental design as antagonistic effects were anticipated with this ore.

\subsubsection{Methodology}

A mineralogical analysis was conducted on the four ores in order to explain their behaviour during flotation and among each other in the experimental design. $2 \mathrm{~kg}$ of each sample was crushed to $-3 \mathrm{~mm}$ and milled with $1 \ell$ water for 60 minutes. The product was filtered and dried overnight. The sample was then split down (with a rotary splitter) to $200 \mathrm{~g}$ and submitted for mineralogical analysis. The mineral liberation analyser (MLA) was used to characterize the ore. The MLA is a scanning electron microscope with an integrated energy X-ray dispersive system. It is capable of measuring multiple samples and it has an interactive data processing system (Rixom, 2004).

The MLA technique uses automated sparse phase liberation measurements to identify and characterize the grains of interest (PGM) in a sample block. Heavy minerals like BMS and PGM have a high atomic number. Thus when bombarded with electrons they will render a high backscatter signal. This technique detects particles with a high backscattered electron image intensity using set grey levels. The greater the backscatter, the brighter the particle. The brightness range, or grey level, of the backscatter electron image is used to differentiate between minerals that have sufficiently different atomic numbers. The particles detected are then analysed using energy dispersive X-ray analysis. Information on the particles of interest and other related phases is collected and processed. Subsequent X-ray spectra collected at centroid positions in various backscatter electron zones can then be used to confirm the chemistry of the mineral. To determine the bulk mineralogical composition the MLA uses an X-ray modal analysis (XMOD). XMOD is a point counting method, in which the mineral identification is determined by one X-ray analysis at each counting point in a sample block.

\subsubsection{Results}

The aim of the mineralogical analysis is to characterize the ores "as is" in an attempt to explain their flotation behaviour. Ore from the four shafts was evaluated with regard to their bulk 
mineralogy, chromite, BMS and PGM mineralogy, which was divided into PGM distribution, PGM association and PGM grain size distribution. The results for the ores are summarized in Table 3.1.

Table 3.1 Mineralogical results.

\begin{tabular}{|c|c|c|c|c|c|}
\hline Property & & Salene & Waterval UG2 & Paardekraal & Townlands \\
\hline $\begin{array}{c}\text { Predominant } \\
\text { minerals of } \\
\text { bulk } \\
\text { mineralogy }\end{array}$ & & $\begin{array}{l}\sim 36 \% \text { chromite } \\
\text { and } \\
\sim 41 \% \text { pyroxene }\end{array}$ & $\begin{array}{l}\sim 43 \% \text { chromite } \\
\text { and } \\
\sim 36 \% \text { pyroxene }\end{array}$ & $\begin{array}{c}\sim 55 \% \\
\text { chromite and } \\
\sim 28 \% \\
\text { pyroxene }\end{array}$ & $\begin{array}{c}\sim 49 \% \text { chromite } \\
\text { and } \\
\sim 33 \% \\
\text { pyroxene }\end{array}$ \\
\hline Chromite & Liberated & $99 \%$ & $99.4 \%$ & $99.4 \%$ & $99.7 \%$ \\
\hline & $\begin{array}{l}\text { Average } \\
\text { grain size }\end{array}$ & $40 \mu \mathrm{m}$ & $42 \mu \mathrm{m}$ & $55 \mu \mathrm{m}$ & $45 \mu \mathrm{m}$ \\
\hline BMS & $\begin{array}{c}\text { Predominant } \\
\text { minerals }\end{array}$ & $\begin{array}{l}\text { Mostly pyrrhotite } \\
\text { with equal } \\
\text { quantity of } \\
\text { pentlandite and } \\
\text { chalcopyrite }\end{array}$ & $\begin{array}{l}\text { Pentlandite and } \\
\text { chalcopyrite, } \\
\text { with lesser } \\
\text { pyrrhotite }\end{array}$ & $\begin{array}{l}\text { Pentlandite } \\
\text { and } \\
\text { chalcopyrite, } \\
\text { with lesser } \\
\text { pyrrhotite }\end{array}$ & $\begin{array}{l}\text { Pentlandite and } \\
\text { equal quantity } \\
\text { of chalcopyrite } \\
\text { and pyrrhotite }\end{array}$ \\
\hline & Liberated & $76.2 \%$ & $93 \%$ & $82 \%$ & $84 \%$ \\
\hline & $\begin{array}{l}\text { Average } \\
\text { grain size }\end{array}$ & $11 \mu \mathrm{m}$ & $8.5 \mu \mathrm{m}$ & $18 \mu \mathrm{m}$ & $16 \mu \mathrm{m}$ \\
\hline \multirow[t]{4}{*}{ PGM } & Distribution & $\begin{array}{l}\text { PGE sulphides } \\
\text { (33\%) and } \\
\text { PGE alloys } \\
(\sim 44 \%)\end{array}$ & $\begin{array}{c}\text { PGE sulphides } \\
\text { contribute } \sim 86 \% \\
\text { to the PGM } \\
\text { distribution }\end{array}$ & $\begin{array}{c}\text { PGE sulphides } \\
\text { contribute } \\
\sim 89 \%\end{array}$ & $\begin{array}{c}\text { PGE sulphides } \\
\text { contribute } \\
\sim 78 \% \text { with } \\
\text { lesser Pd } \\
\text { tellurides } \\
(\sim 9 \%) \text { and } \\
\text { ferroplatinum } \\
(\sim 7 \%)\end{array}$ \\
\hline & Liberation & $\sim 56 \%$ & $\sim 74 \%$ & $\sim 62 \%$ & $\sim 43 \%$ \\
\hline & $\begin{array}{c}\text { Enclosed/ } \\
\text { attached to } \\
\text { BMS }\end{array}$ & $\sim 5.1 \%$ & $\sim 8.9 \%$ & $\sim 21.7 \%$ & $\sim 23.7 \%$ \\
\hline & $\begin{array}{l}\text { Average } \\
\text { grain size }\end{array}$ & $3 \mu \mathrm{m}$ & $7 \mu \mathrm{m}$ & $7 \mu \mathrm{m}$ & $5 \mu \mathrm{m}$ \\
\hline
\end{tabular}




\section{Bulk mineralogy}

The bulk mineralogy of the shafts, in particular the chromite levels, is variable because the mining cuts at each shaft are different and vary from 1 to $1.8 \mathrm{~m}$. The bulk mineralogy is similar for Paardekraal, Townlands and Waterval shafts, with chromite being the most abundant mineral $(>40 \%)$.

\section{Chromite}

Chromite is well liberated in all the shafts, with an average grain size ranging from 40 to $55 \mu \mathrm{m}$. Chromite is naturally hydrophilic and the addition of collectors like sodium isobutyl xanthate (SIBX) will not increase the flotability of chromite. However, the flotability will increase with addition of copper sulphate (Wesseldijk et al., 1999).

\section{Base metal sulphide (BMS)}

The BMSs in the ores are well liberated with $>80 \%$ for Waterval UG2, Townlands and Paardekraal shafts but $<80 \%$ for Salene. The BMSs for the Waterval UG2, Townlands and Paardekraal shafts consist mostly of pentlandite and chalcopyrite. The average BMS grain size of Paardekraal and Townlands is $\sim 18 \mu \mathrm{m}$ and $\sim 16 \mu \mathrm{m}$, respectively, whilst Waterval is finer with an average grain size of $\sim 9 \mu \mathrm{m}$. The mineralogy of the ore from the Salene shaft is more altered. The BMS particles of Salene differ from the other shafts; they are fine grained $(11 \mu \mathrm{m})$ and consist predominantly of pyrrhotite (45\%). SIBX adsorption on pentlandite is higher than on pyrrhotite (Bozkurt et al., 1998). It is therefore expected that the flotation recovery for ore from the Waterval UG2, Townlands and Paardekraal shafts will be higher than for the Salene ore.

\section{Precious group mineral (PGM)}

The PGM particles in Townlands are $~ 66 \%$ liberated (liberated PGMs plus enclosed/attached to BMS), whilst the PGMs in the Paardekraal and Waterval ore are well liberated (83\%). The PGM particles in Salene are $\sim 61 \%$ liberated. The flotation potential of liberated PGM particles as well as PGM particles that are enclosed or attached to BMS is very high and from the above results it is expected that ore from Waterval and Paardekraal will render the highest recovery.

The predominant PGMs in the Salene ore are PGE alloys ( 44\%). PGMs that are associated with the BMS will be concentrated faster, although the flotation behaviour is also dependent on the grain size and type of BMS (Penberthy et al., 2000). For example, chalcopyrite will float faster than pyrrhotite. If the PGMs are locked in gangue or associated with locked BMSs they 
will take longer to float. The liberated PGM grains will also float, but at a slower rate than the BMSs. The smaller the grain size, the longer it will take to float. Due to the higher amount of pyrrhotite and smaller liberated PGM grain size of the Salene ore, it is expected that it will render a smaller flotation recovery than the other shafts.

\subsubsection{Sampling and sample preparation}

Ten-ton bulk samples of each ore were collected and sub sampled by Anglo Research. The material was crushed to $-12 \mathrm{~mm}$ using a cone crusher and split 12 ways with a rotary bulk splitter indicated in Figure 3.1.

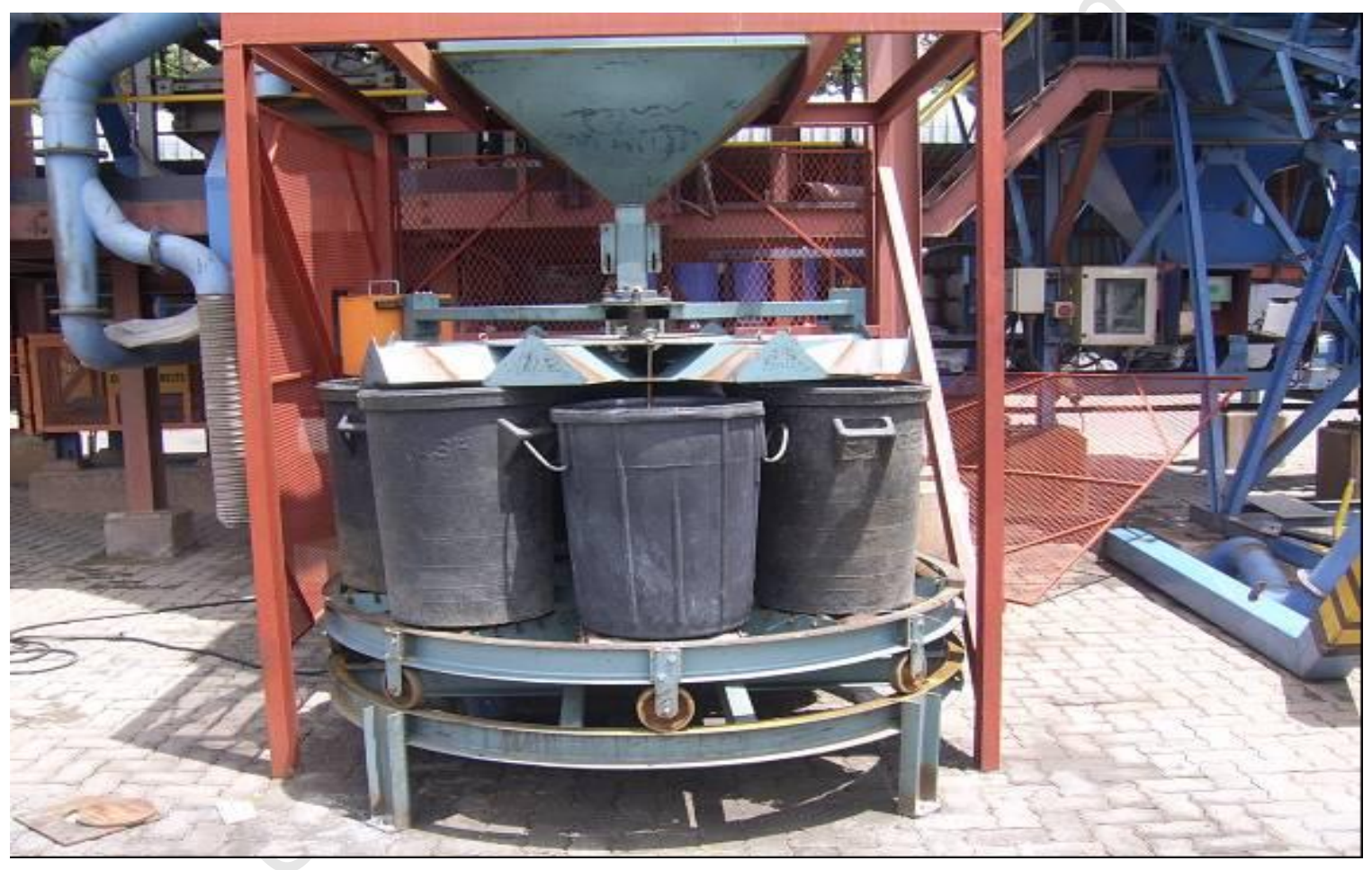

Figure 3.1 Rotary bulk splitter used to split ten-ton bulk sample.

The subsamples from splitting were combined and resplit for homogenization. About 1.25 tons were reserved as a backup. Material was then crushed to $-3 \mathrm{~mm}$ using a jaw crusher and $40 \mathrm{~kg}$ of this material was split eight ways with a rotary splitter to render $5 \mathrm{~kg}$ portions. Each $5 \mathrm{~kg}$ portion was then split ten ways using a rotary splitter (cf. Figure 3.2) to render $500 \mathrm{~g}$ portions, which were used to make up each of the 35 experimental design points. 


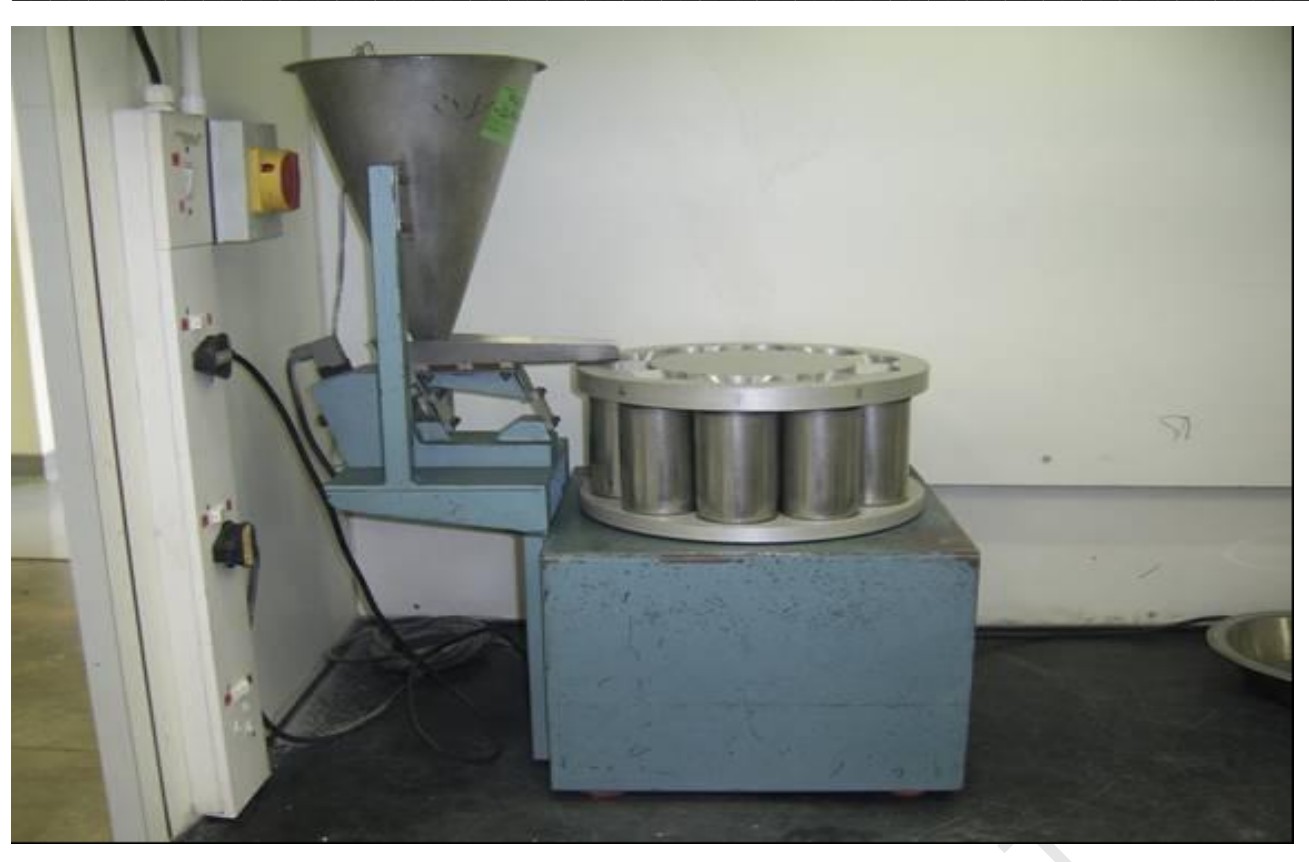

Figure 3.2 Rotary splitter used to split $5 \mathrm{~kg}$ sample to $500 \mathrm{~g}$ portions.

\subsection{MILLING AND FLOTATION EXPERIMENTS}

\subsubsection{Milling}

Laboratory batch milling tests were performed using a standard Yaskuwa $0.25 \mathrm{~kW}$ rod mill with a total rod mass of $15.4 \mathrm{~kg}$, shown in Figure 3.3. The mill speed was $74.6 \mathrm{rpm}$. 


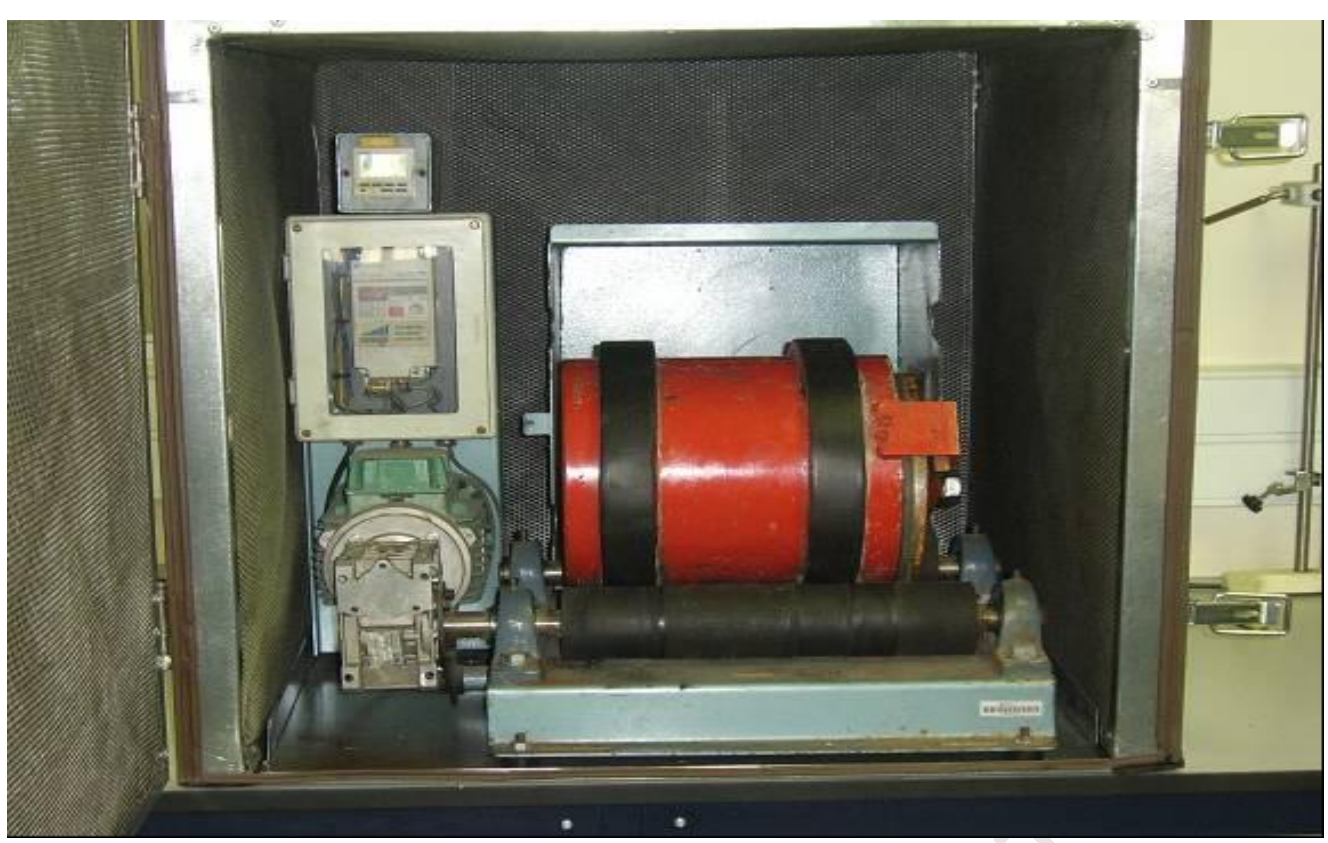

Figure 3.3 Rod mill used for laboratory batch milling.

To ensure proper flotation, standard flotation experiments require a particle size of approximately $60 \%$ mass passing $75 \mu \mathrm{m}$. It has been shown that increasing finesses of grind for some minerals have little impact on the rate of flotation (Bazin et al., 2005). A grinding test was performed on each pure ore to determine the optimum milling time required to obtain a particle size of approximately $60 \%$ mass passing $75 \mu \mathrm{m}$. In order to reduce labour and cost a Malvern analyser was used to estimate the milling time by analysing the full spectrum of samples collected at different milling times. The Malvern analyser measures percentage volume passing $74 \mu \mathrm{m}$. The results were confirmed with wet and dry screening of samples collected from the last three milling times. The screening tests measure percentage mass passing $75 \mu \mathrm{m}$.

Figure 3.4 shows the results for the grindings test. The $\mathrm{x}$-axis represents the milling time in minutes and the y-axis represents the percentage passing (either volume $74 \mu \mathrm{m}$ or mass $75 \mu \mathrm{m}$ ). The results obtained with wet and dry screening of a dry solids sample (indicated by the bullets marked mass in the legend) were compared with those obtained for a slurry sample analysed by the Malvern analyser (indicated by the lines on the graph marked volume in the legend). The sample for dry screening was assumed to be representative as it was correctly prepared (cf. Section 3.2.2). The sample used for the Malvern analyser was a $2 \mathrm{ml}$ grab sample taken from the flotation cell. Although the percentage volume passing $74 \mu \mathrm{m}$ at 60 minutes was always lower 
than the percentage mass passing $75 \mu \mathrm{m}$, both methods corresponded quite well. According to the milling curves, Paardekraal ore rendered the longest milling time (of 60 minutes) to give $60 \%$ passing $75 \mu \mathrm{m}$. Thus 60 minutes was used as default milling time for all the ores. Once this milling time was established, the milling time and conditions were kept constant for all experiments.

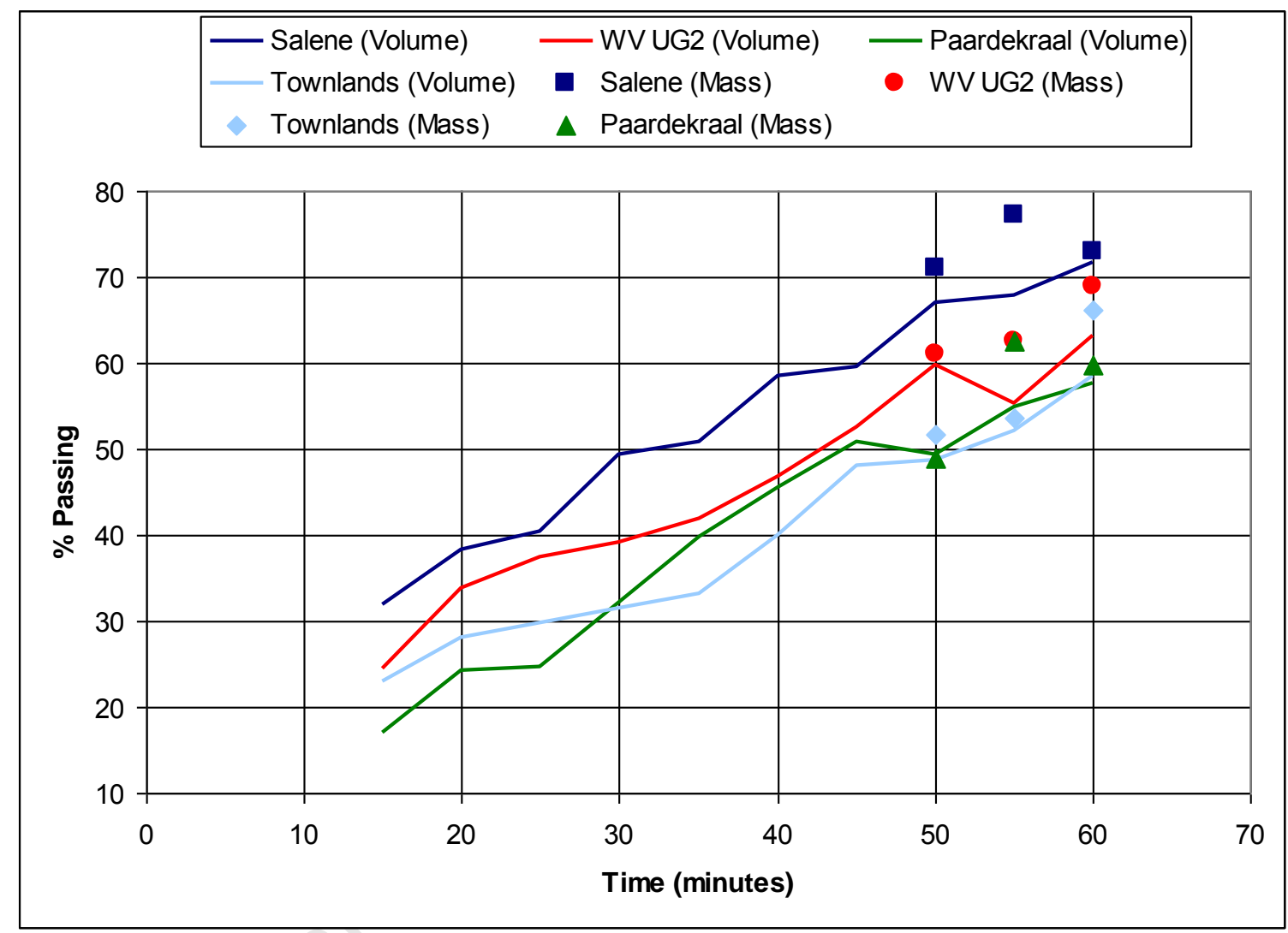

Figure 3.4 Milling curve for all ores indicating both $\%$ mass passing $75 \mu \mathrm{m}$ and $\%$ volume passing $74 \mu \mathrm{m}$.

\subsubsection{Flotation}

Laboratory batch flotation tests were performed using a standard Denver laboratory flotation cell indicated in Figure 3.5. All flotation conditions (for example air pressure, reagents, impeller speed) were kept constant in order to compare the effect of ore blends on the flotation performance alone. The impeller speed was $1000 \mathrm{rpm} .2 \mathrm{~kg}$ of material was used for each flotation experiment and $1 \ell$ of water was added to the sample before milling. Concentrate and tails samples were filtered and dried. Tails samples were split ten ways using a rotary splitter and 
approximately $200 \mathrm{~g}$ from each split were collected for particle size analysis (wet and dry screening). All samples were sent for precious metal and base metal analysis.

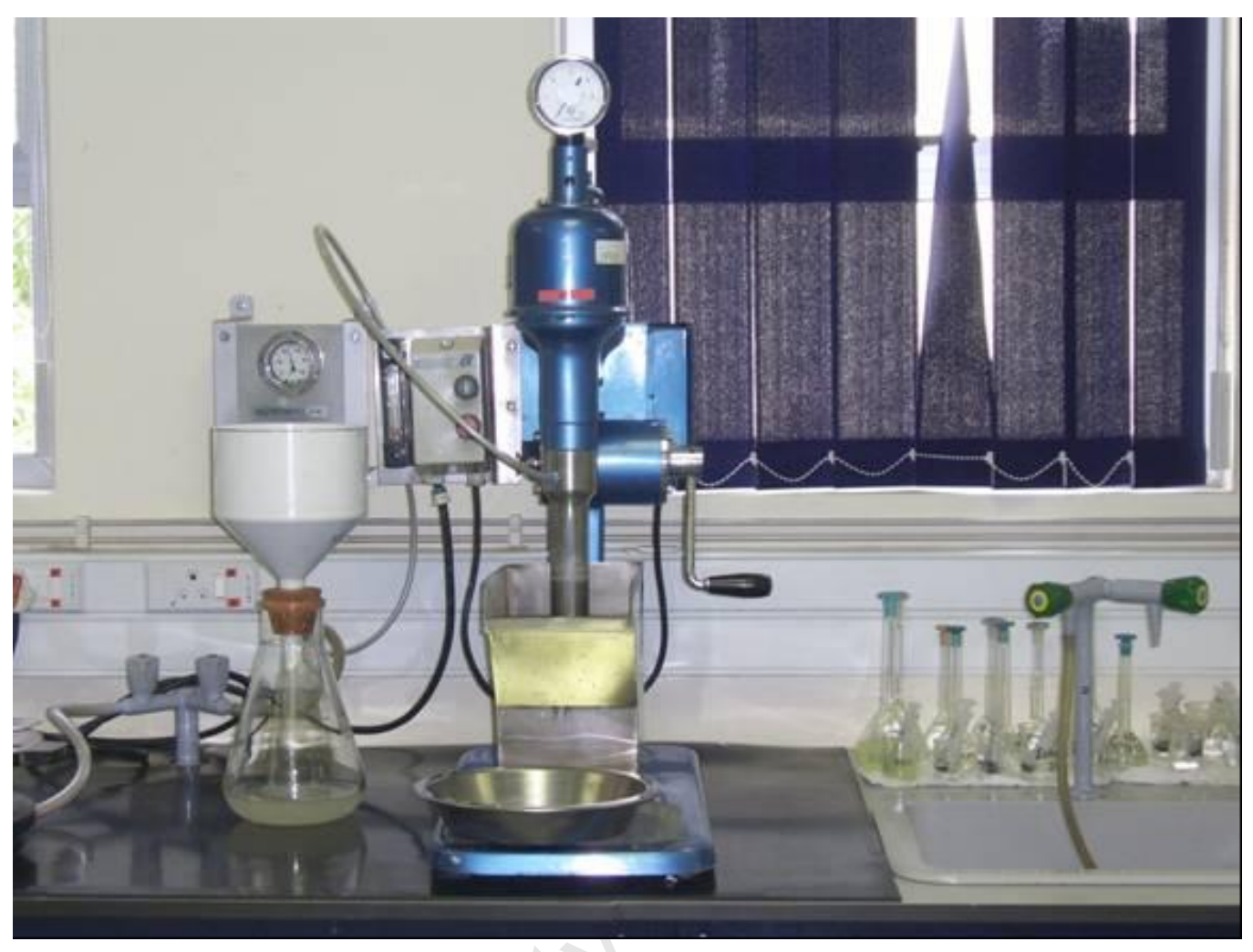

Figure 3.5 Denver flotation cell used for laboratory batch flotation tests.

The following concentrate collection and reagent suite given in Table 3.2 was used for all flotation tests:

Table 3.2 Reagent suite used in flotation tests.

\begin{tabular}{|l|l|l|l|l|l|}
\hline & $\begin{array}{c}\text { Time } \\
(\text { minutes })\end{array}$ & \multicolumn{1}{|c|}{$\begin{array}{c}\text { SIBX } \\
(\mathbf{g} / \mathbf{t})\end{array}$} & $\begin{array}{c}\text { Senkol 65 } \\
(\mathbf{g} / \mathbf{t})\end{array}$ & $\begin{array}{c}\text { KU9 } \\
(\mathbf{g} / \mathbf{t})\end{array}$ & $\begin{array}{l}\boldsymbol{\beta} \text {-Froth } \\
(\mathbf{g} / \mathbf{t})\end{array}$ \\
\hline Condition 1 & 2 & 40 & 40 & & 10 \\
\hline Condition 2 & 2 & & & 40 & \\
\hline Concentrate 1 & 2 & & & & \\
\hline
\end{tabular}




\begin{tabular}{|l|l|l|c|c|c|}
\hline & \multicolumn{1}{|c|}{$\begin{array}{c}\text { Time } \\
(\text { minutes })\end{array}$} & \multicolumn{1}{|c|}{$\begin{array}{c}\text { SIBX } \\
(\mathbf{g} / \mathbf{t})\end{array}$} & $\begin{array}{c}\text { Senkol 65 } \\
(\mathrm{g} / \mathbf{t})\end{array}$ & $\begin{array}{c}\text { KU9 } \\
(\mathbf{g} / \mathbf{t})\end{array}$ & $(\mathrm{g} / \mathbf{t})$ \\
\hline Concentrate 2 & 8 & & & & \\
\hline Condition 3 & 2 & 10 & 10 & & 10 \\
\hline Condition 4 & 2 & & & 10 & \\
\hline Concentrate 3 & 20 & & & & \\
\hline
\end{tabular}

The recovery and grade results were calculated as follows:

Cumulative recovery results: The cumulative recovery for three concentrates was evaluated for each design point. The flotation products were evaluated by mass and grade (in $g / t$ ). Therefore each concentrate as well as the tail were weighed (as a dry mass) and analysed for the precious group metals. The content was then calculated by multiplying the product mass by the product grade. The recovery was determined by dividing the sum of the content (in g) of the three concentrates by the sum of the content (in g) of the three concentrates and the tail as indicated in Equation 3.1.

$$
\left.\% \text { Recovery }=\frac{\text { Concentrate } 1+\text { Concentrate } 2+\text { Concentrate } 3}{\text { Concentrate } 1+\text { Concentrate } 2+\text { Concentrate } 3+\text { Tail }} \times 100 \text { (Eq. } 3.1\right)
$$

Cumulative grade results: The cumulative grade for each design point was evaluated. It was calculated by dividing the sum of the content of the three concentrates by the sum of the mass of the three concentrates as indicated in Equation 3.2.

$$
\text { Cumulative Grade }=\frac{\text { Content } 1+\text { Content } 2+\text { Content } 3}{\text { Mass } 1+\text { Mass } 2+\text { Mass } 3}
$$

Standardization experiments were conducted to determine the recovery and grade results of the pure ores. During these experiments three concentrates were collected over 30 minutes as indicated in the recovery grade curve in Figure 3.6. 


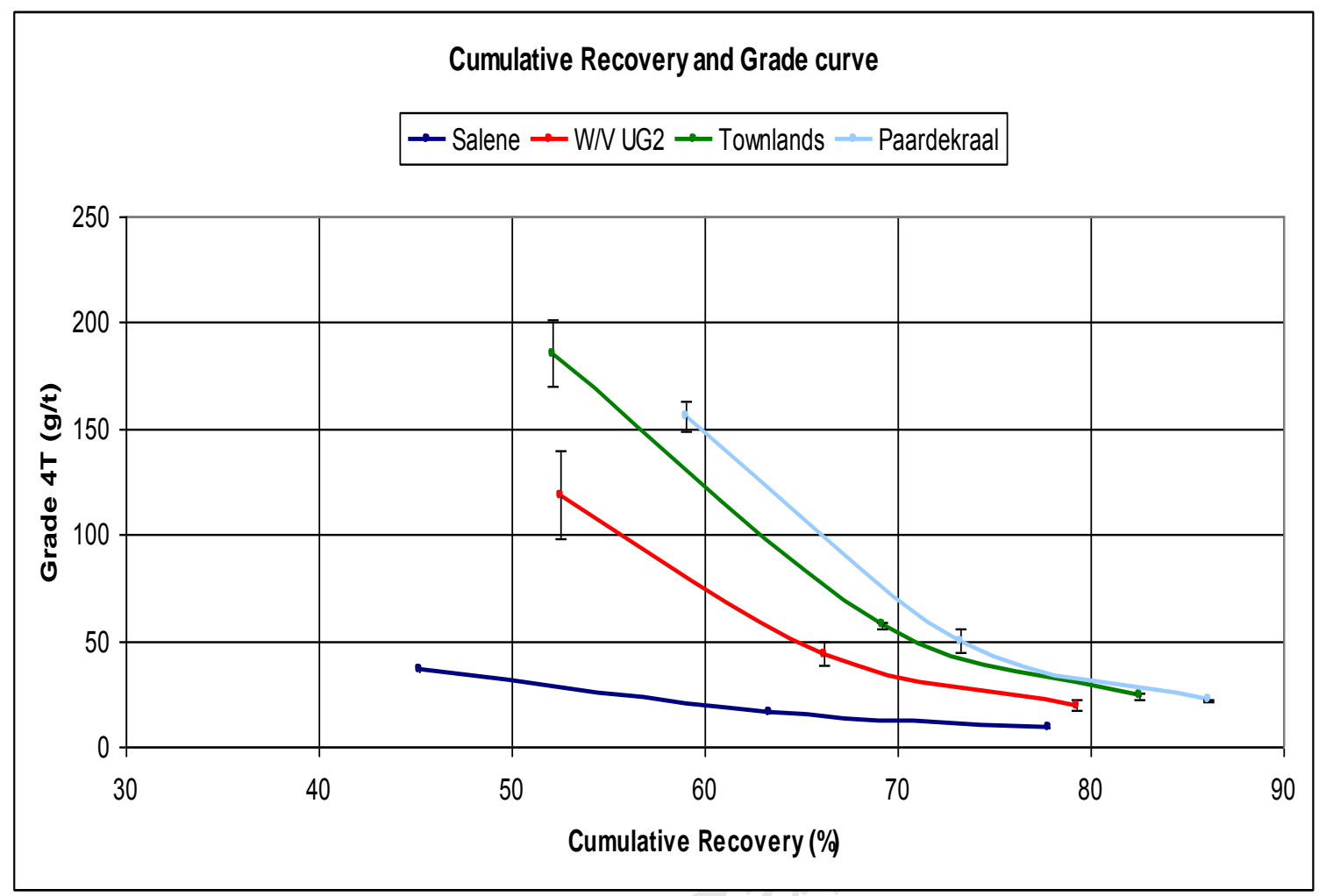

Figure 3.6 Recovery grade curve for the pure ores.

From Figure 3.6 it is evident that each ore has a distinct curve. The errors bars, for grade, for each curve were generated by using the standard deviation of three replicates. Although the errors are a bit higher for the first concentrate, a clear distinction can still be made between all four ores. The error in grade for Salene is too small to be seen with the error bars on the graph. The flotation performance of the ores corresponds with the mineralogical results (cf. Section 3.1.2). As expected, the recovery - grade characteristics of Salene ore are quite bad relative to the other ores while Paardekraal ore rendered the highest recovery. These results also corresponded well with the choice of ores for the experimental design (cf. Section 3.1.2) as Salene ore was selected to evaluate if the experimental design would pick up antagonistic effects. A recovery time curve (indicated in Figure 3.7) was also drawn to validate the number of concentrates collected for the mixture experiments. 


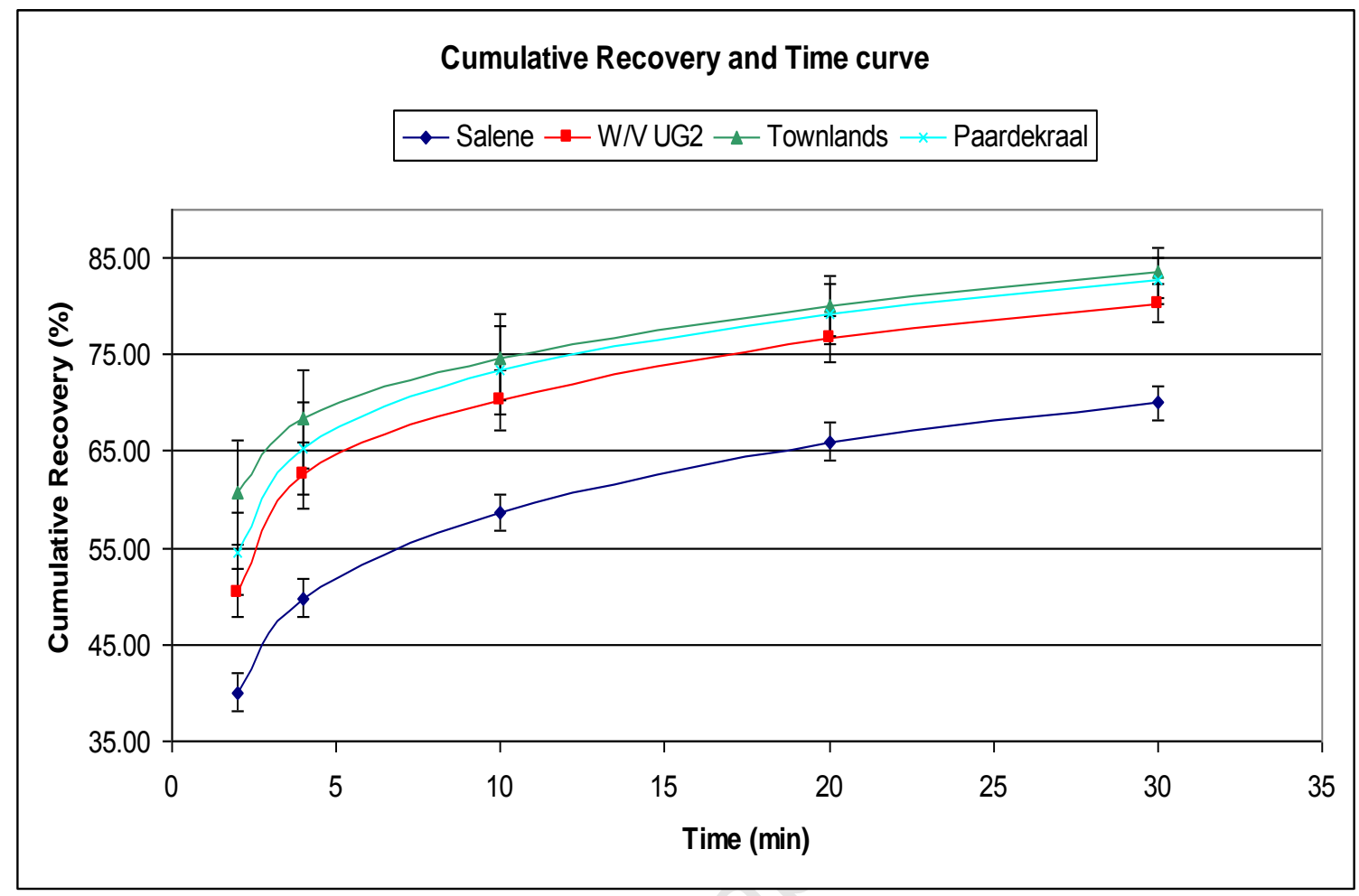

Figure 3.7 Recovery time curve for the pure ores.

\subsubsection{Repeatability and analytical variance}

The repeatability between three replicates of the each pure ore was determined. The error was measured at one standard deviation and was as follows: For cumulative recovery the error was $0.88 \%$ for Salene, $1.34 \%$ for Waterval UG2, $2.76 \%$ for Paardekraal and $1.21 \%$ for Townlands. For cumulative grade the error was $1.83 \mathrm{~g} / \mathrm{t}$ for Salene, $8.04 \mathrm{~g} / \mathrm{t}$ for Waterval UG2, $4.14 \mathrm{~g} / \mathrm{t}$ for Paardekraal and $5.6 \mathrm{~g} / \mathrm{t}$ for Townlands. This renders an average error of $1.5 \%$ for cumulative recovery and $4.9 \mathrm{~g} / \mathrm{t}$ for cumulative grade. The mixture experiments were conducted during the same period as these tests and it was assumed that repeatability would be similar. The uncertainty in grade may also be a function of analytical variance. The total analytical variance for the pure ore and the mixture experiments was $1.2 \mathrm{~g} / \mathrm{t}$ at one standard deviation.

\subsection{SIMPLEX LATTICE DESIGN}

Experiments were performed according to the simplex lattice mixture design. A simplex lattice design is an arrangement of equally spaced points on a simplex as described by Cornell (2002). 
The simplex lattice design was used in this research as it is literature standard. The design points for the simplex lattice design are shown in Table 3.3, where $\mathrm{x}_{1}$ is Salene ore, $\mathrm{x}_{2}$ is Waterval UG2 ore, $\mathrm{x}_{3}$ is Paardekraal ore and $\mathrm{x}_{4}$ is Townlands ore.

Table 3.3 Design points for simplex lattice mixture design.

\begin{tabular}{|c|c|c|c|c|c|c|c|c|c|}
\hline $\begin{array}{c}\text { Design } \\
\text { point }\end{array}$ & $\mathbf{X}_{1}$ & $\mathbf{X}_{2}$ & $\mathbf{X}_{3}$ & $\mathbf{X}_{4}$ & $\begin{array}{c}\text { Design } \\
\text { point }\end{array}$ & $\mathbf{X}_{1}$ & $\mathbf{X}_{2}$ & $\mathbf{X}_{3}$ & $\mathbf{X}_{4}$ \\
\hline 1 & 1 & 0 & 0 & 0 & 19 & 0 & 0.25 & 0.5 & 0.25 \\
\hline 2 & 0 & 1 & 0 & 0 & 20 & 0 & 0.25 & 0.25 & 0.5 \\
\hline 3 & 0 & 0 & 1 & 0 & 21 & 0 & 0.5 & 0.5 & 0 \\
\hline 4 & 0 & 0 & 0 & 1 & 22 & 0 & 0.5 & 0 & 0.5 \\
\hline 5 & 0.25 & 0.25 & 0.25 & 0.25 & 23 & 0 & 0 & 0.5 & 0.5 \\
\hline 6 & 0.5 & 0.5 & 0 & 0 & 24 & 0.75 & 0.25 & 0 & 0 \\
\hline 7 & 0.5 & 0 & 0.5 & 0 & 25 & 0.75 & 0 & 0.25 & 0 \\
\hline 8 & 0.5 & 0 & 0 & 0.5 & 26 & 0.75 & 0 & 0 & 0.25 \\
\hline 9 & 0.5 & 0.25 & 0.25 & 0 & 27 & 0.25 & 0.75 & 0 & 0 \\
\hline 10 & 0.5 & 0.25 & 0 & 0.25 & 28 & 0.25 & 0 & 0.75 & 0 \\
\hline 11 & 0.5 & 0 & 0.25 & 0.25 & 29 & 0.25 & 0 & 0 & 0.75 \\
\hline 12 & 0.25 & 0.5 & 0.25 & $\begin{array}{l} \\
0\end{array}$ & 30 & 0 & 0.75 & 0.25 & 0 \\
\hline 13 & 0.25 & 0.5 & 0 & 0.25 & 31 & 0 & 0.75 & 0 & 0.25 \\
\hline 14 & 0.25 & 0.25 & 0.5 & 0 & 32 & 0 & 0.25 & 0.75 & 0 \\
\hline 15 & 0.25 & & 0.5 & 0.25 & 33 & 0 & 0 & 0.75 & 0.25 \\
\hline 16 & 0.25 & 0 & 0.25 & 0.5 & 34 & 0 & 0.25 & 0 & 0.75 \\
\hline 17 & 0.25 & 0.25 & 0 & 0.5 & 35 & 0 & 0 & 0.25 & 0.75 \\
\hline 18 & 0 & 0.5 & 0.25 & 0.25 & & & & & \\
\hline
\end{tabular}




\section{CHAPTER 4 RESULTS AND DISCUSSION}

This chapter describes the analysis of the simplex lattice mixture design as well as the milling and flotation results. The methodology used for selecting a regression polynomial is discussed in Section 4.1.1. The quadratic, special cubic and stepwise regression polynomials are evaluated using the $\mathrm{R}_{\mathrm{adj}}{ }^{2}$ value, the ANOVA table and residual plots. A description is given in Section 4.1.2 of how the simplex lattice mixture design is interpreted using the regression polynomial as well as binary and ternary plots. In Section 4.1.3 the simplex lattice mixture design is tested on synthetic data to see if synergistic or antagonistic interactions can be detected within the experimental error. Section 4.2 provides a review of the milling and flotation results and the impact on metal accounting. The statistical programs JMP and MINITAB were used for generating the regression polynomials and evaluating data.

\subsection{ANAL YSIS OF THE SIMPLEX LATTICE DESIGN}

\subsubsection{Methodology for selection of the regression polynomial}

This section is a discussion of the methodology behind the final analysis of the simplex lattice mixture design results. The aim is to identify which polynomial is the most efficient for this research project. Initially the quadratic polynomial was evaluated, followed by the special cubic polynomial and then the stepwise regression polynomial. The methodology is based on a case study of the experimental data of this research project. Professor Tim Napier-Munn assisted in the evaluation of data. The evaluation is based on cumulative concentrate grade results.

\subsubsection{Quadratic polynomial}

Table 4.1 shows the estimated coefficients for the quadratic polynomial. The first column shows the various terms for the polynomial containing the components of the mixture design and their interactions, where $x_{1}$ is Salene ore, $x_{2}$ is Waterval UG2 ore, $x_{3}$ is Paardekraal ore and $x_{4}$ is Townlands ore. The second and third columns show the coefficient before each term and the standard error of the coefficient, respectively. The last two columns show the test value and probability that the term exists. At a $90 \%$ confidence the probability value must be $\leq 0.1$ for the term to be significant. From Table 4.1 it is evident that only the ore in its pure form makes a 
significant contribution to the polynomial (the * indicates a very small value). The $\mathrm{R}_{\text {adj }}{ }$ is also at $90.9 \%$, which indicates that $10 \%$ of the data does not correlate well with this polynomial.

Table 4.1 Estimated coefficients for cumulative grade results.

\begin{tabular}{|l|r|r|r|r|}
\hline \multicolumn{1}{|c|}{ Term } & Coefficient & $\begin{array}{r}\text { Standard } \\
\text { error }\end{array}$ & $\begin{array}{r}\text { T-test } \\
\text { value }\end{array}$ & Probability \\
\hline Salene $\left(\mathrm{x}_{1}\right)$ & 17.43 & 3.496 & $*$ & $*$ \\
W/V UG2 $\left(\mathrm{x}_{2}\right)$ & 50.60 & 3.496 & $*$ & $*$ \\
Paardekraal $\left(\mathrm{x}_{3}\right)$ & 68.26 & 3.496 & $*$ & $*$ \\
Townlands ( $\left.\mathrm{x}_{4}\right)$ & 63.49 & 3.496 & $*$ & $*$ \\
Salene*W/V UG2 $\left(\mathrm{x}_{1} \mathrm{x}_{2}\right)$ & -14.04 & 14.241 & -0.99 & 0.334 \\
Salene*Paardekraal $\left(\mathrm{x}_{1} \mathrm{x}_{3}\right)$ & -8.74 & 14.241 & -0.61 & 0.545 \\
Salene*Townlands $\left(\mathrm{x}_{1} \mathrm{x}_{4}\right)$ & -9.49 & 14.241 & -0.67 & 0.511 \\
W/V UG2*Paardekraal $\left(\mathrm{x}_{2} \mathrm{x}_{3}\right)$ & 1.95 & 14.241 & 0.14 & 0.892 \\
W/V UG2*Townlands $\left(\mathrm{x}_{2} \mathrm{x}_{4}\right)$ & 1.58 & 14.241 & 0.11 & 0.913 \\
Paardekraal*Townlands $\left(\mathrm{x}_{3} \mathrm{x}_{4}\right)$ & 11.40 & 14.241 & 0.80 & 0.431 \\
\hline $\mathrm{S}=4.36032$ (Standard deviation) & & & & \\
$\mathrm{R}_{\text {adj }}^{2}=90.91 \%$ & & & \\
\hline
\end{tabular}

Table 4.2 shows the ANOVA results for the quadratic model. Once again, at a $90 \%$ confidence the probability value must be $\leq 0.1$ for the term to be significant. Thus only the linear terms in the quadratic polynomial can be deemed significant. From Tables 4.1 and 4.2 it is evident that the quadratic regression polynomial is insufficient to describe the data and cannot be used to evaluate data from the simplex lattice design.

Table 4.2 ANOVA for cumulative grade results.

\begin{tabular}{|c|l|l|l|l|l|r|}
\hline Source & $\begin{array}{l}\text { Degrees } \\
\text { of } \\
\text { freedom }\end{array}$ & $\begin{array}{l}\text { Sum of } \\
\text { squares }\end{array}$ & $\begin{array}{l}\text { Adjusted } \\
\text { sum of } \\
\text { squares }\end{array}$ & $\begin{array}{l}\text { Adjusted } \\
\text { mean } \\
\text { squares }\end{array}$ & $\begin{array}{l}\text { F-test } \\
\text { value }\end{array}$ & Probability \\
\hline Quadratic & 6 & 45.32 & 45.32 & 7.554 & 0.40 & 0.874 \\
\hline
\end{tabular}


If the polynomial regression equation is not evaluated according to its significant terms only, the interactions between ores can be described as follows: Salene in its pure form has the smallest coefficient and therefore generates the lowest grade. It also interacts antagonistically with the other three ores, as all three binary interactions (that contain Salene) have a negative coefficient. The remaining binary interactions all show synergistic effects. The latter suggests that, for example, a 50:50 mix of Paardekraal and Townlands will produce a higher grade $(68.7 \mathrm{~g} / \mathrm{t})$ than the average $(65.9 \mathrm{~g} / \mathrm{t})$ of the two ores in their pure form. Thus the synergistic effect is at a value of $2.8 \mathrm{~g} / \mathrm{t}$. Similarly the negative coefficient for the Salene/W/V UG2 coefficient suggests that a 50:50 mix of these two will give an antagonistic effect of $3.5 \mathrm{~g} / \mathrm{t}$ less than the calculated mean value $(34.0 \mathrm{~g} / \mathrm{t})$. Due to the lack of significant terms a second polynomial was investigated, which will be discussed in Section 4.1.2.

\subsubsection{Special cubic polynomial}

This polynomial is evaluated in more detail as it is the final polynomial chosen for the analyses of the experimental results. The special cubic model is a commonly used regression model in mixture design experiments. From Table 4.3 it is evident that all binary interactions with Salene ore are antagonistic and significant at $90 \%$ confidence (probability < 0.1 ). Ternary interactions with Paardekraal and Townlands are synergistic and significant at $90 \%$ confidence.

The $\mathrm{R}_{\text {adj }}^{2}$ is also $94.34 \%$, indicating that $5.66 \%$ of the data does not correlate with this polynomial. The S-value at $95 \%$ confidence limits is a good measure of the "prediction limits" of the polynomial. The $\mathrm{S}$ for prediction is around $3.4 \mathrm{~g} / \mathrm{t}$, which implies $95 \%$ prediction limits of $\pm 6.7 \mathrm{~g} / \mathrm{t}$. This is very good for a data range of $53 \mathrm{~g} / \mathrm{t}$. The average $\mathrm{S}$-value for three replicates for flotation experiments of the ores in their pure form is $4.9 \mathrm{~g} / \mathrm{t}$. Thus the polynomial regression standard errors are of the same order as the experimental standard errors. 
Table 4.3 Estimated coefficients for cumulative grade results

\begin{tabular}{|c|c|c|c|c|}
\hline Term & Coefficient & $\begin{array}{c}\text { Standard } \\
\text { error }\end{array}$ & T-test value & Probability \\
\hline Salene $\left(\mathrm{x}_{1}\right)$ & 20.36 & 2.901 & $*$ & * \\
\hline $\mathrm{W} / \mathrm{V} \mathrm{UG} 2\left(\mathrm{x}_{2}\right)$ & 53.19 & 2.901 & $*$ & $*$ \\
\hline Paardekraal $\left(\mathrm{x}_{3}\right)$ & 71.81 & 2.901 & $*$ & $*$ \\
\hline Townlands $\left(\mathrm{x}_{4}\right)$ & 67.01 & 2.901 & $*$ & $*$ \\
\hline Salene*W/V UG2 $\left(\mathrm{x}_{1} \mathrm{x}_{2}\right)$ & -31.92 & 13.728 & -2.32 & 0.030 \\
\hline Salene*Paardekraal $\left(\mathrm{x}_{1} \mathrm{x}_{3}\right)$ & -35.59 & 13.728 & -2.59 & 0.017 \\
\hline Salene*Townlands $\left(\mathrm{x}_{1} \mathrm{x}_{4}\right)$ & -36.10 & 13.728 & -2.63 & 0.016 \\
\hline W/V UG2*Paardekraal $\left(\mathrm{x}_{2} \mathrm{x}_{3}\right)$ & -21.78 & 13.728 & -1.59 & 0.128 \\
\hline W/V UG2*Townlands $\left(\mathrm{x}_{2} \mathrm{x}_{4}\right)$ & -21.91 & 13.728 & -1.60 & 0.125 \\
\hline Paardekraal*Townlands $\left(\mathrm{x}_{3} \mathrm{x}_{4}\right)$ & -21.06 & 13.728 & -1.53 & 0.140 \\
\hline Salene*W/V UG2*Paardekraal $\left(\mathrm{x}_{1} \mathrm{x}_{2} \mathrm{x}_{3}\right)$ & 144.90 & 84.024 & 1.72 & 0.099 \\
\hline Salene*W/V UG2*Townlands $\left(\mathrm{x}_{1} \mathrm{x}_{2} \mathrm{x}_{4}\right)$ & 141.12 & 84.024 & 1.68 & 0.108 \\
\hline Salene*Paardekraal*Townlands $\left(\mathrm{x}_{1} \mathrm{x}_{3} \mathrm{x}_{4}\right)$ & 284.60 & 84.024 & 3.39 & 0.003 \\
\hline $\begin{array}{l}\text { W/V UG2*Paardekraal*Townlands } \\
\left(\mathrm{x}_{2} \mathrm{x}_{3} \mathrm{x}_{4}\right)\end{array}$ & 234.76 & 84.024 & 2.79 & 0.011 \\
\hline $\begin{array}{l}\mathrm{S}=3.44241 \text { (Standard deviation) } \\
\mathrm{R}_{\text {adj }}^{2}=94.34 \%\end{array}$ & & & & \\
\hline
\end{tabular}

Table 4.4 shows the ANOVA results for the special cubic polynomial. Once again, at a 90\% confidence the probability value must be $\leq 0.1$ for the term to be significant. Thus at least one of the terms in the polynomial can be deemed significant and thus the special cubic polynomial explains the data better than the quadratic polynomial where none of the terms was deemed significant. 
Table 4.4 ANOVA for cumulative grade results.

\begin{tabular}{|c|c|r|r|r|r|r|}
\hline Source & $\begin{array}{c}\text { Degrees } \\
\text { of } \\
\text { freedom }\end{array}$ & $\begin{array}{c}\text { Sum of } \\
\text { squares }\end{array}$ & $\begin{array}{c}\text { Adjusted } \\
\text { sum of } \\
\text { squares }\end{array}$ & $\begin{array}{c}\text { Adjusted } \\
\text { mean } \\
\text { squares }\end{array}$ & $\begin{array}{c}\text { F-test } \\
\text { value }\end{array}$ & Probability \\
\hline Special cubic & 4 & 226.46 & 226.46 & 56.614 & 4.78 & 0.007 \\
\hline
\end{tabular}

\section{Residual plots}

The residual plots are only used to validate the regression polynomial and will not be used to interpret results in Section 4.2. Both Menezes et al. (2008) and Eriksson et al. (1998) used normal probability curves to evaluate the residuals. They concluded that a straight line through the plot residual vs expected probability indicates that the distribution of the residuals is normal and that the polynomial regression equation is adequate to predict the response. Menezes et al. (2008) also used the predicted/fitted value vs residual plot and concluded that if they are randomly distributed (and thus uncorrelated), the polynomial regression equation is valid. Figure 4.1a shows that the residuals are normally distributed and thus the polynomial equation is adequate to describe the response value (Menezes et al., 2008 and Eriksson et al., 1998). Figure 4.1b shows that there is no correlation between the residuals and the magnitude of the fitted value (Menezes et al., 2008). Figure 4.1c shows a histogram of fairly normally distributed residuals and Figure 4.1d shows that there is no correlation between the experimental design points and the residuals. Thus the polynomial used describes the data well. 


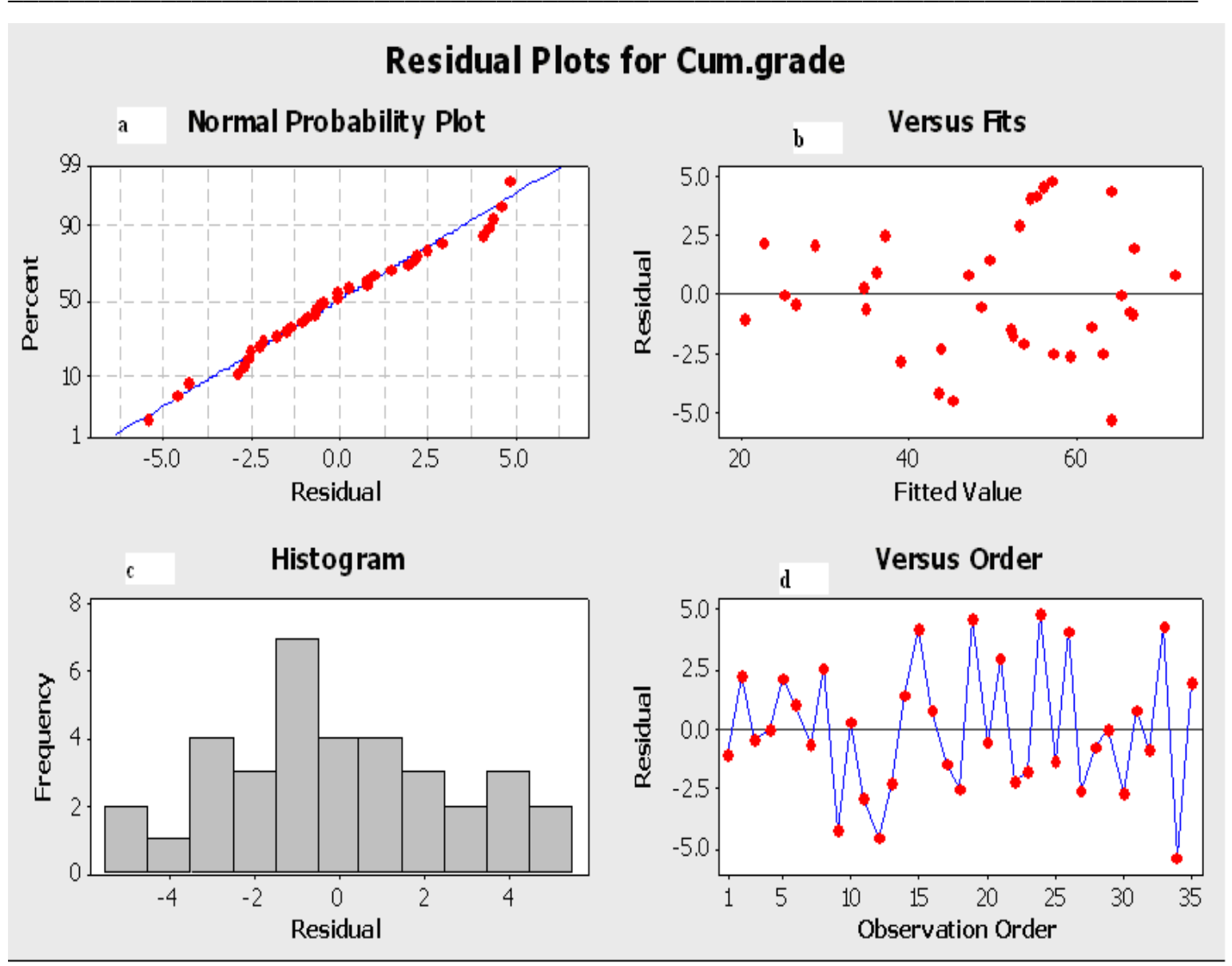

Figure 4.1 Residual plots for the special cubic polynomial for cumulative grade results

Based on the probability values, the $\mathrm{R}_{\mathrm{adj}}{ }^{2}$ value, the standard deviation and the ANOVA table, it can be concluded that the special cubic regression polynomial describes the data for this research reasonably well. The residual plots also show that the residuals are random and uncorrelated. The literature (cf. Section 2.2.2) indicates that the special cubic regression polynomial is used as one of the general canonical forms of mixture models. This polynomial was therefore used to interpret results in Section 4.2.

\subsubsection{Stepwise regression polynomial}

Stepwise regression was used to determine a model with the least number of terms. This resulted in a polynomial with 8 terms and a $\mathrm{R}_{\mathrm{adj}}{ }^{2}$ slightly better than the special cubic model. However, terms were complex combinations of $\mathrm{x}_{1}$ to $\mathrm{x}_{4}$ which have no real significance in interpretation of mixture design data (for example, $\mathrm{x}_{1} \mathrm{x}_{3} \mathrm{x}_{4}{ }^{2}$ ). Therefore the special cubic model was taken as 
giving a comparable fit to the best possible regression model and being of direct relevance to the interpretation of mixture designs (i.e. a standard literature model).

\subsubsection{Interpretation of the simplex lattice mixture design}

The interpretation of a mixture design was discussed in Section 2.2.1.2 in the literature review. As this is the final method with which results from Section 4.2 will be evaluated this section gives a summary of what has been discussed As per the literature review the use of the regression polynomial, binary plots and ternary plots are evaluated:

\subsubsection{The special cubic regression polynomial}

The special cubic regression polynomial equation can be generated from the simplex mixture design which relates the predicated variable (recovery, grade etc.) to the relative proportion of ore in the mixture. Depending on the significance of interactions, the polynomial equation can include linear terms (no interactions), quadratic terms (binary interactions) and cubic terms (ternary interactions). The quality of the mixture design and the resulting polynomial equation were evaluated according to the adjusted coefficient of determination $\left(\mathrm{R}_{\mathrm{adj}}{ }^{2}\right)$, ANOVA (F-test) and parameter estimates.

The polynomial equation can be used to interpret antagonistic (or synergistic) effects in a number of ways. Firstly, by evaluating the sign of the coefficients of the non-linear terms in the polynomial equation, one may determine antagonistic (or synergistic) effects. If the coefficient has a negative sign the interaction is antagonistic. Secondly, the size of the coefficient of the nonlinear terms is also a measure of the extent of the synergistic or antagonistic effect of that term on the final response value.

\subsubsection{Binary plots}

A binary plot is a graph of the predicated variable (recovery, grade etc.) as a function of the relative proportion of two (binary) components. It can be used to graphically identify antagonistic (or synergistic) effects. The plot can be generated using either raw experimental data or the regression polynomial equation. A straight line indicates linear (additive) effects; a downward curvature (concave) indicates antagonistic effects and an upward curvature (convex) indicates synergistic effects. 


\subsubsection{Ternary plots}

A ternary contour plot is a graph of the interactions between three components represented by a triangle. Each side of the triangle represents the proportion of an ore source and contour lines inside the triangle represent the predicted variable (recovery, grade etc.). If the polynomial equation only contained linear terms, there would be no curves in the plot, but only straight lines. Thus binary/ternary interactions between the ores cause the curved lines. The actual response is indicated on the contour lines and is also colour coded. As the contour lines approach a corner (pure component) of the triangle, the predicted variable will either increase or decrease, indicating a synergistic or antagonistic effect.

\subsubsection{Synthetic data analysis}

In order to determine if the simplex lattice design would be able to detect moderate to low levels of antagonistic and synergistic interactions on actual experimental milling and flotation data, despite experimental errors, a preliminary data analysis was conducted on synthetic data. Data was simulated as described in Section 4.1.3.1 and the results were evaluated with the $\mathrm{R}_{\mathrm{adj}}{ }^{2}$ and ANOVA as described in Section 4.1.3.2.

\subsubsection{Methodology}

Data for four ore sources nominated as $\mathrm{x}_{1}, \mathrm{x}_{2}, \mathrm{x}_{3}$ and $\mathrm{x}_{4}$ was simulated as follows:

a. A "true" recovery (indicated as $\mathrm{R}_{t}$ the response value) was simulated for each design point with Equation 4.1. The equation takes into consideration the sum product of the components and the coefficient for the component in its pure form.

$$
\mathrm{R}_{\mathrm{t}}=\sum_{\mathrm{i}=1}^{4} \mathrm{x}_{\mathrm{i}} \mathrm{a}_{\mathrm{i}} \mathrm{R}_{\mathrm{i}}
$$

With $\quad \mathrm{x}_{\mathrm{i}}=$ Component

$a_{i}=$ The coefficient for the component (or the extent of the component's contribution to the response value)

$R_{i}=$ Response value of component in its pure form

b. An experimental response value $\left(\mathrm{R}_{\mathrm{f}}\right)$ was then generated for each design point by using the normal probability distribution with the following parameters in Equation 4.2: 


$$
R_{f}=\sigma \sqrt{2 \ln \frac{1}{\rho(\sigma \sqrt{2 \pi})}}+\mu
$$

$\sigma=$ Standard deviation (\%Error $\mathrm{x}$ Rt/100): an experimental error multiplied by the "true" recovery divided by 100 for the standard deviation

$\rho=$ Probability: a random number for the probability

$\mu=\mathrm{Rt}$ : the "true" response value for the mean

By using Equations 4.1 and 4.2 above "synthetic experimental data" was generated and only the significant terms of the special cubic regression polynomial are indicated. The $R_{t}$ value will differ from the $R_{f}$ value, as the $R_{f}$ value also includes experimental error. Three scenarios were evaluated. An actual measured experimental error of 5\% was used for all three scenarios. They are:

a. The extent of the contribution (noted as $a_{i}$ in Equation 4.1) of each ore source to the recovery was kept constant at 1 for all components. Thus a linear interaction was simulated. The average $R_{t}$ for the 35 design points of the synthetic data was calculated as $75.0 \%$ and the average $R_{f}$ was $75.1 \%$.

b. The extent of the contribution of each ore source to the recovery was changed to 4 for the ore with the worst recovery $\left(x_{4}\right)$. This should have caused an antagonistic effect in the synthetic data. The average $R_{t}$ for the 35 design points of the synthetic data was calculated at $71.8 \%$ and the average $R_{f}$ was $71.9 \%$. This confirms an antagonistic interaction as the average percentage recovery decreased by $3.1 \%$.

c. The extent of the contribution of each ore source to the recovery was changed to 4 for the ore with the best recovery $\left(x_{3}\right)$. This should have caused a synergistic effect in the synthetic data. The average $R_{t}$ for the 35 design points of the synthetic data was calculated at $77.1 \%$ and the average $R_{f}$ was $76.9 \%$. This confirms a synergistic interaction as the average percentage recovery increased by $1.9 \%$. 


\subsubsection{Results}

a. The extent of the contribution (noted as $\boldsymbol{a}_{i}$ in Equation 4.1) of each ore source to the recovery was kept constant at 1 for all components.

This scenario simulated a linear effect. Equation 4.3 indicates the polynomial equation with only the significant terms at a $90 \%$ confidence interval.

$$
y=78.89 x_{1}+74.94 x_{2}+84.07 x_{3}+60.76 x_{4}
$$

$\mathrm{R}_{\mathrm{adj}}{ }^{2}$ is 0.78 , which indicates a moderate fit. The probability value for the ANOVA is 0.0001 , which strongly indicates that at least one of the terms in Equation 4.3 does exist. Thus from the results obtained it is evident that only the components in their pure form have an effect on the recovery and this effect is linear. Therefore the results correspond with the synthetic data where a linear effect was simulated. The average recovery for all design points (predicted by means of the polynomial equation with only the significant interactions) was $75.1 \%$, which was exactly the same as the $\mathrm{R}_{\mathrm{f}}$ value for the synthetic data.

b. The extent of the contribution of each ore source to the recovery was changed to 4 for the ore with the worst recovery $\left(x_{4}\right)$.

This scenario simulated an antagonistic effect. Equation 4.4 indicates the polynomial equation with only the significant terms at a $90 \%$ confidence interval.

$$
\begin{gathered}
y=80.1 x_{1}+75.55 x_{2}+84.93 x_{3}+57.40 x_{4}-22.30 x_{1} x_{4}-15.45 x_{2} x_{4}-25.86 x_{3} x_{4} \\
46.13 x_{3} x_{4}\left(x_{3}-x_{4}\right)
\end{gathered}
$$

$\mathrm{R}_{\mathrm{adj}}{ }^{2}$ is 0.95 , which indicates a good fit. The probability value for the ANOVA is 0.0001 , which strongly indicates that at least one of the terms in Equation 4.4 does exist. All interactions with $\mathrm{x}_{4}$ have a negative coefficient, indicating an antagonistic effect. Thus from the results obtained it is evident that in this scenario the component with the worst 
recovery has an antagonistic effect on the recovery when mixed with other ores. Therefore the results correspond with the synthetic data where an antagonistic effect was simulated. The average recovery for all design points (predicted by means of the polynomial equation with only the significant interactions) was $71.9 \%$, which was exactly the same as the $\mathrm{R}_{\mathrm{f}}$ value for the synthetic data.

c. The extent of the contribution of each ore source to the recovery was changed to 4 for the ore with the best recovery $\left(x_{3}\right)$.

This scenario simulated a synergistic effect. Equation 4.5 indicates the polynomial equation with only the significant terms at a $90 \%$ confidence interval.

$$
y=80.99 x_{1}+76.22 x_{2}+86.34 x_{3}+59.98 x_{4}+33.81 x_{3} x_{4}
$$

$\mathrm{R}_{\mathrm{adj}}{ }^{2}$ is 0.84 , which indicates a moderate fit. The probability value for the ANOVA is 0.0001, which strongly indicates that at least one of the terms in Equation 4.5 does exist. The interaction between $x_{3}$ and $x_{4}$ had a positive coefficient, indicating a synergistic effect. Thus from the results obtained it is evident that in this scenario the component with the best recovery has a synergistic effect on the recovery when mixed with other ores. Therefore the results correspond with the synthetic data where a synergistic effect was simulated. The average recovery for all design points (predicted by means of the polynomial equation with only the significant interactions) was $76.9 \%$, which was exactly the same as the $\mathrm{R}_{\mathrm{f}}$ value for the synthetic data.

From the above analysis it was thus concluded that the simplex lattice design can be used to evaluate and determine synergistic and antagonistic interactions of actual experimental data with moderate experimental error. 


\subsection{MILLING AND FLOTATION RESULTS}

This section presents the milling and flotation results from the laboratory experiments, according to the simplex lattice experimental design. The final results for the effects of blends of Salene $\left(\mathrm{x}_{1}\right)$, Waterval UG2 $\left(\mathrm{x}_{2}\right)$, Paardekraal $\left(\mathrm{x}_{3}\right)$ and Townlands $\left(\mathrm{x}_{4}\right)$ on milling are discussed in Section 4.2.1. The results on cumulative recovery are discussed in Section 4.2.2 and cumulative grade is discussed in Section 4.2.3. The results were evaluated according to the methodology described in Section 4.1.2. The standard polynomial equation with special cubic interactions was used throughout. Binary plots are presented for binary mixtures of the Salene $\left(\mathrm{x}_{1}\right)$ and Townlands $\left(\mathrm{x}_{4}\right)$ ores. These plots are based on raw experimental data as well as predicted data using the polynomial equation. The polynomial equation was also used to plot a linear graph to emphasize synergistic and antagonistic effects. Binary plots for Salene $\left(\mathrm{x}_{1}\right)$ and Townlands $\left(\mathrm{x}_{4}\right)$ are given as they represent two ores with significant antagonistic interaction. Ternary plots are used to illustrate synergistic and antagonistic effects between Salene $\left(\mathrm{x}_{1}\right)$, Paardekraal $\left(\mathrm{x}_{3}\right)$ and Townlands $\left(\mathrm{x}_{4}\right)$ ores. Waterval UG2 $\left(\mathrm{x}_{2}\right)$ was omitted as it proved to be neutral and did not appear to have a major effect on the blend. The implication of blending on metal accounting is then discussed. The methodology is similar to techniques used by Bruns et al. (1996); Jumaa et al. (1998); Eriksson et al. (1998); Cornell (2002) and Menezes et al. (2008).

\subsubsection{Milling results}

\subsubsection{Regression polynomial}

Equation 4.6 gives the polynomial equation for the percentage mass passing $75 \mu \mathrm{m}$ as a function of the relative proportion of ore in the mixture blends with only significant terms shown at $95 \%$ confidence ( $\mathrm{p}$ value $<0.05$ ). The $\mathrm{R}_{\mathrm{adj}}^{2}$ and ANOVA are commonly used to validate the polynomial regression equation. Consequently the $\mathrm{R}_{\mathrm{adj}}{ }^{2}$ and $\mathrm{F}_{\text {crit }}$ of the ANOVA were used to evaluate the regression polynomial for this project. Here, $\mathrm{R}_{\mathrm{adj}}{ }^{2}=0.46$, which indicates a poor fit, and the F-test gave a p-value of 0.0078 , which suggests that at least one term in the equation is significant.

$$
y=70.53 x_{1}+62.57 x_{2}+57.44 x_{3}+58.84 x_{4}+27.89 x_{1} x_{3}-192.62 x_{1} x_{3} x_{4}
$$

where $\mathrm{x}_{1}$ is Salene ore, $\mathrm{x}_{2}$ is Waterval UG2 ore, $\mathrm{x}_{3}$ is Paardekraal ore and $\mathrm{x}_{4}$ is Townlands ore 
Equation 4.6 indicates that the dominant effects are linear but that there may be an antagonistic interaction in the ternary term for $\mathrm{x}_{1}, \mathrm{x}_{3}$ and $\mathrm{x}_{4}$ and synergistic interaction for the binary term between $x_{1}$ and $x_{3}$. However, given the reliability of the regression these observations are purely speculative.

\subsubsection{Binary plots}

Figure 4.2 gives the binary plot for the overall percentage mass passing $75 \mu \mathrm{m}$ for binary mixtures of the $\mathrm{x}_{1}$ and $\mathrm{x}_{4}$ ores for the actual experimental data, data predicted using the polynomial equation and a linear effect. This interaction was evaluated as it was the only significant binary interaction shown in the polynomial equation. This figure shows a weak trend with scatter in the data which is in line with the regression polynomial, i.e. results are speculative.

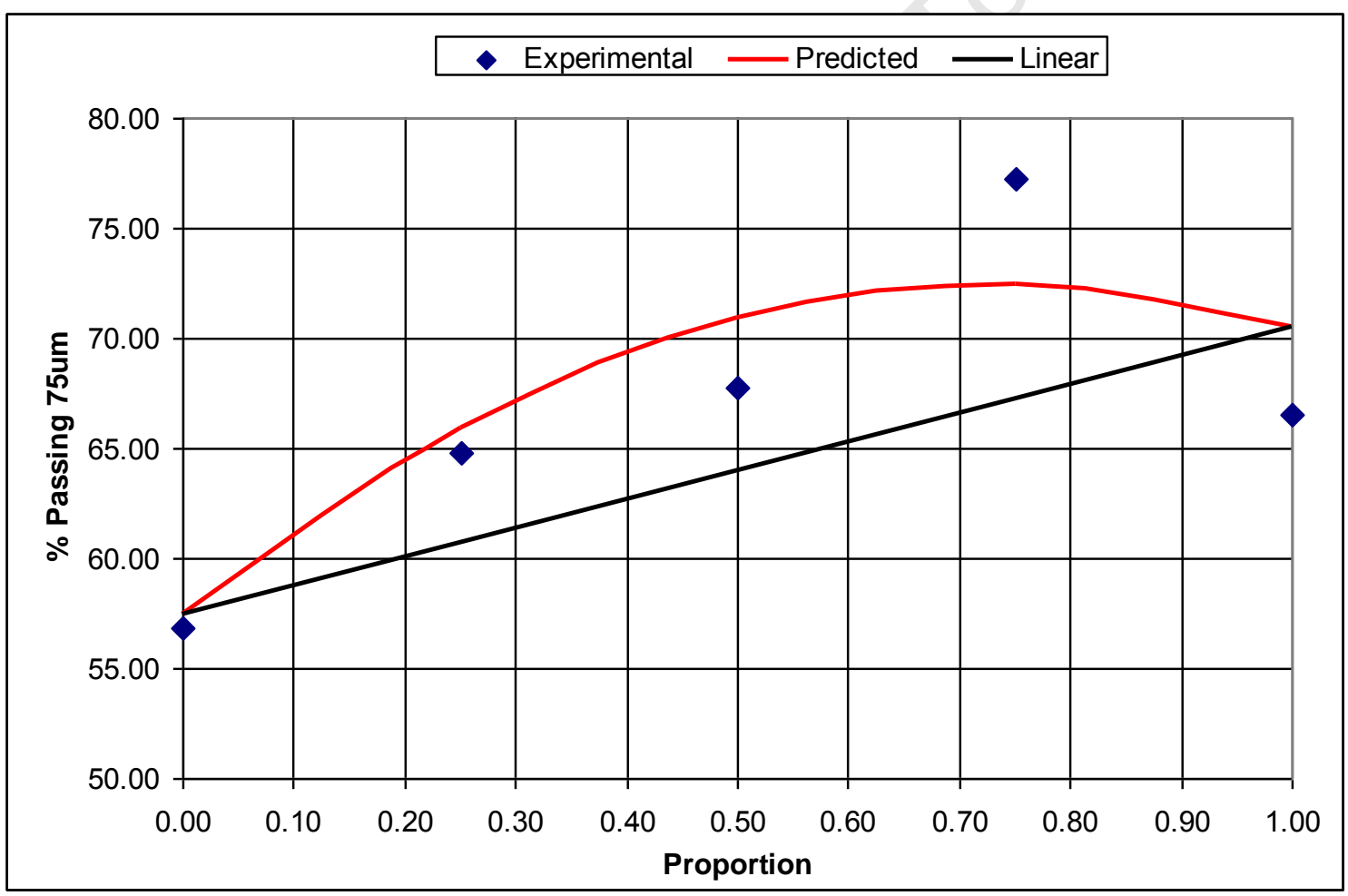

Figure 4.2 Binary plot for the overall percentage mass passing $75 \mu \mathrm{m}$ for binary mixtures of the Salene $\left(\mathrm{x}_{1}\right)$ and Townlands $\left(\mathrm{x}_{4}\right)$. 


\subsubsection{Ternary plots}

Figure 4.3 gives the ternary plot for the overall percentage mass passing $75 \mu \mathrm{m}$ for ternary mixtures of the $x_{1}, x_{3}$ and $x_{4}$ ores for the data predicted using the polynomial equation. Waterval UG2 $\left(\mathrm{x}_{2}\right)$ ore was set at 0 as it has been shown that this ore interacts neutrally with the other ores. The percentage mass passing $75 \mu \mathrm{m}$ is colour coded with the scale (mass percentage passing) given on the left-hand side. Each contour is also labelled to indicate percentage mass passing 75 $\mu \mathrm{m}$. The lower percentage mass passing $75 \mu \mathrm{m}$ is represented by the blue while the higher percentage mass passing $75 \mu \mathrm{m}$ is represented by green and yellow. The plot shows that with an increase in the proportion of $x_{1}$ (left-hand axis base to peak), the percentage mass passing $75 \mu \mathrm{m}$ will increase. The ternary plot also confirms a possible synergistic interaction between $\mathrm{x}_{1}$ and $\mathrm{x}_{3}$ (green to yellow area in plot) as a very small mass increase in the contribution of Salene ore will render a large change in the percentage mass passing $75 \mu \mathrm{m}$. This is shown by the contour lines that are closely spaced at a higher proportion of $\mathrm{x}_{1}$. There might also be a synergistic interaction between $\mathrm{x}_{3}$ and $\mathrm{x}_{4}$ at approximately $50 \%$ or more of $\mathrm{x}_{1}$ as the contour lines curve upwards. It has already been shown in Sections 4.2.1.1 and 4.2.1.2 that the polynomial equation was a) not reliable and b) does not correspond well with the experimental data. Therefore, the results and interpretation remain purely speculative. 


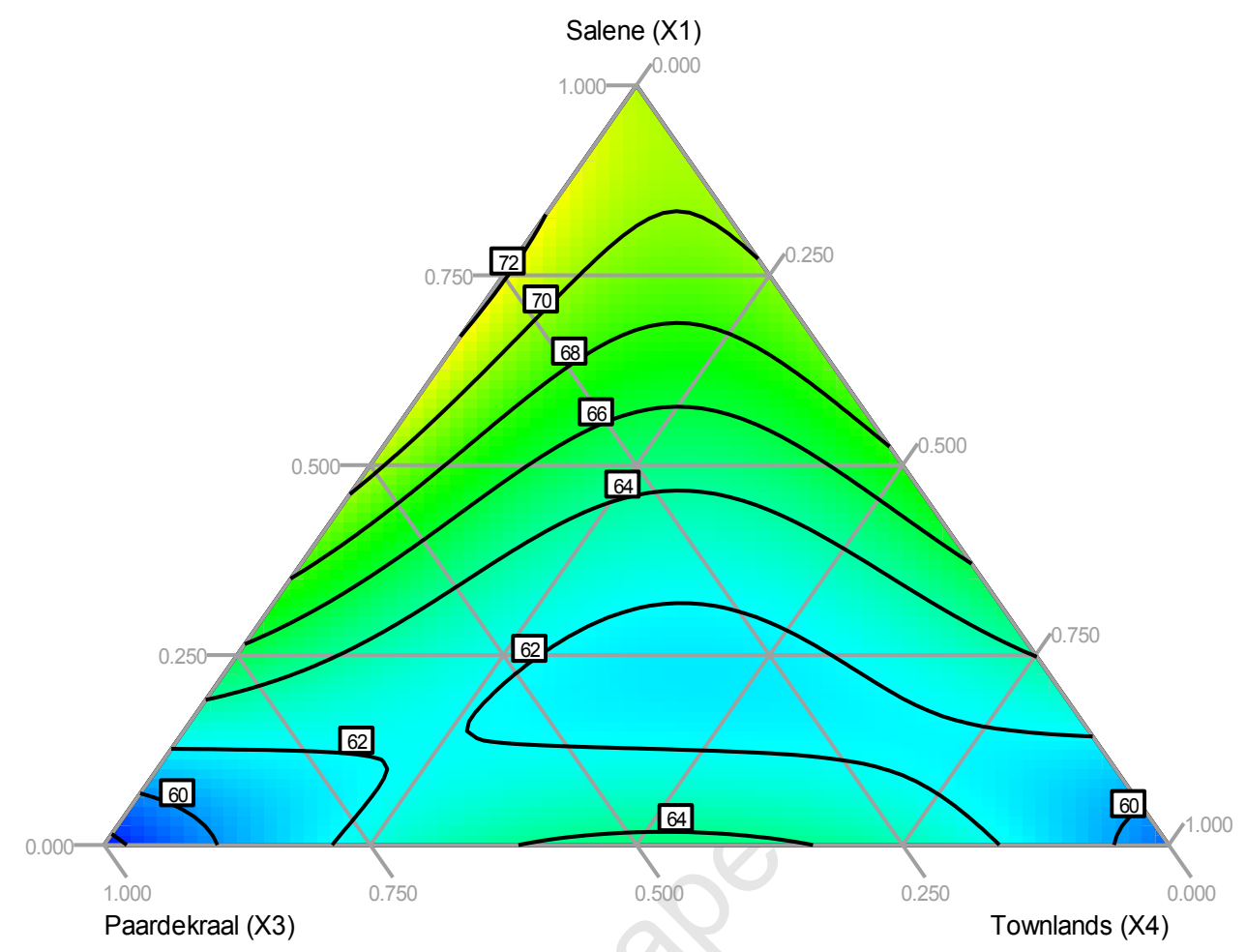

Figure 4.3 Ternary plot for the overall percentage mass passing $75 \mu \mathrm{m}$ for ternary mixtures of the Salene $\left(\mathrm{x}_{1}\right)$, Paardekraal $\left(\mathrm{x}_{3}\right)$ and Townlands $\left(\mathrm{x}_{4}\right)$ ores.

\subsubsection{Implication for metal accounting}

Based on the findings in Sections 4.2.1.1 to 4.2.1.3, it does not appear as if the blending of ore has a significant effect on milling. Only linear effects were noted and thus the milling performance of blends is not affected by synergistic or antagonistic effects.

\subsubsection{Flotation recovery results}

\subsubsection{Regression polynomial}

Equation 4.7 gives the polynomial equation for recovery as a function of the relative proportion of ore in the mixture blends with only significant terms shown ( $\mathrm{p}$-value $<0.05)$. Here, $\mathrm{R}_{\mathrm{adj}}{ }^{2}=$ 0.65 , which indicates a moderate fit, and the F-test gave a p-value of 0.0002 , which strongly indicates that at least one of the coefficients in the polynomial is non-zero. 
$y=76.71 x_{1}+80.0 x_{2}+81.72 x_{3}+85.55 x_{4}-14.31 x_{1} x_{4}+98.81 x_{1} x_{2} x_{3}+95.79 x_{1} x_{2} x_{4}$

where $\mathrm{x}_{1}$ is Salene ore, $\mathrm{x}_{2}$ is Waterval UG2 ore, $\mathrm{x}_{3}$ is Paardekraal ore and $\mathrm{x}_{4}$ is Townlands ore

Equation 4.7 indicates that the dominant effects are linear but that there is antagonistic interaction in the binary term for $\mathrm{x}_{1}$ and $\mathrm{x}_{4}$ and synergistic interactions in the ternary terms containing $\mathrm{x}_{3}$ and $\mathrm{x}_{4}$. The poor quality ore $\left(\mathrm{x}_{1}\right)$ results in antagonistic effects in the binary blend with the best quality ore $\left(\mathrm{x}_{4}\right)$. This is known by conventional wisdom in concentrator operations but has not been demonstrated statistically. However, good blending can be used to overcome this effect. For example, $\mathrm{x}_{3}$ and $\mathrm{x}_{4}$ have higher recoveries. The polynomial equation shows that if $\mathrm{x}_{3}$ or $\mathrm{x}_{4}$ is blended with an additional "neutral" ore (in this case $\mathrm{x}_{2}$ ), it is possible to counteract the antagonistic effect of $\mathrm{x}_{1}$.

\subsubsection{Binary plots}

Figure 4.4 gives the binary plot for the cumulative percentage recovery for binary mixtures of the $\mathrm{x}_{1}$ and $\mathrm{x}_{4}$ ores for the actual experimental data, the data predicted using the normal polynomial equation and a linear effect. This interaction was evaluated as it was the only significant binary interaction shown in the polynomial equation. The experimental as well as predicted data show an antagonistic interaction between $\mathrm{x}_{1}$ and $\mathrm{x}_{4}$, which suggests that the antagonistic term in the polynomial equation is correct. At a 50:50 blend the 'loss' in recovery would be in the order of $4 \%$ relative to a linear interaction, which is highly significant. 


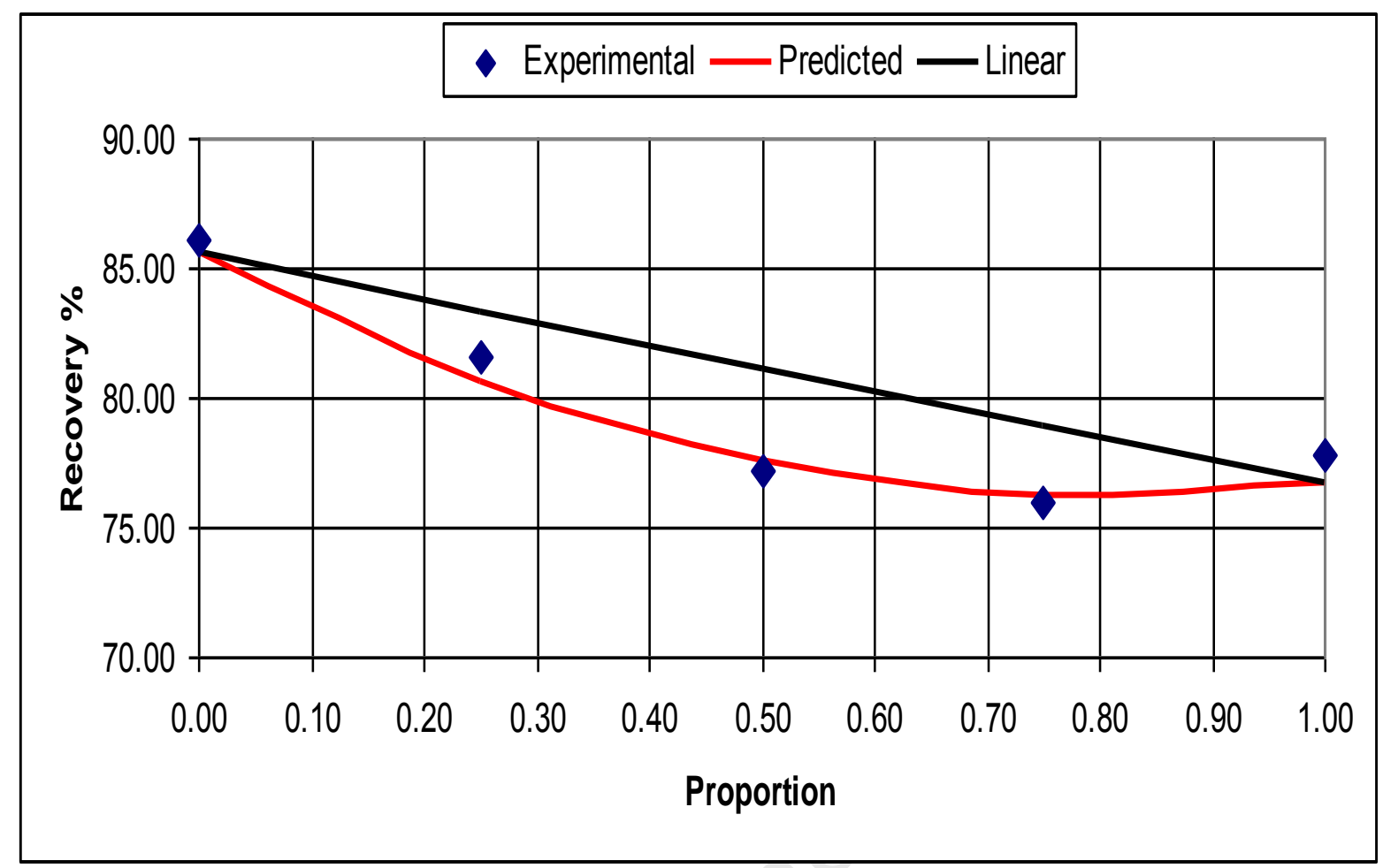

Figure 4.4 Binary plot for the cumulative percentage recovery for binary mixtures of the Salene $\left(\mathrm{x}_{1}\right)$ and Townlands $\left(\mathrm{x}_{4}\right)$ ores.

\subsubsection{Ternary plots}

Figure 4.5 gives the ternary plot for the percentage cumulative recovery for ternary mixtures of the $\mathrm{x}_{1}, \mathrm{x}_{3}$ and $\mathrm{x}_{4}$ ores for the data predicted with the polynomial equation. Waterval UG2 $\left(\mathrm{x}_{2}\right)$ ore was set at 0 as it has been shown that this ore interacts neutrally with the others. The lower percentage cumulative recovery is represented by the blue and green while the higher percentage cumulative recovery is represented by orange and yellow. The plot shows that with an increase in the proportion of $\mathrm{x}_{1}$ (left-hand axis base to peak), the percentage recovery will decrease. There is also an antagonistic interaction between $\mathrm{x}_{1}$ and $\mathrm{x}_{3}$, indicated by the downward curve. Yet, in line with the polynomial equation, when both $\mathrm{x}_{3}$ and $\mathrm{x}_{4}$ are added to the mixture, the recovery improves (relative to the proportion of $\mathrm{x}_{4}$ ), indicated by the yellow and red colouring as well as the green, and are in the plot where the proportion of $\mathrm{x}_{1}$ is below $50 \%$. This is also evident on the left-hand axis (top to base) as the spacing between the contour lines decreases (as the proportion of $\mathrm{x}_{1}$ decreases), resulting in an increase in recovery with a small change in the proportion of $\mathrm{x}_{4}$. 


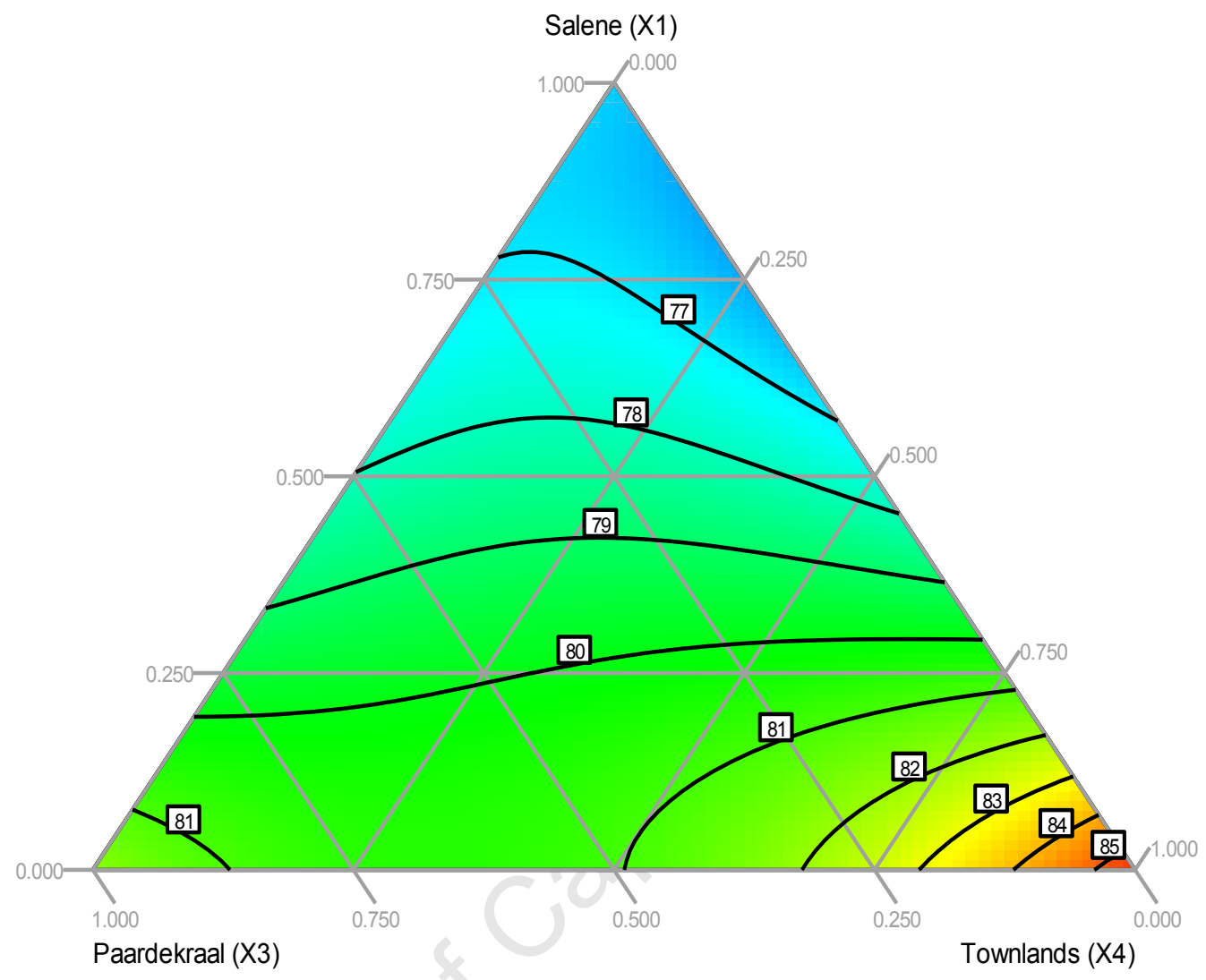

Figure 4.5 Ternary plot for the percentage cumulative recovery for ternary mixtures of the Salene $\left(\mathrm{x}_{1}\right)$, Paardekraal $\left(\mathrm{x}_{3}\right)$ and Townlands $\left(\mathrm{x}_{4}\right)$ ores.

\subsubsection{Implication for metal accounting}

The interaction between ores as well as the relative proportion on the blend will affect recovery. From the binary plots it is evident that if the Waterval UG2 concentrator receives ore from two shafts with one providing an ore with poorer quality than the other, a simple binary mixture of these two ores will result in a lower recovery than expected if a linear effect were assumed. This will affect metal accounting as the concentrator will not be able to explain losses/gains in the final product. Any contractual agreements where recoveries are based on pure ore will never be accurate as interactions between ores result in synergistic/antagonistic effects. As long as the concentrator knows in what proportion the ore is blended for that particular month, the terms in the polynomial equation can be used to predict the true recovery that will be obtained (assuming all process conditions are kept constant). Now if additional ores are added with at least a 50\% 
contribution to the blend, then the effect of the ore with the lower recovery can be overcome, rendering a synergistic effect in recovery. Thus if the concentrator can control its blends it will be possible to still process ore blends in small portions without decreasing the metal accounting output. Based on the findings in Sections 4.2.2.1 to 4.2.2.3, the simplex lattice design is a useful methodology to evaluate the effect of blending on cumulative recovery.

\subsubsection{Flotation grade results}

\subsubsection{Regression polynomial}

Equation 4.8 gives the polynomial equation for grade as a function of the relative proportion of ore in the mixture blends with only significant terms shown (p-value $<0.05$ ). Here, $\mathrm{R}_{\mathrm{adj}}{ }^{2}=0.94$, which indicates a good fit, and the F-test gave a p-value of 0.0007 , which (strongly) indicates that at least one of the coefficients in the polynomial is non-zero.

$$
\begin{aligned}
y= & 20.36 x_{1}+53.19 x_{2}+71.81 x_{3}+67.01 x_{4}-31.92 x_{1} x_{2}-35.59 x_{1} x_{3}-36.1 x_{1} x_{4} \\
& +284.6 x_{1} x_{3} x_{4}+234.76 x_{2} x_{3} x_{4}
\end{aligned}
$$

where $\mathrm{x}_{1}$ is Salene ore, $\mathrm{x}_{2}$ is Waterval UG2 ore, $\mathrm{x}_{3}$ is Paardekraal ore and $\mathrm{x}_{4}$ is Townlands ore

Equation 4.8 indicates clear antagonistic interactions in all binary terms containing $\mathrm{x}_{1}$ and synergistic interactions in ternary terms containing $\mathrm{x}_{3}$ and $\mathrm{x}_{4}$. Here the antagonistic effect of $\mathrm{x}_{1}$ is much stronger than for recovery, as all binary terms associated with $\mathrm{x}_{1}$ are significantly antagonistic. The higher grade of the pure ores $x_{3}$ and $x_{4}$ is also accentuated by the significant synergistic interaction of the ternary terms containing both $\mathrm{x}_{3}$ and $\mathrm{x}_{4}$, while ternary terms with $\mathrm{x}_{1}$, $\mathrm{x}_{2}$ and either $\mathrm{x}_{3}$ or $\mathrm{x}_{4}$ came out as significant for recovery. The polynomial equation shows that if $\mathrm{x}_{3}$ or $\mathrm{x}_{4}$ is blended with an additional ore (in this case $\mathrm{x}_{2}$ ) it is possible to counteract the antagonistic effect of $\mathrm{x}_{1}$.

\subsubsection{Binary plots}

Figure 4.6 gives the binary plot for the cumulative grade for binary mixtures of the $\mathrm{x}_{1}$ and $\mathrm{x}_{4}$ ores for the actual experimental data, the data predicted using the polynomial equation and a linear effect. The binary interactions between $x_{1}$ and $x_{2}$ as well as $x_{1}$ and $x_{3}$ will render the same graph because the coefficients are similar to the interaction between $\mathrm{x}_{1}$ and $\mathrm{x}_{4}$. The experimental as well 
as predicted data show an antagonistic interaction between $\mathrm{x}_{1}$ and $\mathrm{x}_{4}$, which suggests that the antagonistic term in the polynomial equation is correct. As noted previously, antagonistic effects are observed between these two ore types since they represent a relatively poor quality ore mixed with a relatively good quality one. As with recovery, it is interesting to note that at a 50:50 blend the 'loss' of grade would be in the order of $10 \mathrm{~g} / \mathrm{t}$ relative to a linear interaction (indicated by the black line in the graph).

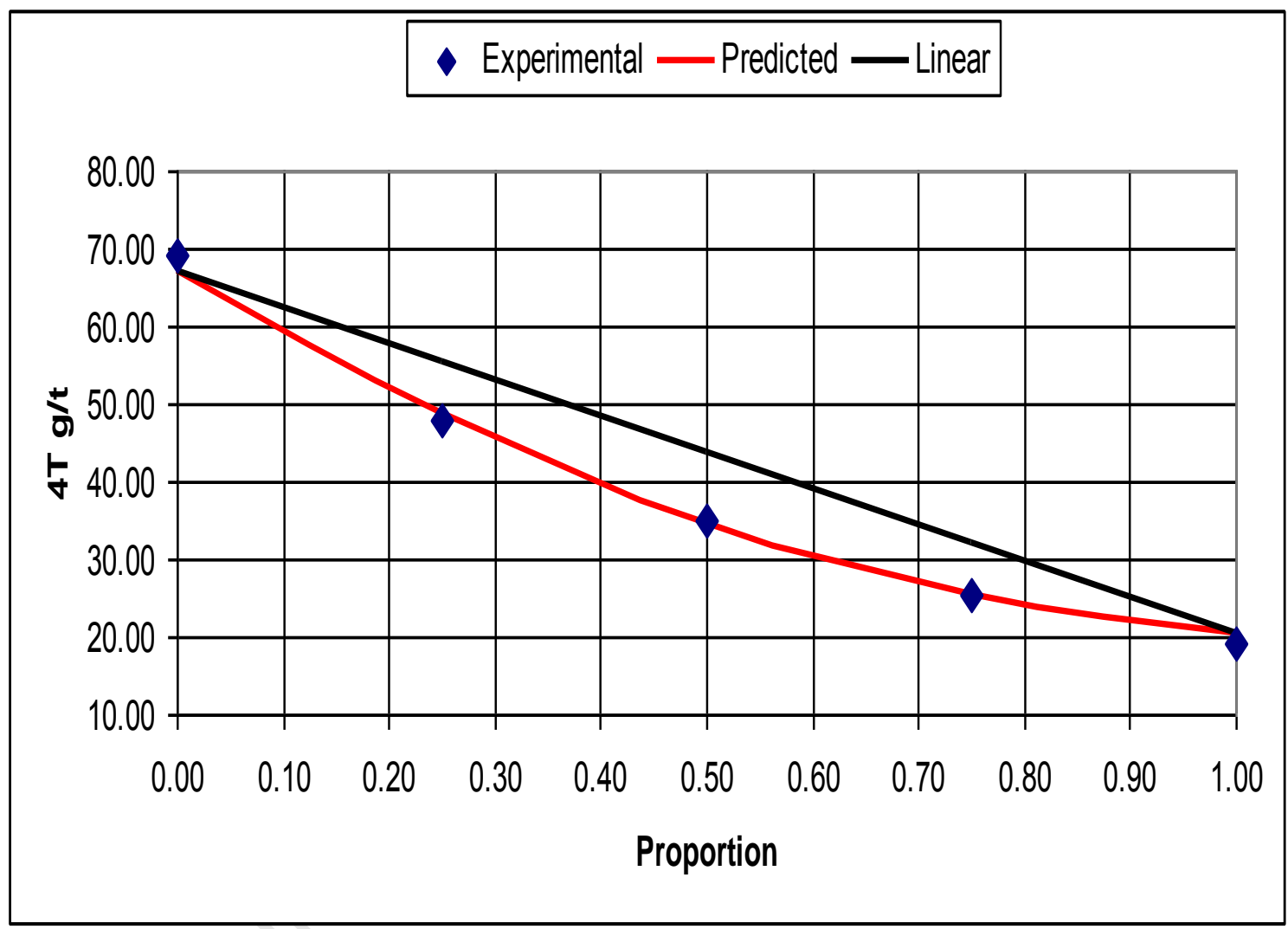

Figure 4.6 Binary plot for the cumulative grade for binary mixtures of the Salene $\left(\mathrm{x}_{1}\right)$ and Townlands $\left(\mathrm{x}_{4}\right)$ ores.

\subsubsection{Ternary plots}

Figure 4.7 gives the ternary plot for the cumulative grade for ternary mixtures of the $\mathrm{x}_{1}, \mathrm{x}_{3}$ and $\mathrm{x}_{4}$ ores for the data predicted using the polynomial equation. The lower grade is represented by the blue and green while the higher grade is represented by orange and yellow. The plot shows that with an increase in the proportion of $\mathrm{x}_{1}$ (left-hand axis base to peak), the grade will decrease. This is evident by the change in colour (from orange to blue) as well as the spacing of the contour 
lines which increases as the proportion of $\mathrm{x}_{1}$ increases. In line with the polynomial equation, once $\mathrm{x}_{4}$ is added to the mixture there is a synergistic interaction (indicated by the upward curvature) of the contour lines.

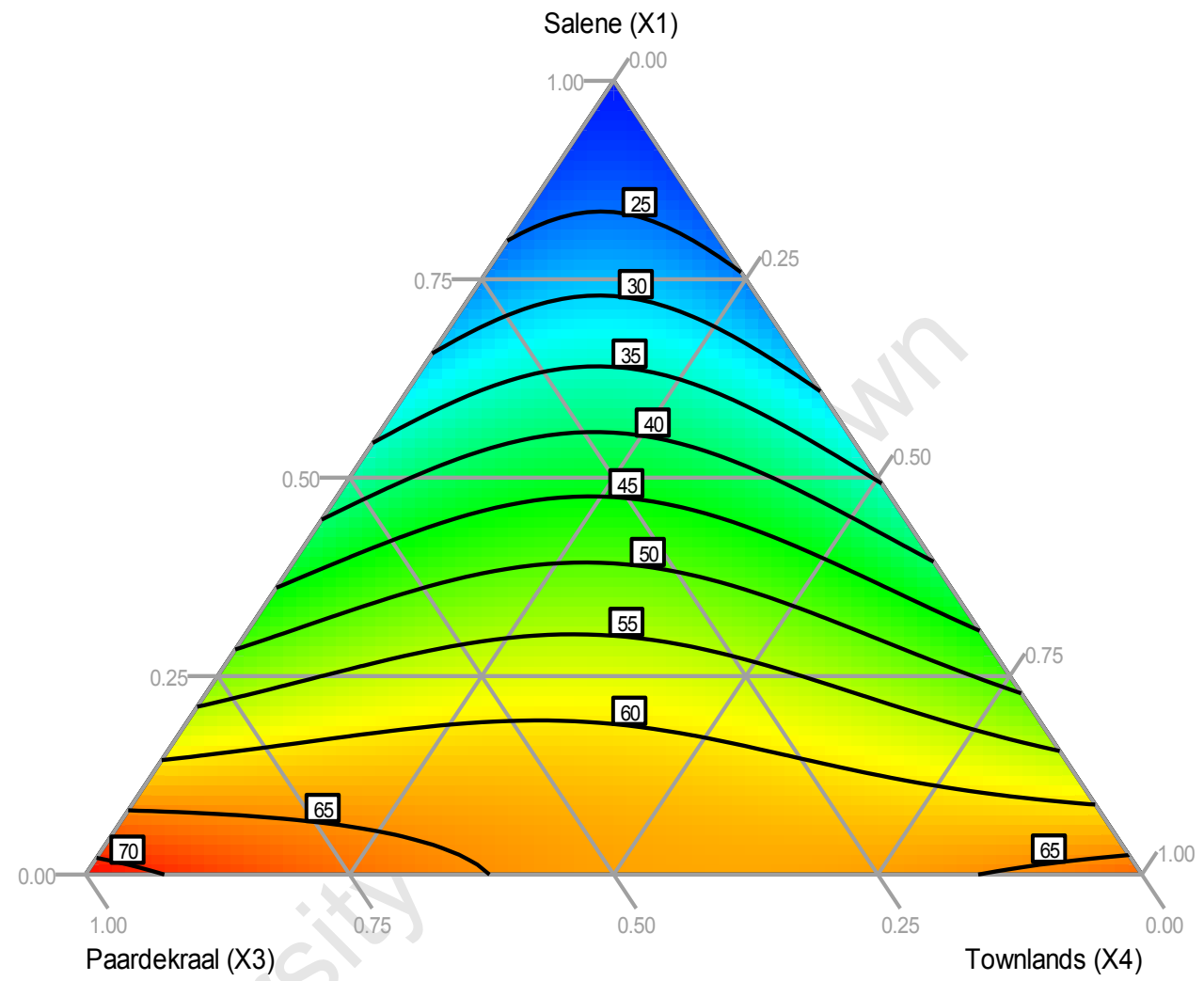

Figure 4.7 Ternary plot for the cumulative grade for ternary mixtures of the Salene $\left(\mathrm{x}_{1}\right)$, Paardekraal $\left(\mathrm{x}_{3}\right)$ and Townlands $\left(\mathrm{x}_{4}\right)$ ores

\subsubsection{Implication for metal accounting}

The quality of ore as well as the relative proportion on the blend will affect grade. From the binary plots it is evident that if the Waterval UG2 concentrator receives ore from two shafts with one providing an ore with a lower grade than the other, a simple binary mixture of these two ores will result in a lower grade than expected. As with recovery this again will affect metal accounting and contractual agreements because the concentrator will not be able to explain losses/gains in the final product. Based on the findings in Sections 4.2.3.1 to 4.2.3.3, the simplex lattice design is a useful tool to detect the effect of blending on cumulative grade. 


\section{CHAPTER 5 SUMMARY AND CONCLUSIONS}

The objective of this thesis was to investigate the effect of blends on milling and flotation performance. Although some research has been done on the effect of ore blends in mineral processing, none of the research conducted used an experimental mixture design. The experimental mixture design for this research assumes that if all the process factors and the total amount of ore per experiment is kept constant, the change in the value of the response is only due to changes made in the relative proportions of each ore source making up the mixture. The behaviour of the response is thus a function of the joint blending property of the ore proportions in the mixture. The only constraint on the design is that for each experiment, the sum of all proportions (of each ore source) must add up to 1. Based on these conditions it was hypothesized that the experimental mixture design will be able to provide an effective method to explain milling and flotation performance of ore mixtures.

In order to test the experimental mixture design, large bulk samples of four ore source were collected and subsampled. The ores were sourced from the following four shafts: Salene ore $\left(\mathrm{x}_{1}\right)$, Waterval UG2 ore $\left(x_{2}\right)$, Paardekraal ore $\left(x_{3}\right)$ and Townlands ore $\left(x_{4}\right)$. The four ores were characterized in terms of their mineralogy to explain milling and flotation behaviour. Standardization tests were then conducted to determine repeatability, an optimum milling time and the flotation behaviour of the pure ores. Milling and flotation tests were conducted according to the experimental design. The results of this thesis provide the minerals processing industry with a method to understand the effect of ore mixtures on milling and flotation performance. They can also be used to predict recovery and grade of an ore mixture and thus assist in optimization of a process. This chapter summarizes the key findings of this research as well as the conclusions and recommendations for future work. 


\subsection{SUMMARY OF KEY FINDINGS}

\subsubsection{Experimental design}

The simplex lattice experimental mixture design was identified as a suitable design to evaluate the effect of blends on milling and flotation performance. The design is comprehensive in that it generates enough design points, but is also simple enough for a polynomial without complex terms to be fitted to the design. Different polynomial equations that may fit this design were statistically evaluated. The special cubic polynomial was found to adequately describe the milling and flotation response. Although the stepwise regression method generated slightly better results than the special cubic polynomial, it included complex quadratic terms that would inhibit (rather than promote) understanding of the effect of the mixture on the response value. Thus due to the small difference in the $\mathrm{R}_{\mathrm{adj}}{ }^{2}$ value between the two, the use of the special cubic polynomial was more practical. The residual plots also assisted in the validation of the method.

\subsubsection{Milling}

The results obtained from the milling experiments were not conclusive. Data analysis showed a lot of uncertainty in the model and the binary plots showed some deviations between the experimental data and the predicted data. The ternary plot was used as a visual reflection of the polynomial equation and assisted in evaluating the data.

\subsubsection{Cumulative recovery}

The results obtained from the flotation experiments were more conclusive. Data analysis showed some uncertainty in the model but the binary plots showed a better relation between the experimental data and the predicted data. The dominant effects were linear but there was antagonistic interaction in the binary term for $\mathrm{x}_{1}$ and $\mathrm{x}_{4}$ and synergistic interactions in the ternary terms containing $\mathrm{x}_{3}$ and $\mathrm{x}_{4}$. These findings are in line with what is known about the ore.

\subsubsection{Cumulative grade}

The results obtained from the flotation experiments were very conclusive. Data analysis showed little uncertainty in the model and the binary plots showed a good relation between the experimental data and the predicted data. The model showed clear antagonistic interactions in all binary terms containing $\mathrm{x}_{1}$ and synergistic interactions in ternary terms containing $\mathrm{x}_{3}$ and $\mathrm{x}_{4}$. Here the antagonistic effect of $\mathrm{x}_{1}$ was much stronger than for recovery, and the higher grade of 
the pure ores $\mathrm{x}_{3}$ and $\mathrm{x}_{4}$ was also accentuated by the significant synergistic interaction of the ternary terms containing both $\mathrm{x}_{3}$ and $\mathrm{x}_{4}$.

\subsection{CONCLUSIONS}

Based on the findings of this thesis, the following conclusions can be made:

a. The simplex lattice mixture designs can be used as a method to evaluate and predict the milling and flotation performance of ore mixtures. Although various interactions can be evaluated, it was found that the special cubic model generated simple terms that could easily explain interactions between ores and rendered good correlation between the experimental data and the prediction formula. The statistical techniques, for example the residual plots, can also be used to evaluate the validity of the results and to scrutinize the data for systematic experimental errors.

b. The milling results were not conclusive. However, flotation results showed antagonistic binary interaction with the poor quality Salene $\left(\mathrm{x}_{1}\right)$ ore and a good quality ore like Townlands $\left(\mathrm{x}_{4}\right)$ for both recovery and grade. It was also found that the antagonistic interaction can be counteracted if a third ore with a higher quality is added to the blend.

c. Implications for metal accounting are that any contractual agreements where recoveries are based on pure ore will never be accurate as interactions between ores result in synergistic/antagonistic effects. As long as the concentrator knows in what proportion the ore is blended for that particular month, the terms in the polynomial equation can be used to predict the true recovery/grade that will be obtained (assuming all process conditions are kept constant). The effect of the ore with the lower recovery can be overcome by managing the proportions in the blend. Thus if the concentrator can control its blends it will be possible to still process ore with lower recoveries by adding it in small portions in blends, without decreasing the metal accounting output, and even obtain synergistic effects and thus a higher output. However, the pragmatism of blending may be limited in some cases. Apart from the capacity and design issues mentioned in Section 1.4, stockpiling is also not recommended for good concentrator metal accounting. Depending on the material residence time and quality of the blend, 
reclaiming of stockpiles will also introduce variability in the material, which will affect mathematical predictions.

\subsection{RECOMMENDATIONS}

Based on the findings of this research project, the following recommendations can be made:

a. Although the results of this research are conclusive, they are based on experiments done at laboratory scale. Process conditions at a concentrator or even a pilot plant may vary substantially and may mask/hide some of these findings. However, this research only evaluated some of the most basic mixture designs as a first step in investigating the application of these mixture designs in the field of mineral processing. Depending on the objective, much more complex designs can be used as described by Cornell (2002). Even the basic designs do also have the option to vary process variables, which will be advantageous if further tested in a pilot plant or concentrator.

b. The mixture designs are not only used to explain interactions between mixture components, but can also be used to predict the outcome/response value for specific blends. Once the regression polynomial equation is known, an optimizer (usually supplied by the mixture design software) can be used to determine the best possible blend for the optimum flotation performance. Although the final prediction may not hold $100 \%$ true (due to variable process conditions), it does bring the concentrator one step closer in processing ore from various sources without sacrificing flotation performance.

c. Once the effect of a blend is known it must still be determined how to account for each ore source separately. As mentioned in Section 1.2.2 the current metal accounting system at the concentrator uses the grade and tonnage provided by each shaft as well as the recovery of ore in its pure form (based on the head grade provided by the shaft) to allocate metals in the final product to the various shafts. The ratio of metal content in ore from the shafts to metal content in the final product is used as a factor to allocate any excess/shortage of metal in the final product to the various shafts. The use of the regression polynomial equation (as opposed to results obtained from the ore in its pure form) should be investigated. 


\section{REFERENCES}

1. Aaseng, R.E. and Harrison, S.W. In-pit blending for daily ore control at Ispat Inland Mining Company’s Minorca Mine, Control 2000: Mineral and Metallurgical Processing, 2000, 223-226.

2. Abouzeid, A.Z.M. and Fuerstenau, D.W. Mixture grinding in the high pressure rod mill. Proceedings of the XXI International Mineral Processing Congress, 2000, A4: 60-68.

3. Aguilera-Vázquez, L., Soto-Cruz, N.O., Saucedo-Castañeda, G. and Gutiérrez-Rojas, M. A model system for co-composting hydrocarbon contaminated soil by using water activity and porosity as response values. Chemical Engineering Journal, 2001, 81: 197202.

4. Bakker, C. 2005. Numerical modeling of an ocillatory baffled column. MSc thesis, University of Cape Town, South Africa.

5. Bazin, C., Fortin, C., Hodouin, D. and Cayouette, J. Effect of fineness of grind on semibatch flotation test results. Mineral Engineering, 2005, 18: 367-370.

6. Bourke, T.M., Brown, D.N. and Troth, D.A. Sampling and blending practice for a 5000 tonne/day iron blast furnace. Sampling symposium, 1976, the Aus. I.M.M. Melbourne branch.

7. Bozkurt, V., Xu, Z. and Finch, J.A. Pentlandite/pyrrhotite interaction and xanthate adsorption. International Journal of Minerals Processing, 1998, 52: 203-214.

8. Bradshaw, D.J. 1997. Synergistic effects between thiol collectors used in the flotation of pyrite. PhD thesis, University of Cape Town, South Africa.

9. Brandvik, P.J. Statistical simulation as an effective tool to evaluate and illustrate the advantage of experimental designs and response surface methods. Chemometrics and Intelligent Laboratory Systems, 1998, 42: 51-61. 
10. Brown, M. Mineralogy of the UG2 from 4 shafts in Rustenburg. Unpublished confidential internal report, Anglo American plc., Report no. M/07/208, March 2008.

11. Bruns, R.E., de Andrade, J.C., Reis, C. and Nakai, D. Is statistical lack of fit a reliable criterion for chemical complexity? Chemometrics and Intelligent Laboratory Systems, 1996, 33: 159-166.

12. Canning, R.A. Blending benefits: kaolin for European ceramics. Industrial Minerals, 2000, 390: 75-79.

13. Chakraborty, M. and Chandra, M.K. Multicriteria decision making for optimal blending for beneficiation of coal: a fuzzy programming approach. Omega, 2005, 33: 413-418.

14. Cornell, J. Experiments with mixtures. New York: John Wiley and Sons, 2002, p.3-4; 28-29 and 532.

15. Davies, J. Waterval UG2 concentrator. Anglo technical division, Techno News, 2002, p.1-3.

16. Deglon, D.A., 1998. A hydrodynamic investigation of fine particle flotation in a batch flotation cell. PhD thesis, University of Cape Town, South Africa.

17. Ekmekçi, Z., Bradshaw, D.J., Allison, S.A. and Harris, P.J. Effects of frother type and froth height on the flotation behavior of chromite in UG2 ore. Minerals Engineering, 2003, 16: 941-949.

18. Eriksson, L., Johansson, E. and Wikström, C. Mixture design - design generation, PLS analysis, and model usage. Chemometrics and Intelligent Laboratory Systems, 1998, 43: 1-24.

19. Fragomeni, D., Boyd, L., Charland, A., Kormos, L., Lotter, N.O. and Potts, G. The use of end members for grind-recovery modeling, tonnage prediction and flows sheet development at Raglan. Proceedings of the Canadian Mineral Processors, 2005, Falconbridge. 
20. Girard, M., Flament, F. and Cornish, B. Production accounting and metallurgical accountant at Antamina Peru. Copper, 2003, 3: 114-157.

21. Hey, P.V. and Malysiak, V. Mineralogical and metallurgical investigation of hanging wall, reef and Tarentaal footwall samples ex Richard shaft, UNION section. Unpublished confidential internal report, Anglo Platinum Management Services (Pty) Ltd., Report no. M/03/88, November 2003.

22. Hiçyilmaz, C., Ulusoy, U. and Yekeler, M., Effects of the shape properties of talc and quartz particles on the wettability based separation processes. Applied Surface Science, 2004, 233: 204-212.

23. Jumaa, M., Kleinebudde, P. and Müller, B.W. Mixture experiments with the oil phase of parental emulsions. European Journal of Pharmaceutics and Biopharmaceutics, 1998, 46: 161-167.

24. Khanal, M. and Morrison, R. Discrete element method study of abrasion. Minerals Engineering, 2008, 21: 751-760.

25. Kumral, M. Bed blending design incorporating multiple regression modeling and genetic algorithms. The Journal of the South African Institute of Mining and Metallurgy, 2006, 106: $229-236$.

26. Lewis, J.S. 2003. Hydrodynamic effects on the flotation of platinum ore in a pilot flotation plant. MSc thesis, University of Cape Town, South Africa.

27. Lundstedt, T., Seifert, E., Abramo, L., Thelin, B., Nyström, A., Pettersen, J. and Bergman, R. Experimental design and optimization. Chemometrics and Intelligent Laboratory Systems, 1998, 42: 3-40.

28. Malysiak, V. and Towell, J.R. The effect of widening the mining cut on flotation response at UNION section. Unpublished confidential internal report, Anglo Platinum Management Services (Pty) Ltd., April 2004. 
29. Menezes, R.R., Malzac Neto, H.G., Santana, L.N.L., Lira, H.L., Ferreira, H.S. and Neves, G.A. Optimization of wastes in ceramic tiles using statistical design of mixture experiments. Journal of the European Ceramic Society, 2008, 28: 3027-3039.

30. Miller, J.D. Integration of beneficiation process into iron ore resource utilization. Mineral Processing and Extractive Metallurgy, 2003, 112: C1-C9.

31. Miller, J.D., Li, J., Davidtz, J.C. and Vos, F. A review of pyrrhotite flotation chemistry in the processing of PGM ores. Minerals Engineering, 2005, 18: 855-865.

32. Naes, T., Bjerke, F. and Faergestad, E.M. A comparison of design and analysis techniques for mixtures. Food Quality and Preference, 1999, 10: 209-217.

33. NIST/SEMATECH e-Handbook of statistical methods, What is a mixture design? [Online]. Available: http://www.itl.nist.gov/div898/handbook/, 2003.

34. Papini, R.M., Guimarães, R.C. and Peres, A.E.C. Technical note study on the flotation selectivity of a problem phosphate ore. Minerals Engineering, 2001, 14 no 6: 681-684.

35. Penberthy, C.J., Oosthuyzen, E.J. and Merkle, R.K.A. The recovery of platinum-group elements from the UG2 chromitite, Bushveld complex - a mineralogical perspective. Mineralogy and Petrology, 2000, 68: 213-222.

36. Richardson, J.M. Reconciliation of mine site, mineral processing plant, concentrate and tailings inventories. Mineral Industry and Resources, 1991, 61-71.

37. Rixom, P. South African geological Bushveld complex and the Zimbabwe great dyke. Unpublished confidential short course on Geology and Mineralogy, 2004.

38. Roberts, J.R., Hey, P.V. and Rixom, P.M. A comparative mineralogical assessment of four stockpiles from the PPL open pit. Unpublished confidential internal report, Anglo Platinum Management Services (Pty) Ltd., QEM*SEM Report no. 1/129, 8 February 1999. 
39. Romagnoli, M. and Andreola, F. Mixture of deflocculants: a systematic approach. Journal of the European Ceramic Society, 2007, 27: 1871-1874.

40. Romagnoli, M. and Rivasi, M.R. Optimal size distribution to obtain the densest packing: a different approach. Journal of the European Ceramic Society, 2007, 27: 1883-1887.

41. Rushdi, A., Sharma, A. and Gupta, R. An experimental study of the effect of coal blending on ash deposition. Fuel, 2004, 83: 495-506.

42. Salazar, J.L., Magne, L., Acuña, G. and Cubillos, F. Dynamic modeling and simulation of semi-autogenous mills. Minerals Engineering, 2009, 22: 70-77.

43. Schouwstra, R.P., Kinloch, E.D. and Lee, C.A. A short geological review of the Bushveld complex. Platinum Metals Revision., 2000, 44: 33-39.

44. Sivertsvik, M. The optimized modified atmosphere for packaging of pre-rigor filleted farmed cod (Gadus morhua) is $63 \mathrm{ml} / 100 \mathrm{ml}$ oxygen and $37 \mathrm{ml} / 100 \mathrm{ml}$ carbon dioxide. LWT, 2007, 40: 430-438.

45. Ulusoy, U., Yekeler, M. and Hiçyilmaz, C. Determination of the shape, morphological and wettability properties of quartz and their correlations. Minerals Engineering, 2003, 16: $951-964$.

46. van der Westhuizen, A.P.P. 2004. The evaluation of solids suspension in a pilot scale mechanical flotation cell. MSc thesis, University of Cape Town, South Africa.

47. Vuthaluru, H.B., Brooke, R.J., Zhang, D.K. and Yan, H.M. Effects of moisture and coal blending on Hardgrove grindability index of Western Australian coal. Fuel Processing Technology, 2003, 81: 67-76.

48. Weiss, N.L. SME mineral processing handbook. New York: American Institute of Mining, Metallurgical and Petroleum Engineers, Inc., 1985, p.32-39. 
49. Wesseldijk, Q.I., Reuter, M.A., Bradshaw, D.J. and Harris, P.J. The flotation behavior of chromite with respect to the beneficiation of UG2 ore. Minerals and Engineering, 1999, 12: $1177-1184$.

50. Wills, A.B. and Napier-Munn, T. Wills' mineral processing technology. Julius Kruttsschnitt Mineral Research Centre: Elsevier, 2006, p.146-170.

51. Xiao, Z. and Laplante, A.R. Characterizing and recovering the platinum group minerals - a review. Minerals and Engineering, 2004, 17: 961-979.

52. Yan, D. and Eaton, R. Breakage properties of ore blends. Minerals Engineering, 1994, 7: $185-199$.

53. Zhong, Z., Ooi, J.Y. and Rotter, J.M. Predicting the handlability of a coal blend from measurements on the source coals. Fuel, 2005, 84: 2267-2274.

54. Zorba, Ö. and Kurt, Ş. Optimization of emulsion characteristics of beef, chicken and turkey meat mixtures in model system using mixture design. Meat Science, 2006, 73: 611-618. 


\section{APPENDIX A MILLING TEST DATA}

Table A-1 Salene data

\begin{tabular}{|c|c|c|}
\hline $\begin{array}{c}\text { Milling time } \\
\text { (minutes) }\end{array}$ & $\begin{array}{c}\text { \% volume passing } \\
\mathbf{7 4} \boldsymbol{\mu m}\end{array}$ & $\begin{array}{c}\text { \% mass passing 75 } \\
\boldsymbol{\mu m}\end{array}$ \\
\hline 15 & 31.86 & - \\
\hline 20 & 38.34 & - \\
\hline 25 & 40.35 & - \\
\hline 30 & 49.41 & - \\
\hline 35 & 50.8 & - \\
\hline 40 & 58.47 & - \\
\hline 45 & 59.51 & - \\
\hline 50 & 66.92 & 71.10 \\
\hline 55 & 67.93 & 77.27 \\
\hline 60 & 71.7 & 73.01 \\
\hline
\end{tabular}

Table A-2 Waterval UG2 data

\begin{tabular}{|c|c|c|}
\hline $\begin{array}{c}\text { Milling time } \\
\text { (minutes) }\end{array}$ & $\begin{array}{c}\text { \% volume passing } \\
\mathbf{7 4} \boldsymbol{\mu \mathbf { m }}\end{array}$ & $\begin{array}{c}\text { \% mass passing 75 } \\
\boldsymbol{\mu m}\end{array}$ \\
\hline 15 & 24.5 & - \\
\hline 20 & 33.73 & - \\
\hline 25 & 37.47 & - \\
\hline 30 & 39.22 & - \\
\hline 35 & 42 & - \\
\hline 40 & 46.71 & - \\
\hline 45 & 52.63 & - \\
\hline 50 & 59.73 & 61.0 \\
\hline 55 & 55.34 & 62.6 \\
\hline 60 & 63.18 & 68.9 \\
\hline
\end{tabular}


Table A-3 Paardekraal data

\begin{tabular}{|c|c|c|}
\hline $\begin{array}{c}\text { Milling time } \\
\text { (minutes) }\end{array}$ & $\begin{array}{c}\text { \% volume passing } \\
\mathbf{7 4} \boldsymbol{\mu m}\end{array}$ & $\begin{array}{c}\text { \% mass passing 75 } \\
\boldsymbol{\mu m}\end{array}$ \\
\hline 15 & 17.01 & - \\
\hline 20 & 24.32 & - \\
\hline 25 & 24.74 & - \\
\hline 30 & 32.11 & - \\
\hline 35 & 39.74 & - \\
\hline 40 & 45.44 & - \\
\hline 45 & 50.86 & - \\
\hline 50 & 49.28 & 48.95 \\
\hline 55 & 54.96 & 62.57 \\
\hline 60 & 57.6 & 59.85 \\
\hline
\end{tabular}

Table A-4 Townlands data

\begin{tabular}{|c|c|c|}
\hline $\begin{array}{c}\text { Milling time } \\
\text { (minutes) }\end{array}$ & $\begin{array}{c}\text { \% volume passing } \\
\mathbf{7 4} \boldsymbol{\mu m}\end{array}$ & $\begin{array}{c}\text { \% mass passing 75 } \\
\boldsymbol{\mu m}\end{array}$ \\
\hline 15 & 22.95 & - \\
\hline 20 & 28.04 & - \\
\hline 25 & 29.81 & - \\
\hline 30 & 31.55 & - \\
\hline 35 & 33.27 & - \\
\hline 40 & 40.08 & - \\
\hline 45 & 48.02 & - \\
\hline 50 & 48.72 & 51.63 \\
\hline 55 & 52.13 & 53.61 \\
\hline 60 & 58.51 & 66.25 \\
\hline
\end{tabular}




\section{APPENDIX B EXPERIMENTAL DESIGN RESULTS}

Table B-1 Milling results

\begin{tabular}{|c|c|c|}
\hline $\begin{array}{l}\text { Design } \\
\text { point }\end{array}$ & $\begin{array}{c}\% \text { volume } \\
\text { passing } 74 \mu \mathrm{m}\end{array}$ & $\begin{array}{c}\text { \% mass passing } \\
75 \mu \mathrm{m}\end{array}$ \\
\hline 1 & 66.85 & 66.5 \\
\hline 2 & 59.36 & 63.8 \\
\hline 3 & 58.8 & 56.8 \\
\hline 4 & 54.3 & 56.9 \\
\hline 5 & 58.77 & 65.8 \\
\hline 6 & 57.66 & 63.7 \\
\hline 7 & 63.17 & 67.8 \\
\hline 8 & 58.33 & 66.8 \\
\hline 9 & 63.3 & 66.5 \\
\hline 10 & 61.07 & 66.1 \\
\hline 11 & 56.6 & 63.9 \\
\hline 12 & 61.53 & 62.5 \\
\hline 13 & 60.99 & 67.6 \\
\hline 14 & 59.91 & 64.7 \\
\hline 15 & 59.68 & 61.1 \\
\hline 16 & 56.77 & 61.8 \\
\hline 17 & 60.39 & 59.6 \\
\hline 18 & 54.73 & 64.5 \\
\hline 19 & 55.51 & 63.4 \\
\hline 20 & 56.87 & 61.9 \\
\hline 21 & 57.21 & 65.8 \\
\hline 22 & 54.62 & 57.7 \\
\hline 23 & $\begin{array}{r}59.72 \\
\end{array}$ & 64.3 \\
\hline 24 & 64.94 & 75 \\
\hline 25 & 71.75 & 77.2 \\
\hline 26 & 66.03 & 71.7 \\
\hline 27 & 59.91 & 68.4 \\
\hline 28 & 57.95 & 64.8 \\
\hline 29 & 58.38 & 65.4 \\
\hline 30 & 60.57 & 64.6 \\
\hline 31 & 53.85 & 60.5 \\
\hline 32 & 63.16 & 68.3 \\
\hline 33 & 54.65 & 62.3 \\
\hline 34 & 57.9 & 62.8 \\
\hline 35 & 63.01 & 64.8 \\
\hline
\end{tabular}


Table B-2 Flotation recovery results

\begin{tabular}{|c|c|c|c|}
\hline \multirow{2}{*}{$\begin{array}{c}\text { Design } \\
\text { point }\end{array}$} & \multicolumn{3}{|c|}{ Cumulative recovery \% } \\
\hline $\mathbf{n}$ & Concentrate 1 & Concentrate 2 & Concentrate 3 \\
\hline $\mathbf{2}$ & 67.015 & 74.021 & 77.774 \\
\hline $\mathbf{3}$ & 72.041 & 76.409 & 79.278 \\
\hline $\mathbf{4}$ & 74.824 & 79.781 & 82.481 \\
\hline $\mathbf{5}$ & 70.880 & 84.024 & 86.078 \\
\hline $\mathbf{6}$ & 64.028 & 81.083 & 83.151 \\
\hline $\mathbf{7}$ & 71.862 & 71.453 & 75.450 \\
\hline $\mathbf{8}$ & 68.492 & 76.707 & 79.338 \\
\hline $\mathbf{9}$ & 71.774 & 73.785 & 77.193 \\
\hline $\mathbf{1 0}$ & 68.919 & 77.096 & 79.807 \\
\hline $\mathbf{1 1}$ & 70.269 & 74.707 & 77.878 \\
\hline $\mathbf{1 2}$ & 71.069 & 75.711 & 78.757 \\
\hline $\mathbf{1 3}$ & 74.152 & 76.328 & 79.527 \\
\hline $\mathbf{1 4}$ & 74.936 & 79.392 & 80.827 \\
\hline $\mathbf{1 5}$ & 69.109 & 74.772 & 81.654 \\
\hline $\mathbf{1 6}$ & 74.169 & 78.845 & 77.943 \\
\hline $\mathbf{1 7}$ & 73.065 & 77.555 & 81.314 \\
\hline $\mathbf{1 8}$ & 71.277 & 76.437 & 80.361 \\
\hline $\mathbf{1 9}$ & 72.526 & 78.450 & 81.579 \\
\hline $\mathbf{2 0}$ & 74.131 & 78.842 & 81.397 \\
\hline $\mathbf{2 1}$ & 72.395 & 78.208 & 80.989 \\
\hline $\mathbf{2 2}$ & 78.174 & 81.095 & 83.189 \\
\hline $\mathbf{2 3}$ & 75.310 & 79.625 & 82.262 \\
\hline $\mathbf{2 4}$ & 61.979 & 70.643 & 74.344 \\
\hline $\mathbf{2 5}$ & 65.020 & 72.618 & 76.039 \\
\hline $\mathbf{2 6}$ & 65.763 & 72.369 & 75.946 \\
\hline $\mathbf{2 7}$ & 68.127 & 74.426 & 78.211 \\
\hline $\mathbf{2 8}$ & 70.549 & 76.037 & 79.295 \\
\hline $\mathbf{2 9}$ & 74.887 & 78.854 & 81.526 \\
\hline $\mathbf{3 0}$ & 71.605 & 77.159 & 80.366 \\
\hline $\mathbf{3 1}$ & 69.039 & 74.441 & 78.155 \\
\hline $\mathbf{3 2}$ & 69.817 & 76.116 & 79.656 \\
\hline $\mathbf{3 3}$ & 69.512 & 76.404 & 79.848 \\
\hline $\mathbf{3 4}$ & 70.150 & 76.171 & 81.474 \\
\hline $\mathbf{3 5}$ & 75.011 & 79.287 & \\
\hline & & & 894 \\
\hline
\end{tabular}


Table B-3 Flotation grade results

\begin{tabular}{|c|c|c|c|c|c|}
\hline \multirow[b]{2}{*}{$\begin{array}{c}\text { Design } \\
\text { point }\end{array}$} & \multicolumn{5}{|c|}{ Grade in $\mathrm{g} / \mathrm{t}$} \\
\hline & $\begin{array}{c}\text { Concentrate } \\
1\end{array}$ & $\begin{array}{c}\text { Concentrate } \\
2\end{array}$ & $\begin{array}{c}\text { Concentrate } \\
3\end{array}$ & Tails & $\begin{array}{c}\text { Cumulative } \\
\text { grade }\end{array}$ \\
\hline 1 & 36.245 & 16.235 & 8.606 & 0.877 & 19.31 \\
\hline 2 & 118.628 & 43.931 & 19.663 & 0.840 & 56.14 \\
\hline 3 & 185.652 & 57.269 & 23.847 & 0.876 & 72.62 \\
\hline 4 & 156.122 & 49.817 & 21.867 & 0.879 & 68.98 \\
\hline 5 & 121.842 & 34.935 & 19.715 & 0.804 & 59.39 \\
\hline 6 & 62.525 & 25.665 & 13.350 & 0.847 & 30.92 \\
\hline 7 & 85.226 & 28.659 & 13.363 & 0.809 & 39.72 \\
\hline 8 & 69.325 & 26.576 & 13.780 & 0.803 & 34.95 \\
\hline 9 & 79.584 & 28.224 & 12.932 & 0.795 & 37.13 \\
\hline 10 & 68.828 & 26.186 & 13.251 & 0.806 & 34.14 \\
\hline 11 & 82.664 & 30.152 & 14.442 & 0.785 & 39.25 \\
\hline 12 & 82.161 & 32.646 & 15.673 & 0.813 & 40.66 \\
\hline 13 & 87.927 & 28.839 & 14.419 & 0.727 & 41.57 \\
\hline 14 & 108.575 & 36.681 & 16.623 & 0.780 & 51.13 \\
\hline 15 & 111.461 & 40.4 & 21.554 & 0.958 & 54.79 \\
\hline 16 & 138.918 & 42.322 & 20.286 & 0.822 & 60.72 \\
\hline 17 & 109.125 & 36.012 & 15.897 & 0.749 & 47.85 \\
\hline 18 & 141.038 & 44.97 & 21.859 & 0.898 & 60.49 \\
\hline 19 & 166.622 & 51.856 & 23.275 & 0.845 & 65.87 \\
\hline 20 & 166.168 & 47.2 & 20.600 & 0.846 & 65.31 \\
\hline 21 & 161.81 & 47.838 & 20.713 & 0.878 & 61.90 \\
\hline 22 & 114.25 & 39.298 & 18.854 & 0.716 & 58.70 \\
\hline 23 & 176.858 & 50.886 & 21.724 & 0.806 & 68.51 \\
\hline 24 & 51.43 & 21.975 & 9.877 & 0.824 & 24.82 \\
\hline 25 & 56.316 & 21.567 & 10.064 & 0.792 & 26.10 \\
\hline 26 & 46.463 & 20.206 & 10.909 & 0.758 & 25.21 \\
\hline 27 & 70.83 & 30.408 & 15.493 & 0.840 & 36.10 \\
\hline 28 & 109.364 & 40.629 & 19.104 & 0.936 & 50.78 \\
\hline 29 & 100.821 & 33.173 & 17.202 & 0.738 & 48.04 \\
\hline 30 & 106.19 & 43.208 & 19.994 & 0.872 & 51.59 \\
\hline 31 & 96.012 & 38.811 & 22.435 & 0.936 & 50.77 \\
\hline 32 & 149.528 & 48.878 & 23.226 & 0.987 & 60.50 \\
\hline 33 & 163.582 & 54.564 & 25.204 & 0.983 & 65.78 \\
\hline 34 & 133.773 & 45.382 & 21.096 & 0.882 & 56.75 \\
\hline 35 & 144.362 & 42.394 & 19.013 & 0.814 & 58.86 \\
\hline
\end{tabular}

Note: Grades are given as 4T (platinum, palladium, rhodium and gold) 